\title{
EXPERIMENTAL CHARACTERIZATION OF 3D PRINTED THERMOPLASTIC PLATES SUBJECTED TO LOW VELOCITY IMPACT
}

\author{
by \\ Hari Prasad Prudhvi Desu \\ Bachelor of Engineering, Hindustan Institute of Technology and Sciences (2017)
}

\author{
A project \\ presented to Ryerson University \\ in partial fulfilment of the \\ requirements for the degree of \\ Master of Engineering \\ in the program of \\ Aerospace Engineering
}

Toronto, Ontario, Canada, 2019

CHari Prasad Prudhvi Desu, 2019 


\section{AUTHOR'S DECLARATION FOR ELECTRONIC SUBMISSION OF A PROJECT}

I hereby declare that I am the sole author of this project. This is a true copy of the project, including any required final revisions, as accepted by my examiners.

I authorize Ryerson University to lend this project to other institutions or individuals for scholarly research.

I further authorize Ryerson University to reproduce this project by photocopying or by other means, in total or in part, at the request of other institutions or individuals for the purpose of scholarly research.

I understand that my project may be made electronically available to the public. 


\title{
EXPERIMENTAL CHARACTERIZATION OF 3D PRINTED THERMOPLASTIC PLATES SUBJECTED TO LOW VELOCITY IMPACT
}

\author{
Hari Prasad Prudhvi Desu \\ Master of Engineering, Aerospace engineering, Ryerson university, Toronto (2019)
}

\begin{abstract}
Poly Lactic Acid (PLA) is a biodegradable material which is being extensively used in industrial applications. Due to its low glass transition temperature and cost, PLA is ideal as a feed stock in 3D printing applications. However, it has a brittle nature which makes it vulnerable to impact loads. In this paper, PLA is used to make 3D printed plates that are impact tested using an in-house low velocity impact test apparatus. A high-speed camera and an infrared thermography system are used to investigate the impact damage properties of the material. The plates manufactured with $0^{\circ}$ orientation are used to conduct two different experiments; one with varying energies and the other with varying thickness at two different impact locations, namely at plate's centre and close to a clamped edge. At $1 \mathrm{~J}$ impact energy, the plates showed a tensile crack behaviour (cracks between extrudates) and for $3 \mathrm{~J}$ energy it showed a mixed crack behaviour of tensile and shear (cracks along and across extrudates) with more energy dissipations than the $1 \mathrm{~J}$ impact. For the $1 \mathrm{~J}$ impact, more energy is dissipated at the centre of the plate (42.3\%) than the impact close to a clamped edge $(32.8 \%)$, whereas for the $3 \mathrm{~J}$ impact more energy is dissipated near clamped edges $(97.1 \%)$ compared to the centre of the plate (54.9\%). Subsequently, the $3 \mathrm{~J}$ impact is used for the second experiment due to the higher energy dissipation. Finally, an experimental study is conducted on plates with varied layer thickness from $0.10 \mathrm{~mm}$ to $0.18 \mathrm{~mm}$. Results show that the increase in layer thickness (decrease in number of layers) increases the impact absorption for plates impacted at their centre. For plates impacted near their clamped edge, a zig-zag impact damage pattern of increasing and decreasing magnitudes is observed, but the energy dissipation values are higher than the centre impacted plates.
\end{abstract}




\section{ACKNOWLEDGEMENTS}

First, I would like to thank my supervisors Dr. Zouheir Fawaz and Dr. Kazem Fayazbakhsh of the Department of Aerospace Engineering at Ryerson University. Their valued guidance and support helped me advance my knowledge and understanding in the field of 3D printing, thermoplastics, and testing standards. Their continuous feedback has been very significant in steering my project work in the right direction.

I thank my fellow graduate students Anthony Rossi and Zainab Al-Hajaj for their assistance and thoughts that helped me better execute this project. Likewise, I would like to express my gratitude to Dr. Kazem Fayazbakhsh for his contribution during the manufacturing and testing phases of my project.

Finally, I would like to thank my family for their understanding, support and encouragement throughout the course of this project. 


\section{TABLE OF CONTENTS}

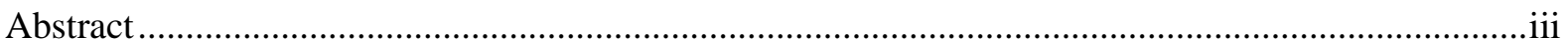

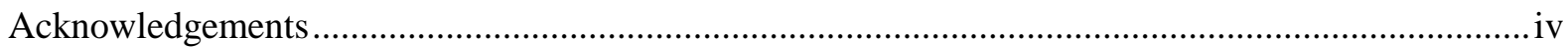

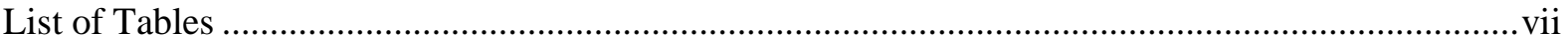

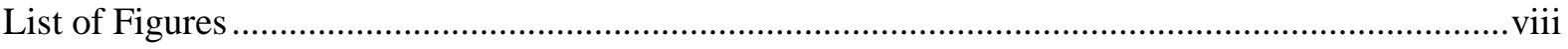

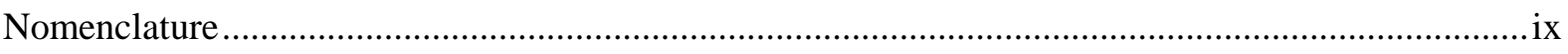

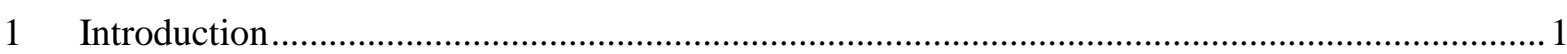

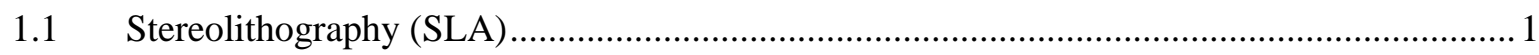

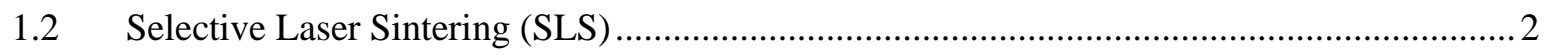

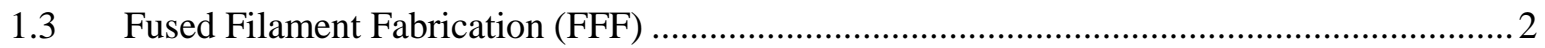

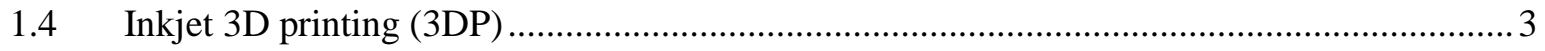

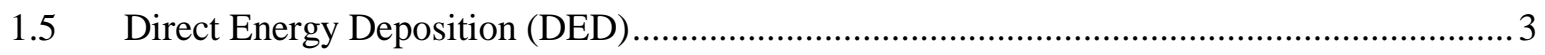

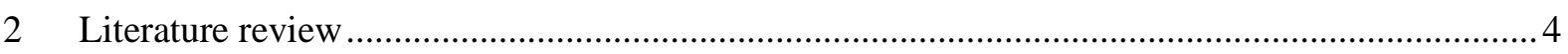

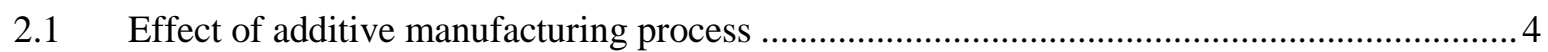

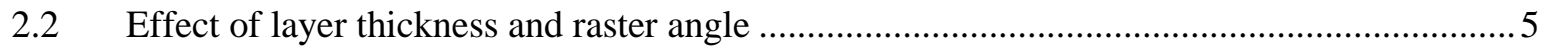

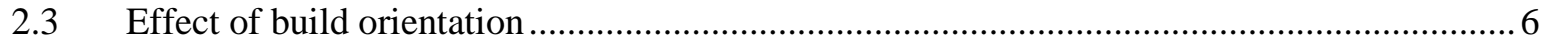

2.4 Effect of deposition angle and trajectory .......................................................................

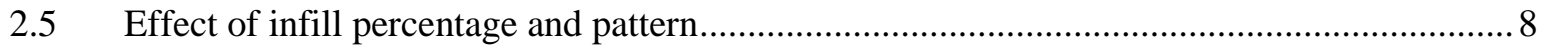

2.6 Effect of testing temperature

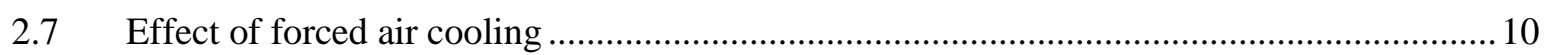

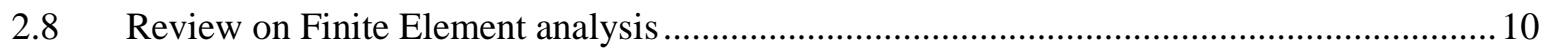

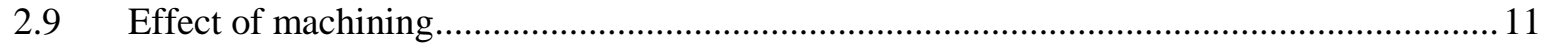

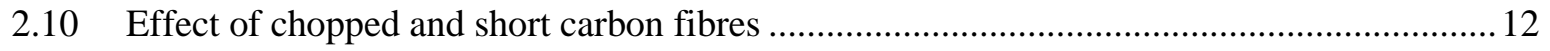

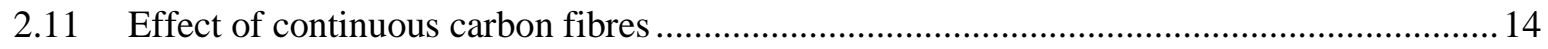

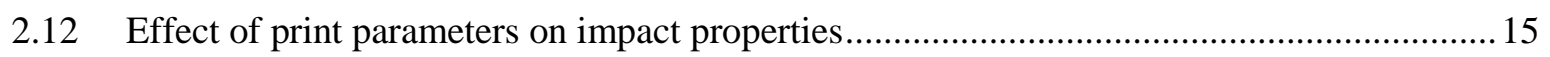

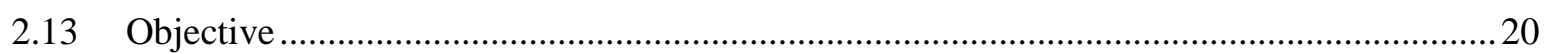

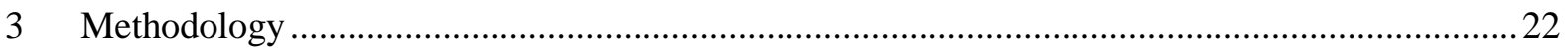

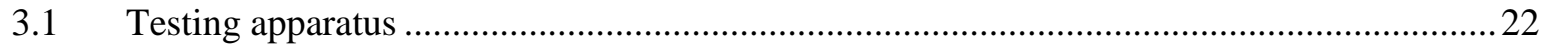

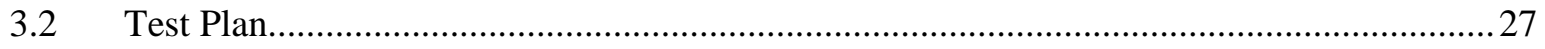

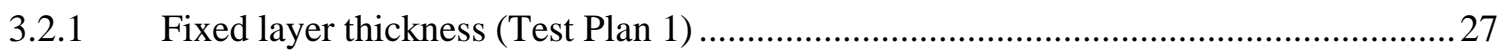

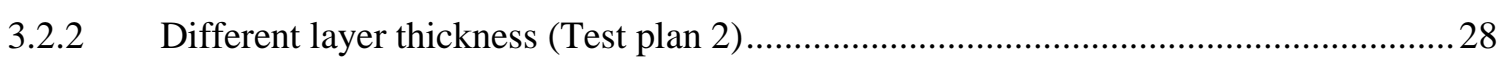

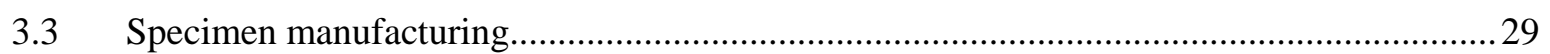

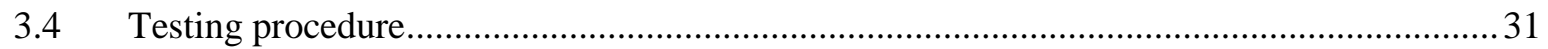

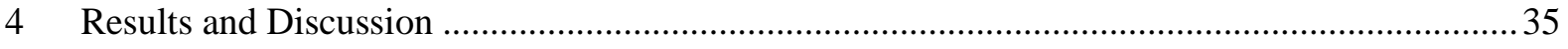

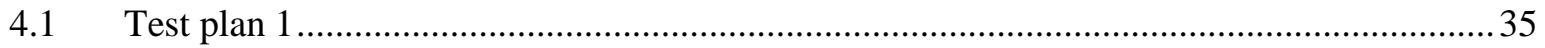

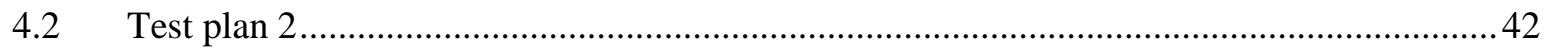

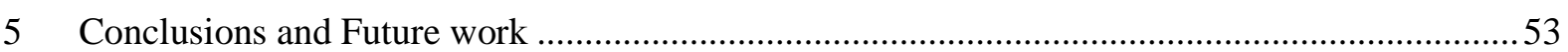




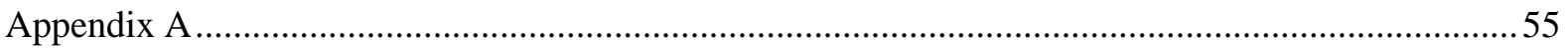

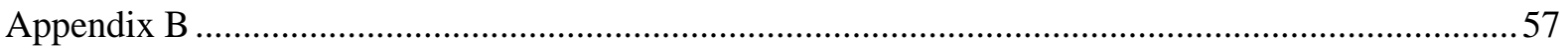

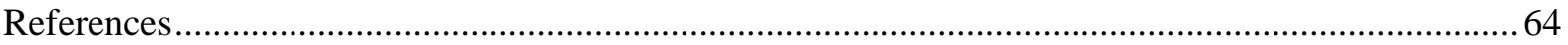




\section{LIST OF TABLES}

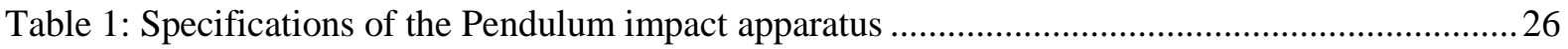

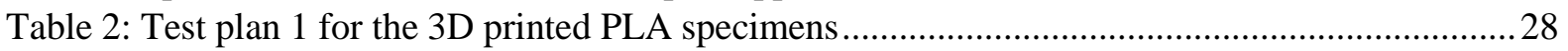

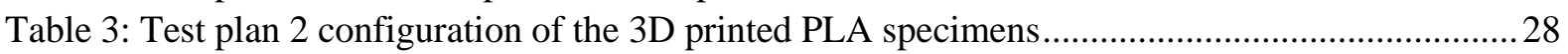

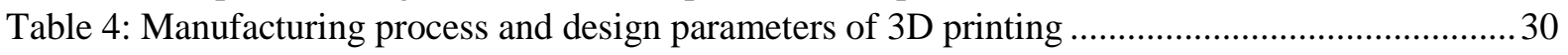

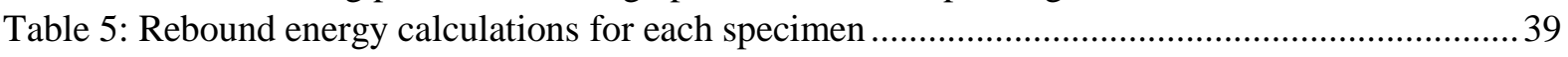

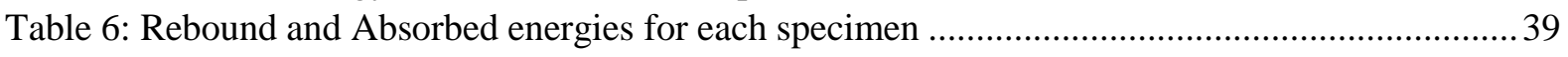

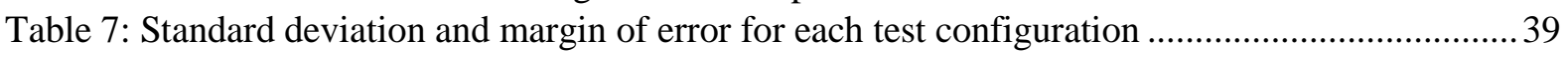

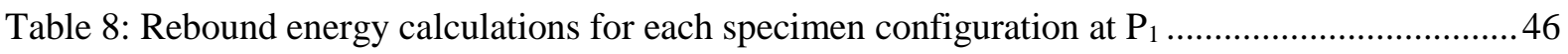

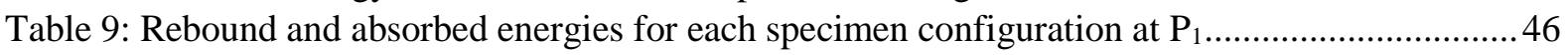

Table 10: Standard deviation and Margin of error for each test configuration at $\mathrm{P}_{1} \ldots \ldots \ldots \ldots \ldots \ldots \ldots \ldots \ldots . . . . . . . . . . . .66$

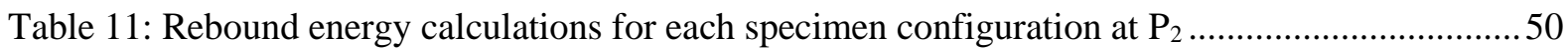

Table 12: Rebound and absorbed energies for each specimen configuration at $\mathrm{P}_{2} \ldots \ldots \ldots \ldots \ldots \ldots \ldots \ldots \ldots \ldots . . . . . . . . . . . .50$

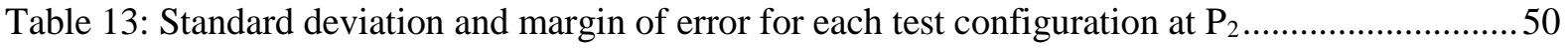

Table 14: Comparison of Absorbed energy percentages between $\mathrm{P}_{1}$ and $\mathrm{P}_{2}$ impact locations .............52 


\section{LIST OF FIGURES}

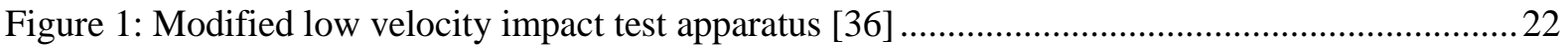

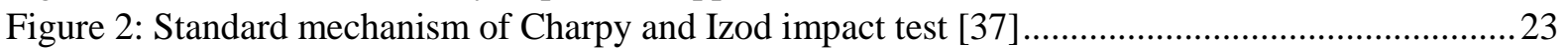

Figure 3: Impact comparison between drop weight and low velocity impact test apparatus [38] ........24

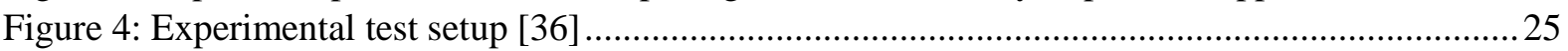

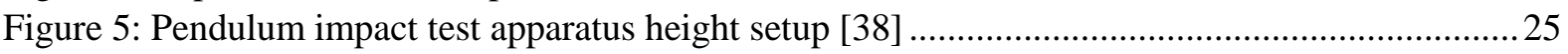

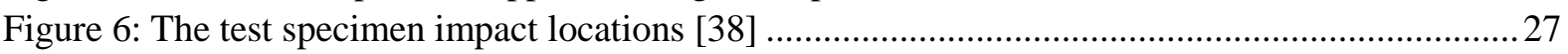

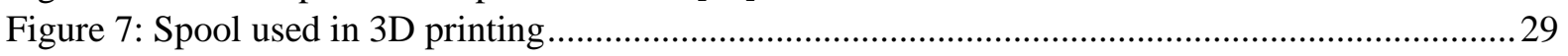

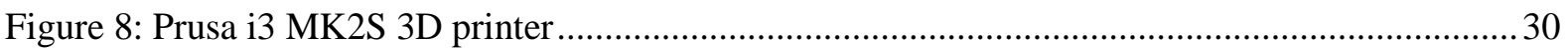

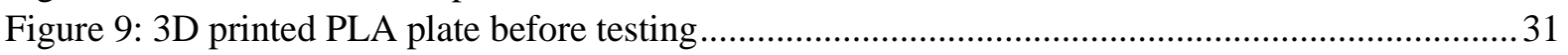

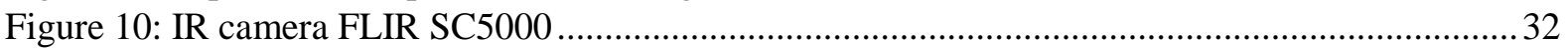

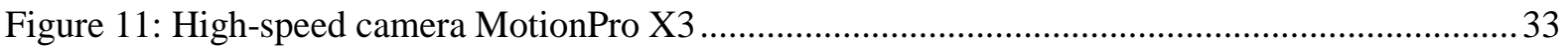

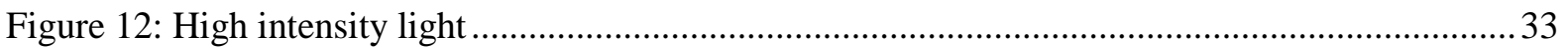

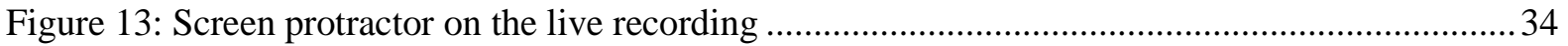

Figure 14: Specimens after testing (a) 5J energy level (b) 4J energy level ....................................... 35

Figure 15: Specimens at $1 \mathrm{~J}$ energy level (a) specimen after impact at $\mathrm{P}_{1}$ location, (b) thermal imaging

for $\mathrm{P}_{1}$ location, (c) specimen after impact at $\mathrm{P}_{2}$ location, (d) thermal imaging for $\mathrm{P}_{2}$ location............. 36

Figure 16: Specimens at $3 \mathrm{~J}$ energy level (a) specimen after impact at $\mathrm{P}_{1}$ location, (b) thermal imaging

for $\mathrm{P}_{1}$ location, (c) specimen after impact at $\mathrm{P}_{2}$ location, (d) thermal imaging for $\mathrm{P}_{2}$ location..............37

Figure 17: Absorbed energy percentage versus impact energy at $\mathrm{P}_{1}$ location ........................................ 40

Figure 18: Absorbed energy percentage versus impact energy at $\mathrm{P}_{2}$ location ...................................40

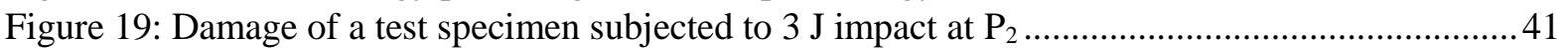

Figure 20: Specimens with $\mathrm{P}_{1}$ impact location and 25 layers (a) specimen after testing; (b) thermal

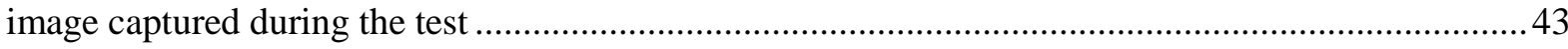

Figure 21: Specimens with $\mathrm{P}_{1}$ impact location and 21 layers (a) specimen after testing; (b) thermal

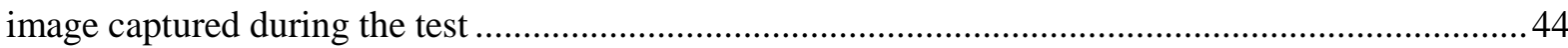

Figure 22: Specimens with $\mathrm{P}_{1}$ impact location and 16 layers (a) specimen after testing; (b) thermal

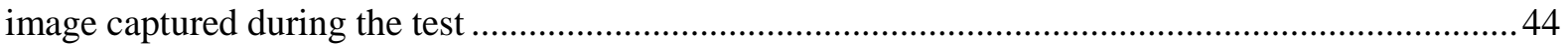

Figure 23: Specimens with $\mathrm{P}_{1}$ impact location and 16 layers (a) specimen after testing; (b) thermal

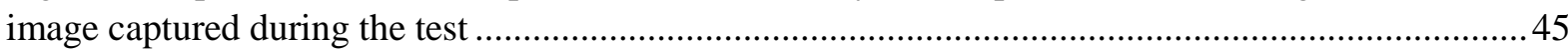

Figure 24: Specimens with $P_{1}$ impact location and 14 layers (a) specimen after testing; (b) thermal

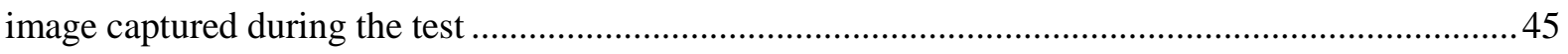

Figure 25: Absorbed energy percentage versus layer thickness at $P_{1}$ location ................................... 47

Figure 26: Specimens with $\mathrm{P}_{2}$ impact location and 25 layers (a) specimen after testing; (b) thermal image captured during the test

Figure 27: Specimens with $\mathrm{P}_{2}$ impact location and 21 layers (a) specimen after testing; (b) thermal

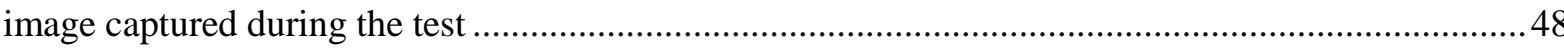

Figure 28: Specimens with $\mathrm{P}_{2}$ impact location and 16 layers (a) specimen after testing; (b) thermal

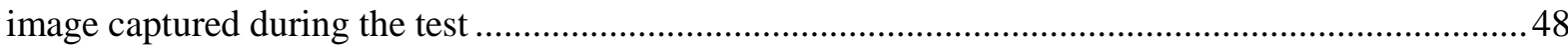

Figure 29: Specimens with $\mathrm{P}_{2}$ impact location and 16 layers (a) specimen after testing; (b) thermal

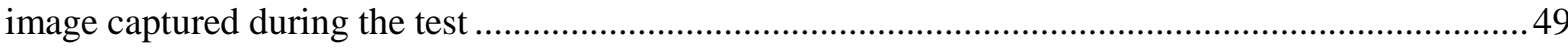
Figure 30: Specimens with $\mathrm{P}_{2}$ impact location and 14 layers (a) specimen after testing; (b) thermal

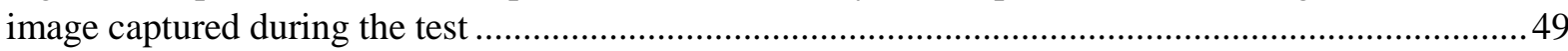

Figure 31: Absorbed energy percentage versus layer thickness at $\mathrm{P}_{2}$ location ....................................51 


\section{NOMENCLATURE}

$\begin{array}{ll}\text { AM } & \text { Additive Manufacturing } \\ \text { SLS } & \text { Selective Laser Sintering } \\ \text { SLA } & \text { Stereolithography } \\ \text { FFF } & \text { Fused Filament Fabrication } \\ \text { 3DP } & \text { Inkjet 3D printing } \\ \text { DED } & \text { Direct Energy Deposition } \\ \text { PLA } & \text { Polylactic acid } \\ \text { ABS } & \text { Acrylonitrile Butadiene Styrene } \\ \text { PEEK } & \text { Polyether ether ketone } \\ \text { ASTM } & \text { American Society for Testing and Materials } \\ \text { FF } & \text { FlexFoam } \\ \text { UV } & \text { Ultra Violet } \\ \text { IR } & \text { InfraRed } \\ \text { FRAMES } & \text { Facility for Research on aerospace Materials and Engineered Structures } \\ \text { BVID } & \text { Barely Visible Impact Damage } \\ \text { PU } & \text { Polyuretane } \\ \text { BMS } & \text { Bi-material Structures } \\ \text { SEM } & \text { Scanning Electron Microscopy } \\ \text { DSC } & \text { Differential Scanning Calorimetry } \\ \text { XRD } & \text { X-Ray Diffraction } \\ \text { POM } & \text { Polarized Optical Microscope } \\ \text { J } & \text { Joules } \\ \text { mm } & \text { millimetres }\end{array}$




\section{INTRODUCTION}

3D printing has been introduced in the 1980's and still research has been running to improve the technology. 3D printing is also called Additive manufacturing (AM) or Rapid prototyping (RP). In this technology we can design extensive series of structures and geometries using three-dimensional model data. The 3D model is built by printing sequential layers of materials with required shapes and angles. This method of printing help to create 3D model with less cost and waste. In the early stages of 3D printing only plastic parts were printed; however, these days 3D printing is used for aerospace, mechanical, civil and even biomedical applications. Lots of applications made the 3D printing developed and to use different materials like metals, alloys, nanomaterials, composites, biomedical materials, concrete, etc. The industries are encouraging 3D printing which made them develop new 3D printing techniques with advantages in making complex structures, low material waste, flexibility and precision in the design and personal customization. Even printing a composite material by using the fibres and the matrix has become easier which helps in making complex parts. The main drawback of the 3D printing is that, manufacturing large structures is difficult and expensive. The process of printing also takes time as the size and complexity increases [1,2].

Different methods are developed in 3D printing as they need to provide the mechanical performance and strength compared to the parts made of conventional methods like injection moulding. They include as Fused Filament Fabrication (FFF), inkjet 3D printing (3DP), Selective Laser Sintering (SLS), stereolithography (SLA), direct energy deposition (DED) and Vat photopolymerization (VP). These methods have their own pros and cons which are based on the process and the material. The processes have been improved to meet requirements of a better finished product, defects reduction and good mechanical properties. These AM processes follow different ASTM standards with respect to its production and the output product depends on several parameters such as print speed, nozzle temperature, bed temperature, raster angle, percentage infill, resolution, and material. A brief description of the most popular AM processes is given below.

\subsection{STEREOLITHOGRAPHY (SLA)}

Stereolithography is one of the initial additive manufacturing techniques. The principle of making the product by SLA is process of photopolymerization. In this process the part is designed by using photo curable resin which is cured by using UV light at specific wavelength. Generally, epoxy or acrylic resins are used in this process. The UV light is focused on the liquid 
bed with resin in the desired pattern which solidifies the part in the shape. This process is performed layer by layer by moving down after completion of each layer until the last layer is completed. The product is almost $80 \%$ cured during photopolymerization and the remaining is cured after the product is taken out. The surface finish and the texture obtained is very fine. Even the machine does not use any nozzle for printing which does not create any problem of clogging. As a good finished product can be fabricated, but the process is very slow, and the equipment is very costly which make its use not frequent $[3,4]$.

\subsection{Selective LASER Sintering (SLS)}

This is a type of powder bed fusion, where the powdered metal, polymer or resin is heated fully or partially which is solidified to form a 3D structure. The powdered material and the bed are pre heated before the process, then the powdered material is layered up on the bed which is heated by using high power laser beam. The laser melts the powder in the required patter and then the remaining powder is removed from the bed for the subsequent layers. The bed moves upwards when each layer is completed which results in a 3D shape. This step is repeated till the last layer until the product is completed. The final product is submerged is powder coat which is shaken off to see the finished product. The size of the powder particles, power the laser beam, scan spacing, and speed are all the important factors which affect the finish of the product. This process is limited to only few polymer, metals and ceramics and the cost of the setup is also high due the usage of high-power laser. The surface smoothness is much better in SLA technique than the SLS $[5,6]$.

\subsection{FuSED FiLAMENT FABRiCATION (FFF)}

Fused Filament Fabrication (FFF) is most broadly used method in AM techniques. In this method, plastic parts are generally used as they are cost effective, create less wastage and allow for a range of materials. Currently, even fibre reinforced plastics can be fabricated by extruding the fibres mixed with thermoplastics. In this process, first a STL data file is created which is used as a 3D model for printing as it slices the CAD model into layers. The process starts with feeding the filament spool into the liquefier head which melts it into a semi liquid stage. This liquid is layered in the design pattern through the extrusion nozzle. The nozzle and the bed are maintained at a constant temperature which get an even texture for the product. The nozzle moves in a 2-D plane which lays the first layer, then the machine goes to the next layer following the design. In this method, a different/similar colour second filament is used as a support material which can be removed later mechanically or chemically. The drawback in this 
method is that the material should be in filament form and are restricted only for a group of materials which have low glass transition temperature and high viscosity. Other than that, FFF is used frequently because it is cost effective and a faster manufacturing technique compared with the other techniques $[7,8]$.

\subsection{INKJET 3D PRINTING (3DP)}

3DP is a type of powder bed fusion which is developed by Massachusetts Institute of Technology. In this technique the powdered material is spread on the bed which is combined by a binder in the desired 2D shape. When the 2D layer is obtained the platform lowers, which is continued for the subsequent layers. This process is repeated until the final layer is completed and the final product is obtained after the unrestrained material is removed. The quality of the product is determined by the size of the powder particles, speed of binder deposition, binder viscosity and the interaction between the binder and the powder. The main advantage of this process is that it is low cost and provides flexibility in materials selection. On the other hand, the surface quality is poor, and the printer resolution is limited $[5,9]$.

\subsection{DireCt ENERGY DePOSITION (DED)}

Direct energy deposition (DED) technique is a type of FFF process and is different from powder bed fusion. In this process a high energy electron or laser beam is focus on a small area of continuous flow the metal material. This energy is used to melt the metal and the molten material is deposited and cooled down. The difference between the DED and powder bed fusion method is that the energy is directly focused on the feed stock which melts the metal and deposited, but in powder fusion the metal is melted in layers on a powder bed. It is a type of FFF process which is printed in layers through a nozzle. The resolution and the quality of the product is based on the energy of the heat source. This can be used for multiple materials and can be printed in different directions, but it is a slow and a bit expensive process $[3,9]$. 


\section{LITERATURE REVIEW}

Researchers had investigated the effect of 3D printing design and process parameters on the mechanical performance of the manufactured parts. Most researchers concluded that a lot of parameters influence the properties of 3D printed parts. Some of them are layer thickness, build orientation, raster angle, infill percentage, temperature of the bed and the nozzle, feed rate, printing speed. Including all these parameters even the printing technique also affects the mechanical properties of the material.

\subsection{EFFECT OF ADDITIVE MANUFACTURING PROCESS}

Dizon et al. [4] evaluated the mechanical properties of the Poly Lactic Acid (PLA), Acrylonitrile Butadiene Styrene (ABS) and Poly Ether Ether Ketone (PEEK) which were 3D printed. There are a lot of types of additive manufacturing techniques in the industry and some of them were explained, and the impact on the mechanical properties due to the processes was described. In the FFF process, the polymer parts were influenced by the thickness and the raster angle of the print. Good tensile strength properties were exhibited at $45^{\circ}$ orientation for PLA samples and at $0^{\circ}$ orientation for ABS and PEEK. The layer thickness also affected the mechanical properties which showed that the increase in layer thickness decreased stiffness and ultimate strength. The compression, bending, and impact properties were good at $0^{\circ}$ orientations and the fatigue properties were better observed at $45^{\circ}$ raster angle. This all showed that, the optimal value was found for each type of polymer with respect to the mechanical properties helped in 3D printing. In the SLA process, the orientation had impact on the mechanical properties; however, layer thickness had more influence. When layer thickness was increased, the tensile strength was increased as well, but the impact and flexural properties was decreased. They concluded that due to good bonding, resulting from polymerization of the new layer with prior layer, coupons showed good stiffness and strength properties, while this caused the coupons to behave like a brittle material and lowered impact properties. The variation in energy density of the laser also caused a difference in mechanical behaviour of the coupons causing weaker bonds and defects in the layers for SLS process. When manufactured correctly with right parameters, they exhibited high strength and stiffness properties, but low compression values. The orientation perpendicular to the laser scanning of the printed samples produced high flexural properties. The main problem in the SLS process was the porosity, caused due to an unreliable powder deposition. This caused in weak layer bonding resulting in low mechanical properties. This was even observed in the 3DP process as it is also a type of powder bed fusion. When the powder consistency and the laser strength was maintained, they 
gave good manufactured coupons. Mechanical properties were affected by roughness of the surface in poly jet processing and orientation of the printing in laminated object printing. As a result, each process has its own pros and cons, which should be considered for printing a part.

\subsection{EFFECT OF LAYER THICKNESS AND RASTER ANGLE}

The change in raster angle and layer thickness during 3D printing affects the mechanical properties which were investigated by $\mathrm{Wu}$ et al. [25]. They worked on finding the optimal print parameters of Polyether ether ketone (PEEK) by varying layer thickness and raster angle. Later, they compared the mechanical properties of 3D printed PEEK and Acrylonitrile Butadiene Styrene (ABS) parts. When the tests were performed on changing the layer thickness from 200 $\mu \mathrm{m}$ to $400 \mu \mathrm{m}$ and altering the raster angles $\left(0^{\circ} / 90^{\circ}, 30^{\circ} /-60^{\circ}\right.$, and $\left.45^{\circ} /-45^{\circ}\right)$ the optimal value obtained were $300 \mu \mathrm{m}$ on layer thickness and $0^{\circ} / 90^{\circ}$ for raster angle. The PEEK tensile strength value was $108 \%$ higher than the ABS specimens. In addition, the compressive and bending strength values of PEEK were also $114 \%$ and $15 \%$ higher than the ABS ones. These results showed that the 3D printed PEEK had better mechanical properties than 3D printed ABS. When the $3 \mathrm{D}$ printed values were compared to injection moulded values, they were comparatively less. This was due to weak layer bonding and void formation, which need to be improved to increase mechanical performance [25]. Raster angle, layer thickness, and raster width have an impact on tensile properties of the FFF printed PLA coupons and were investigated by Rajpurohit and Dave [16]. The coupons were printed with different levels of orientations $(0,30,45,60$, and 90), different layer thicknesses $(100,150,200,250$, and $300 \mu \mathrm{m})$ and different raster widths $(400,500,600$, and $700 \mu \mathrm{m})$. This all makes 100 coupons for one test with all configurations and this test was performed 3 times in total. The tensile test is followed by ASTM D638, maintaining the cross-head speed at $5 \mathrm{~mm} / \mathrm{min}$. When the tests were performed every parameter showed an effect on the tensile properties of 3D printed PLA. When the graphs of each configuration were observed, high tensile strength of $47.5 \mathrm{MPa}$ was observed at $0^{\circ}$ raster angles showing the high tensile strength properties at $0^{\circ}$ raster angle and low tensile properties at $90^{\circ}$ orientation. This confirmed a major effect on 3D printed PLA coupons due to raster angle. The layer thickness also showed some significance in the values that tensile strength values were higher for lower layer thickness than the higher ones. This can be said that due to low layer thickness there was better bonding area between the layer interfaces. Higher tensile values were obtained for high raster width that can be related to the thermal mass of the raster. The failure observed in the specimens was due to the void formations between the layers resulting in low tensile strengths values [16]. 


\subsection{EFFECT OF BUILD ORIENTATION}

Afrose et al. [19] worked on the impact of build orientation on the mechanical properties of the 3D printed PLA parts. They followed ASTM D638 standards and printed the PLA coupons with $0^{\circ}, 90^{\circ}$ and $45^{\circ}$ orientation which are tensile tested. The results showed that the tensile strength was higher in $0^{\circ}$ orientation coupons which can be explained as the extrudates are parallel to the tensile load. Since the direction of print is parallel to the applied load it carries the maximum load compared to the $90^{\circ}$ and $45^{\circ}$ orientations. This helps with manufacturing small parts using desktop 3D printers to yield good strength to the printed parts [19]. The research on 3D printing extended to build the coupons in different planes, varying layer thicknesses and feed rates. Chacon et al. [10] investigated the tensile and fatigue behaviour of the PLA coupons printed in different positions, with different layer thickness and feed rate. Commercial SMARTFIL PLA filament and WitBox 3D printer was used for manufacturing the coupons. ASTM D638 and ASTM D790 were used for tensile and flexural testing, respectively. The orientations used for the testing are Flat $(\mathrm{F})$, On edge $(\mathrm{O})$ where the fused filament deposition was positioned in the same direction as pull direction, and Upright (U) where the layers were deposited perpendicular to the pull direction. In addition to this, four thicknesses, i.e. $0.06,0.12,0.18,0.24 \mathrm{~mm}$ and three feed rates i.e. $20,50,80 \mathrm{~mm} / \mathrm{s}$ were used for manufacturing specimens. Combining five coupons for each configuration, a total 360 coupons were manufactured and tested in this work. Uniaxial tensile and 3-point bend tests were performed for obtaining tensile and flexural results. Both the tests were conducted according to the ASTM standards and temperatures were maintained constant. By observing the results and the failure modes, it can be concluded that there was an effect of build orientation, layer thickness and feed rate on the mechanical properties of the 3D printed parts. The build orientation has a significant effect on the tensile and flexural properties. The upright orientation had the lowest strength and stiffness compared to flat and on-edge samples that have similar results. This difference was mainly due to the inter-layer fusion bond failure and trans-layer failure. Inter-layer fusion bond failure was observed in upright orientation i.e. the layers were deposited perpendicular to the load direction. As a result, only the bond between the layers carried the load not the extrudates, which caused a brittle fracture. In flat and on edge orientations the layers were deposited parallel or transverse to the load applied (with the same plane), so the load was carried by the extrudates which causes a ductile fracture. The layer thickness and the feed rate also influenced mechanical properties of 3D printed coupons. The results showed that the tensile strengths decreased with an increase in thickness. It was also 
mentioned that when there was a decrease in thickness, there will be an increase in flexural strength values due to an increase in coupons stiffness. Considering the results for different feed rates, only upright orientation had a significant difference than the other orientations. when the feed rate was increased, the mechanical properties decreased in upright configuration, while the change was not significant in flat and on-edge orientations. As a result, a low feed rate was recommended when the samples were printed in the upright configuration and a high feed rate was suggested for flat and on-edge condition to save time as there was not much significant change in the properties. Authors concluded that for high mechanical properties, on-edge and flat orientations should be used with low thickness and high feed rate to get an ideal printing time, strength, and stiffness [10].

\subsection{EFFECT OF DEPOSITION ANGLE AND TRAJECTORY}

A research work completed on the mechanical behaviour of the PLA printed parts and influence of the deposition angle also helped researchers to investigate the properties of the additive manufactured parts. Ahmed et al. [12] printed plain and crack-like notched PLA coupons by different deposition angle. These were tested to obtain the tensile results of the different coupons. The tensile results showed that the effect of deposition angle was not much significant; however, the stress - strain graphs and the fracture surface proved that the coupons had better mechanical properties at $0^{\circ}$ and $90^{\circ}$. They showed an elastic behaviour, while the coupons made from another angle were brittle. They concluded that the coupons were best fabricated horizontally and the mechanical behaviour was modelled using a simple linear elastic constitutive law [12]. The optimization of the filament deposition trajectory can improve the mechanical properties of the 3D printed material. Gardan et al. [32] worked on the optimization of deposition trajectory and improvement of fracture toughness was observed in thermoplastic polymers. The classic deposition was analysed, and it was found that the ABS has high strength along the filament direction rather than the perpendicular direction. Then, the trajectory of the printing was optimized in which the filament deposition was followed along the stress tensor. The filament deposition trajectory was enhanced by using stress criterion and finite element simulation of the linear elastic model. The modifications for G-code was given to print in optimized deposition trajectory. When printing the samples one crack test specimen was printed in a linear infill with $45^{\circ}$ depositing alternate layers (classical way) and the other specimen was printed in the generative trajectory method (optimized way). The results show that the optimized sample require more energy to crack than the classical sample. The crack length was verified with respect to load applied which showed that the optimized sample had 
less crack length when compared to the classical sample. Strain concentration region was more in the optimized specimen than the classical specimen which showed that crack propagation was much faster in classical sample than the modified sample. The classical sample showed a brittle like crack behaviour but due to the optimization the other sample showed ductile like behaviour [32].

\subsection{EFFECT OF INFILL PERCENTAGE AND PATTERN}

The significance of model infill was investigated by Beniak et al. [14]. They performed experiments on 3D printed PLA parts based on four different parameters, i.e. model filling, filling shape, layer thickness and model orientation. These parameters were tested with 2 levels with two different set of parameters. To obtain an optimal condition, the parameters were changed in a matrix form and tensile strength results were compared with respect to the parameters. As a result, sixteen experiments were performed to compare the tensile strength values of each set-up with respect to parameters. As the tensile values were arranged and plotted on a graph, the model infill percentage showed a significant change in the tensile properties. When the infill density was low, there was more air gap in the coupons which caused them to fail easily. The other factors, like filling shape and layer thickness did not show much impact, but they also had an influence on the 3D printing. This showed model infill had a significant effect on material and 3D printing [14]. The infill pattern also affected the mechanical performance of the 3D printed coupons. To explore the mechanical behaviour Giovanni et al. [17] performed fatigue testing on 3D printed PLA parts. The specimens were printed with two infill patters, i.e. rectilinear and honeycomb with changing layer height, nozzle diameter, infill density, and print velocity. A total of 27 configurations were tested for each infill pattern. They were formed by Taguchi experimental design which gave a wide factor to evaluate the properties and reduce the number of runs. The specimens were manufactured in a cylindrical shape and tested with a concentrated load of $15 \mathrm{~N}$ on all the specimens and to obtain the Wohler curve, tests were performed with varied loads from $10 \mathrm{~N}$ to $22 \mathrm{~N}$. Comparing the results it showed that, honeycomb infill pattern had high fatigue life and the infill percentage showed a significant difference in failure of the specimens. The high infill percentage showed a ductile behaviour followed by low shear fracture which gave longer fatigue life than the other infill densities. The print speed did not show any significant effect on the specimens but there was a little effect due to nozzle diameter and layer height. A combination of $75 \%$ infill density, $0.5 \mathrm{~mm}$ nozzle diameter and $0.3 \mathrm{~mm}$ layer height with honeycomb infill pattern gave the highest value of fatigue life [17]. Similarly, Cristian lubonmbo and Michael A. Huneault [11] 
worked on the infill patterns of 3D printing. The PLA filament and RepRap 3D printer with $0.5 \mathrm{~mm}$ nozzle diameter was used for manufacturing. General ASTM standards of tensile and flexural testing were used, i.e. ASTM D638-14 and ASTM D790-10. One and three perimeter cells were used for the fabrication. The infill densities were fixed as $15 \%, 30 \%$ and $50 \%$ and were used as low, medium and high relative densities for 3 perimeter cells for manufacturing. The infill densities were adjusted to print one perimeter cell as to obtain the same relative densities of three perimeter cells. Five different patterns were used which are hexagonal, triangular, square, square-diagonal and reinforced square diagonal. All the one perimeter cells were printed with $0.75 \mathrm{~mm}$ thickness and $0.60 \mathrm{~mm}$ thickness was used for three perimeter cells. The tests were performed on every specimen and results were obtained for tensile and flexural properties. The obtained results showed that the hexagonal type resulted in higher mechanical properties than expected in both tensile and flexural tests. The square cells showed the best results in tensile tests than any other pattern followed by hexagonal pattern, but hexagonal pattern showed the best flexural results in both flat-wise and edge-wise testing compared to triangular and square patterns. Considering the perimeter, three perimeter cells outperformed the one perimeter cell due to the alignment of the cells which the loading direction. They concluded that high perimeter cells and had better loading and bending properties in which hexagonal and square patterns showed best results [11].

\subsection{EFFECT OF TESTING TEMPERATURE}

The materials during printing were affected by the ambient temperature as well. Research was performed by Grasso et al. [15] on this parameter to evaluate the mechanical properties of the PLA coupons. The plain filaments and the extruded 3D printed coupons were tensile tested at five different temperatures $(20,30,40,50$ and 60 degrees) five specimens for each configuration. The printed PLA coupons were printed with three different orientations $0^{\circ} / 90^{\circ},-30^{\circ} / 60^{\circ}$ and $\pm 45^{\circ}$, making a total of 75 coupons for testing. When the filaments were tested at $30,40,50$ and $60^{\circ} \mathrm{C}$, failure was observed in each case, but the filament did not fail at $60^{\circ} \mathrm{C}$. This was due to increase in high strain rate and the free chain movement of the molecules forms a glass transition phase which means continuous extension of the filament. Compared to the 3D printed coupons values, it was observed that when temperature increases the modulus of elasticity decreases. The strength values were high when the ambient temperature was low, while an increase in temperature caused an increase in the failure strain and a reduction in strength [15]. 


\subsection{EFFECT OF FORCED AIR COOLING}

Air cooling was also played an important aspect in change of mechanical properties which was investigated by Chun-Ying Lee and Chung-Yin Liu [13]. They worked on the impact of forced air cooling on the mechanical performance of 3D printed parts. The 3D printer was modified and equipped with a three series of fans for forced air cooling. The forced air flow was used based on the requirement and the material selected. This made the forced airflow cooling as a parameter during FFF printing. It was fixed with pulse width modulation controller for controlling the air velocity, an air filter to avoid debris and valve gate modulator for regulating the air flow for different velocities. They followed ASTM D638 standards for printing and $0^{\circ}$ and $90^{\circ}$ coupons uniaxial tensile testing. The tensile properties were high when the air velocity was zero and reduced gradually with the increase in air velocity. This is due to the voids created in between the layers during the cooling process. When airflow is low, there is a high deposition temperature, which helps in bonding the layers. With an increase in airflow, the deposition temperature decreases causing voids between the layers. The airflow caused decrease in layer bonding, but it increased the dimensional quality. This was observed in both horizontal and vertical printing, but compared to vertical direction, printed coupons in horizontal direction had more tensile strength properties. To check the airflow requirement of the material, they created a Rubik's cube. The parts of the cube were printed in different speeds and were tested. The cover plates and puller shafts need strength which can be obtained with $0 \mathrm{~m} / \mathrm{s}$ velocity airflow, but the centre socket ball was fabricated with a cooling airflow of $3 \mathrm{~m} / \mathrm{s}$ velocity to get better dimensional quality as it needs to give good performance [13].

\subsection{REVIEW ON Finite ELEMENT ANALYSIS}

Finite element analysis on the tested 3D printed coupons gave much more details in the bonding of the layers and crack behaviour. Garg and Bhattacharya [18] worked on FE analysis of the tensile test coupons to investigate the fracture behaviour of 3D printed ABS specimens. The specimens were manufactured according to ASTM D638 with different raster angles $\left(0^{\circ}, 90^{\circ}\right.$ and $\left.0^{\circ} / 90^{\circ}\right)$ and layer thicknesses $(0.178,0.254,0.330 \mathrm{~mm})$. The specimens were manufactured with grippers and were placed inside the Universal Testing Machine for tensile testing. Specimens with $0^{\circ}$ showed a higher tensile strength at low layer thickness, which was decreased and then increased by increase in layer thickness. In low layer thickness, there were more fine layers in the loading direction, in which the total load was taken by each layer making it stronger. There was an increase in layer thickness in which the number of layers were less, but the intra-layer necking was more which behaved like a solid metal material giving it more 
strength. It can be observed in the cross-sectional FE analysis that every layer was taking the load which gave more strength to the sample. In $90^{\circ}$ orientation the layers were transverse to the load direction in which the failure was dependent on the adhesion of the layers. The failure happened in the centre of the gauge length and was due to delamination or the layer separation. The cross-sectional analysis showed that the failure started from the outer layer to the inner layers causing it to bare less load which made it fail quickly. The $0^{\circ} / 90^{\circ}$ orientation specimens behaved in a different manner when compared to $0^{\circ}$ and $90^{\circ}$. The $90^{\circ}$ layers in $0^{\circ} / 90^{\circ}$ layup failed easily when compared to the $0^{\circ}$ layers. Since the $90^{\circ}$ layers were placed alternatively with $0^{\circ}$ layers, they were pulling the $0^{\circ}$ layers making them fracture easily. By observing the FE analysis of the cross-section, it can be seen that more stresses were concentrated on $0^{\circ}$ layers. When the thickness was increased, the overlap region also increased, which helped in stronger bonding between the layers making them load bearable. The specimens were also manufactured in different part orientations, i.e. XYZ, YXZ, and ZXY and tested. These orientations also had an effect on the printed coupons. High strengths were obtained when the coupons were printed in $\mathrm{XYZ}$ or $\mathrm{YXZ}$ orientations compared to $\mathrm{ZXY}$ orientation. In conclusion, they stated that the layers which were parallel to the loading direction were load bearable which helped in giving high tensile strength. The layers perpendicular to loading failed due to delamination and this also affected the $0^{\circ} / 90^{\circ}$ orientation and it was optimal to fabricate in XYZ or YXZ orientations than the ZXY [18].

\subsection{EFFECT OF MACHINING}

Generally, when we see research work in 3D printing, coupons were printed with change in different parameters, but Song and his group [20] worked on the mechanical response of the 3D printed PLA coupons which were manufactured from rectangular blocks which were 3D printed and injection moulded. To obtain the optimal porosity which is a key factor for 3D printing, trail tests were run with change in extruder temperature, layer height, and printing speed. The optimal parameters were extruder temperature of $220{ }^{\circ} \mathrm{C}, 0.2 \mathrm{~mm}$ in layer height and $60 \mathrm{~mm} / \mathrm{s}$ printing speed which were obtained from the trail runs for printing the rectangular blocks. Rectangular blocks were printed in $0^{\circ}, 90^{\circ}$ and $45^{\circ}$ directions in which the tensile, compression, and fracture specimens were machined per required ASTM standards. In a similar fashion rectangular blocks were injection moulded and the specimens were machined for tensile, compression and fracture tests with notch. The notch on both types of specimens was sharpen by a surgical scalpel to the required radius. In addition, extruded filaments were also produced for mechanical testing to compare with the machined coupons. The strain in tensile 
test was measured with strain gauges fixed on the specimens and laser extensometer were used for compression and fracture test. When pure filaments were compared to extruded filaments they did not had much effect on its crystal behaviour after extrusion which almost showed same stress strain graphs. The 3D printed the injection moulded coupons were compared which showed almost same peak values, while the fracture behaviour was different. A brittle fracture was observed in injection moulded specimens with a sudden failure, but the 3D printed specimens showed a ductile elasto-plastic behaviour. The Scanning Electron Microscopy (SEM) images of fracture surfaces also showed the difference in crack growth. In 3D printed specimens the extrudates act as the fibres which take more load compared to a solid specimen, so it performed better than the injection moulded specimens in the mechanical tests. Considering the orientation of specimens, the specimens with $45^{\circ}$ showed better results for tensile and compression tests followed by $0^{\circ}$ and $90^{\circ}$ specimens, respectively. The $0^{\circ}$ specimens performed well in 3-point bend test and gave better fracture results then the injection moulded specimens [20].

\subsection{EFFECT OF CHOPPED AND SHORT CARBON FIBRES}

As we extend our research in 3D printing, only plastics were manufactured using AM processes but in later researches, thermo plastics reinforced with carbon fibres were investigated by Ning et al. [21] in which they worked on the effects of carbon fibre content on the mechanical properties and porosity of ABS plastic. The carbon fibre powder of $100 \mu \mathrm{m}$ and $150 \mu \mathrm{m}$ in length were used in the fabrication process of the test specimens. Different carbon fibre content 3,5 , $7.5,10$, and $15 \%$ by weight) were used and mixed with the plastic pellets in a blender and were extruded. The extruded filaments were cut in to pieces, processed and extruded again to increase the bulk density of the filament. This filament was used to print the tensile and flexural specimens with dimensions per ASTM D638-10 and ASTM D790-10, respectively. The layer thickness was maintained at $0.2 \mathrm{~mm}$, with 14 layers of $\pm 45^{\circ}$ orientation keeping $100 \%$ infill density. Testing was performed according to the ASTM standards on five specimens for each configuration. For carbon fibre with $100 \mu \mathrm{m}$ in length, it was observed that there was an increase in the tensile strength and Young's modulus when the carbon fibre content was increased from $0 \%$ to $5 \%$, but these reduced for a higher content of $7.5 \%$ to $15 \%$. For $150 \mu \mathrm{m}$ carbon fibre specimens there was an increase in the tensile strength of the material with respect to the carbon fibre content. Flexural test on $0 \%$ and $5 \%$ carbon content specimens showed the highest flexural modulus and strengths for $5 \%$ carbon content specimens. A SEM analysis was performed to further investigate these variations and it was found that the porosity acted as a 
main factor for the change in properties. When the weight percentage was increased above $7.5 \%$, the porosity was increased which caused specimens to fail earlier. In conclusion the addition of carbon fibres in the plastic gave an increase in the tensile strength and Young's modulus, but a decrease in toughness and ductility [21]. Ning et al. [22] extended their previous work and investigated printing parameters, like raster angle, nozzle temperature, layer thickness, and infill speed. Cong et al. [22] worked on the evaluation of tensile properties of the carbon fibre reinforced composites. Two types of raster angles were used, i.e. $0^{\circ} / 90^{\circ}$ and $\pm 45^{\circ}$, printing speeds were varied from $15 \mathrm{~mm} / \mathrm{s}$ to $35 \mathrm{~mm} / \mathrm{s}$, nozzle temperature was changed from $200{ }^{\circ} \mathrm{C}$ to $240{ }^{\circ} \mathrm{C}$, and five-layer thicknesses were used from $0.15 \mathrm{~mm}$ to $0.35 \mathrm{~mm}$. Considering the change in the raster angle, $0^{\circ} / 90^{\circ}$ specimens had higher tensile properties compared with $\pm 45^{\circ}$ ones. This was due to poor adhesion between the matrix and fibres as the tensile load was effectively transferred from matrix to fibres, the load acting in the direction of fibres can take more stress compared to the other directions. When the printing speed was increased, it decreased the tensile properties with an inflection point at $25 \mathrm{~mm} / \mathrm{s}$. At very low speeds the raster from the bottom layers were broken, and when the speed was very high there was not enough time for the bonding which made them to have less tensile properties which can be verified by SEM analysis as well. Considering the nozzle temperature, highest tensile values were obtained at $220^{\circ} \mathrm{C}$. At low nozzle temperatures, there was not enough energy to create strong bonds with subsequent layers and the increase in nozzle temperature showed that the strong bonds were formed at $220{ }^{\circ} \mathrm{C}$. With an increase after optimum temperature, it contributed to completely merging the layers causing more pores, which led to less tensile properties. Experiments regarding the change in layer thickness showed that the increase in layer thickness reduced the tensile strength. When the layer thickness was low, each layer was tightly coalesced with each other, which was observed in SEM images, increasing the interbonding strength and reducing pores. On the other hand, with an increase in the layer thickness, the bonding strength was weak, and layers were not tightly packed, which created voids causing it fail easily [22]. As they worked on chopped carbon fibres reinforced composites, Ferreira et al. [26] performed mechanical tests on PLA specimens reinforced with short fibres. The filament used was drawn by mixing the $15 \%$ weight fraction short Carbon Fibres with PLA $(\mathrm{PLA}+\mathrm{CF})$. Since during 3D printing fibres were aligned it behaved as a composite and had two tensile modulus, two Poisson ratios, one shear modulus, and related strength properties. The coupons were printed with ASTM D638-10 and ASTM D3518-13 for tensile and in plane shear test with three different orientations $\left(0^{\circ}, 90^{\circ}, \pm 45^{\circ}\right)$ up to 16 layers. PLA and PLA+CF test results were compared, and SEM analysis was performed to compare the fracture surfaces. 
The tensile results showed that the tensile modulus of PLA+CF is higher than the PLA, while its tensile strength values were almost same as the PLA specimens. This showed that the addition of carbon fibres did not affect any strength values of PLA. This might be because of the short length of fibres and the poor adhesion between PLA and carbon fibres. This also indicated that the addition of carbon fibres in PLA caused it to fail at lower stains and making it more brittle [26].

\subsection{EFFECT OF CONTINUOUS CARBON FIBRES}

Previous research work were continued and improved by working of continuous carbon fibre reinforced composites which can be seen by Blok et al. [24] who performed tests on carbon fibre reinforced thermoplastic parts 3D printed by FFF method. They performed mechanical tests, like tensile, flexural and shear tests and compared 3D printed continuous carbon fibre composites and 3D printed short carbon fibre composites. The continuous carbon fibres were added at $27 \%$ of volume fraction and short fibres at $6 \%$ volume fraction with nylon thermoplastic filament matrix. In continuous fibre 3D printing tensile and flexural specimens were printed at $0^{\circ}$ orientation following ASTM D3039 and ASTM D7264, respectively. The shear samples were printed with fibre at $13^{\circ}$ and the end tabs are at $21^{\circ}$ angle. The short fibre specimens were made at $0^{\circ}$ orientation following ASTM D638, rectangular fill pattern for flexural samples following ASTM D7264, and $\pm 45^{\circ}$ shear specimens with ASTM D3518. They used 4 samples for each test and the average values were considered for evaluation. The results were very promising for continuous fibre composites with high tensile properties; however, the flexural properties and shear modulus were lower. For the short fibre samples, the tensile properties were not high, but the shear and flexural values were good with respect to its volume fraction. This difference of mechanical properties between was due to a lower quality in fabrication. The images from optical microscopy showed lower flexural and shear properties in the continuous fibre composites was due to high porosity and voids in the samples. They concluded that highly aligned short fibres when used for 3D printing give better results in performance and processing than unaligned short fibres and aligned continuous fibres [24]. These research on continuous carbon fibre reinforced composites in 3D printing was continued by reinforcing it with $\mathrm{ABS}$ in which, Yang et al. [23] evaluated the mechanism and performance of the continuous carbon fibre reinforced thermoplastic composites. Tensile, flexural, and interlaminar shear tests were conducted on the $3 \mathrm{D}$ printed composites. In continuous carbon fibre composite printing, the extrusion head receives carbon fibre insulated and coated with the thermoplastic which was printed in the required dimensions and 
orientations. International Standards Organization (ISO) 14125:1998, ISO 527:1997 and ISO 14130:1998 standards were followed for three-point bend, tensile, and interlaminar shear tests, respectively. ABS thermoplastic with $10 \mathrm{wt} \%$ continuous carbon fibre was used to manufacture the specimens. The results showed that the tensile and flexural values had increased and were higher than the pure ABS parts which were 3D printed and injection moulded. It almost reached the tensile and flexural values of the injection moulded $10 \mathrm{wt} \% \mathrm{CCF} / \mathrm{ABS}$. Due to the surface tension fracture which was meant that, the thermoplastic was failed first followed by the fibre breakage. The results for tensile and flexural were promising for continuous carbon fibre 3D printed composites; however, the values for interlaminar shear test were significantly lower than injection moulded specimens. This can be related to meso, nano and micro scale interfaces in 3D printing composites. The adhesion between the fibres and the matrix was low. They did not have enough time for bonding between each filling line and the layers, which made them weak to hold the fibres causing low shear strength [23].

\subsection{EFFECT OF PRINT PARAMETERS ON IMPACT PROPERTIES}

There are not many papers on low velocity impact tests of 3D printed plates and damage through thickness. As a result, multiple papers are summarized in this section to explore the impact behaviour of different coupon geometries. Wang et al. [27] performed tests to verify the effects of print parameters on the impact properties of the 3D printed PLA. The coupons were printed using a MakerBot experimental 3D printer and the dimensions were followed per ASTM D256-10. Layer height $(0.2 \mathrm{~mm}$ and $0.4 \mathrm{~mm})$ and build plate temperature $\left(30^{\circ} \mathrm{C}\right.$ and $160^{\circ} \mathrm{C}$ ) were varied with an infill density of $100 \%$ for every specimen. To compare the impact properties of 3D printed PLA, injection moulded parts were also produced and tested. Injection moulded specimens were notched separately, and the tests were conducted per Izod impact procedure. The morphology was studied by Scanning Electron Microscopy (SEM), Differential Scanning Calorimetry (DSC), X-Ray Diffraction (XRD) and Polarized Optical Microscope (POM) observations. The coupons were grouped as IM- injection moulded, A- $0.2 \mathrm{~mm} 30^{\circ} \mathrm{C}$, B- $0.2 \mathrm{~mm} 160^{\circ} \mathrm{C}, \mathrm{C}-0.4 \mathrm{~mm} 30^{\circ} \mathrm{C}$ and D- $0.4 \mathrm{~mm} 160^{\circ} \mathrm{C}$. IM coupons showed better impact strength than group A and C, but their values were lower than group B and D. Using the morphological studies of the broken specimens, it can be concluded that when the bed temperature is high, the diffusion degree between each layer and strand is high which results in smaller voids. The lower layer thickness gives much smaller voids as the strands are much closer resulting in high impact properties. When DSC results were observed the heat flow variations showed that annealing of the coupons due to high bed temperature caused high 
crystallinity. Due to this high crystallinity and low heat flow variation, the coupons in group B and D had high impact strength compared to other coupons. The XRD, SEM and POM results showed that there was higher crystallinity in the specimens which were printed at higher temperature and thinner thickness compared to other specimens stating giving them more impact strength than the other coupons [27]. Impact absorption of 3D printed PLA parts were tested by Tsouknidas et al. [28] and showed significant results due to a change in infill density, layer height, and infill patterns. A 3D printer with $3 \mathrm{~mm}$ nozzle diameter was used to print the cylindrical coupons. They tested five different printing speeds ranging from $30 \mathrm{~mm} / \mathrm{s}$ to 220 $\mathrm{mm} / \mathrm{s}$ and selected an optimal printing speed of $100 \mathrm{~mm} / \mathrm{s}$. Three-layer heights $(0.1,0.2$, and $0.3 \mathrm{~mm}$ ), infill densities $(25,50$, and 100) and infill patterns (rectilinear, octagonal, and concentric) were varied for the experimental tests making 27 configurations with three specimens tested for each configuration. The low-density specimens were porous and absorbed less energy than the bulk parts. The bulk specimens with rectilinear infill pattern showed highest impact toughness with low layer thickness. The shock absorption properties with respect to volume fraction were good in lower infill density. Considering the energy absorbed per volume fraction with respect to the infill densities, layer thickness and infill patterns the specimens with less density performed well with the impact absorption. The optimal parameters for energy absorption were $25 \%$ infill density and rectilinear fill pattern as they dissipate high energy values for low force rates [28].

There will be an affect due to the stress concentrators in the printed coupons. These properties were investigated by Roberson et al. [29] who performed impact tests on 3D printed polymers to compare the stress concentrator of printed and milled specimens with different orientations. They used a desktop 3D printer and manufactured ABS coupons for impact testing per ASTM D256-10 standards. The specimens were printed with four different orientations where: XYZ printing with notch on $\mathrm{XZ}$ plane parallel to Z-direction, $\mathrm{XYZ}$ printing with notch on $\mathrm{XY}$ plane parallel to $\mathrm{Y}$-direction, printing on $\mathrm{XY}$ plane at $45^{\circ}$ with notch on $\mathrm{XY}$ plane and ZXY printing with notch on ZX plane parallel to X-direction. These were categorized in two groups, i.e. the notch was printed during the fabrication, and the notch was milled after the printing. In a similar way, an industrial grade 3D printer was used to manufacture ABS, PC, ABS-PC and Ultem 9085 specimens. These were also printed in same way but a little change in the orientations that the Type A was printed in XYZ orientation with $45^{\circ}$ raster and notch on $\mathrm{XZ}$ plane parallel to $\mathrm{X}$-direction, Type $\mathrm{B}$ was printed on $\mathrm{XY}$ plane at $45^{\circ}$ with raster parallel to its length and notch on XY plane, Type C was printed same as Type A but notch on XY plane parallel to Y- 
direction and Type $\mathrm{D}$ was printed upwards in $45^{\circ}$ raster with notch on $\mathrm{ZX}$ plane parallel to Xdirection. Comparing ABS specimens, there was not significant difference between milled and printed notches, but comparatively the milled notches had higher impact resistance. The specimen with $45^{\circ}$ raster showed high impact results and specimen printed upright demonstrated low impact strength values. The results of industrial grade printer specimens followed the same trend but changed with material. The ABS and ABS-PC showed almost similar results with less significance of the milled or printed notch, but comparatively the milled notches showed better results than the printed notches for the PC and Ultem 9085 specimens. The $45^{\circ}$ oriented coupons of type A, C, and D showed good impact results for ABS, PC, and PC-ABS materials. The printed notches created voids at the notch reducing its structural integrity. So, the milled notches showed more impact resistance compared to the printed notches [29].

Pure polymers were investigated in previous studies. Bax and Mussig studied [30] the impact and tensile properties of PLA specimens reinforced with natural fibres. Cordenka rayon fibres and Flax fibres are the 2 types of natural fibres reinforced with the PLA material by injection moulding process. They used three different fibre-mass compositions (10\%, 20\% and 30\%) for PLA/flax composites and four different compositions (10\%, 20\%, 30\% and 40\%) for PLA/Cordenka composites. Seven coupons were tested for each configuration for impact test (DIN EN ISO 179) and tensile test (DIN EN 61). Charpy's impact test and a uniaxial tensile test were conducted on the specimens. Scanning electron microscopy (SEM) was used to study the fractured surfaces of the composites. After the completion of tests, it was observed that the mechanical properties were increased when there was an increase in composition percentage. Both the impact and tensile values were higher for PLA/cordenka composites. On the other hand, the properties for PLA/flax were lower than the pure PLA. The impact value of PLA/Cordenka composites decreased after 30\% composition which can be observed in SEM analysis as many fibres were not enclosed by the matrix leading to lower adhesion between the fibres and matrix. The Young's modulus value was higher for the PLA/flax composites compared to PLA/Cordenka specimens. In SEM analysis of both composites fracture surfaces, pulled out fibre and their respective holes were observed, which confirmed very poor adhesion between the fibres and the matrix. Compared to these fibre, other natural fibres, like jute and kenaf showed better results in their mechanical properties [30].

The change in impact properties due to the addition of carbon fibres to pure polymers was investigated by Caminero et al. [34]. The investigation was performed to identify the effects of 
the layer thickness and the laminate stacking sequence of the carbon/epoxy ply by conducting a low velocity impact test. The specimens were fabricated and drop weight impact test was conducted per ASTM D7136 standards. The thickness variations were 8, 16 and 24 ply specimens. Two types of sequences were used, i.e. sub-laminate and ply-level sequencing. In sub-laminate type the symmetry was increased, but in ply level type the individual plies were increased for increase in thickness. Cross ply, angle ply and quasi-isotropic lay-ups were used in this experiment. The evaluation of damage and delamination were examined by ultrasonic $\mathrm{C}$-scanned inspection. For each configuration, five samples were tested, and the average values were taken as the result. As this was a low velocity impact test, the damage type was BVID which is the reason for performing ultrasonic scan for damage detection. Two energies were used, i.e. 20.8 and $31.4 \mathrm{~J}$ with a constant mass of $9 \mathrm{~kg}$. The peak force, absorbed energy, force time graph, energy time graph and force displacement graphs were recorded for the study. As the impact energy was increased, the damage extent was increased in both stacking sequences. The energy absorbed showed that as the thickness was increased, the impact force was increased, and absorbed energy was decreased. This showed that the thinner laminates failed with higher depth and more absorbed energy than the thicker plates. The quasi isotropic laminate performed well as it absorbed less energy compared to the cross ply and angle ply. The fracture was caused due to the bending and fibre debonding which resulted in reduced stiffness. The sub-laminate stacking sequence performed better than the ply-level and this was confirmed by the ultrasonic images that the area of damage is more in ply-level sequence than the sub laminate sequence. The increase in blocked plies resulted in reduction of impact resistance due to larger delamination of the available interfaces [34]. Later, research was continued on the reinforcement of carbon fibres with thermoplastics. 3D printing with continuous fibre reinforced thermoplastics was a new technology for making composite parts. Caminero et al. [31] extended his work on impact damage resistance of 3D printed fibre reinforced with thermo plastic composites. They used FFF technique for printing with Carbon, Kevlar and Glass fibres with Nylon polymer as matrix. They investigated the effects of the process parameters such as build orientation, layer thickness, and fibre volume fraction on the impact resistance of 3D printed fibre reinforced composites. The specimens were printed in flat and on-edge orientations with three different layer thicknesses $(0.1,0.125,0.2 \mathrm{~mm})$ and three different fibre volume fractions. ASTM D6110 standards were used for impact damage resistance and Charpy's impact test is performed on the specimens. The unreinforced specimens with the flat orientation showed high impact strength compared to on-edge. When the layer thickness was increased in flat built orientation, the impact value was also increased, 
which was due to lower number of layers with high bonding strength leading to ductile fracture. On the other hand, in on-edge orientation, the impact strength was decreased with an increase in layer thickness since there were more air voids and higher porosity causing brittle fracture. The reinforced specimens showed a different fracture behaviour compared to the unreinforced ones. The glass fibre reinforced specimens showed higher impact performance than the carbon fibre reinforced ones. This was due to the weak adhesion and inter layer bonds of the nylon to the fibres as all the fibres did not adhere to the matrix. Considering the SEM images, carbon fibres specimens showed a more brittle fracture due to high stiffness. The impact resistance was also increased when the volume fraction of fibres was increased. The increase in fibre content to some extent can reduce the crack failure by preventing the crack propagation in the defects which improved the impact performance of the specimens. Comparatively, on-edge specimens showed highest results than the flat ones because in on-edge specimens the load was resisted by the individual fibre layers but in flat specimens the impact load was taken by the inter layer bonding of the adjacent fibre layers [31].

Stacking sequence and number of layers in the specimen also effects the impact properties of the carbon composites. A Low Velocity Drop Impact (LVI) test was performed on the carbon/epoxy laminates by Panettieri et al. [33]. The tests were performed to provide a benchmark value for the LVI for two types of laminates i.e. LAM 16 with 16 layers [0/+45/45/90]2s, and LAM 24 with 24 ply layers, [0/+45/-45/90]3s. ASTM D7136 standard was followed and two impactor masses $(2.5 \mathrm{~kg}$ and $4.6 \mathrm{~kg})$ were chosen for four different load applications. LAM 16 was of $2.32 \mathrm{~mm}$ thick and LAM 24 was of $3.82 \mathrm{~mm}$ thick, which were clamped on four sides of the plate for testing. The energies used for testing LAM 16 were 4.5, $10,16.4,19.3 \mathrm{~J}$ and this was $7.3,15.5,24.1,30.5 \mathrm{~J}$ for LAM 24. The force time graphs were compared in which the energies used for their respective set of specimens showed good responses. The average Delamination Threshold Load (DTL) values noted for the laminates were $2.3 \mathrm{kN}$ and $4.2 \mathrm{kN}$ for LAM 16 and LAM 24, respectively. These values were verified with the literatures and were confirmed as benchmark values. The damage pattern of the laminates was examined by ultrasonic inspection to evaluate the shape and extent of the damage since all of them were Barely Visible Impact Damages (BVID). The ultrasonic images showed that the damages found were linearly dependent with the impact load. The difference in the maximum forces and impact times lead to perform a FE analysis on the impactor machine as there was a loss of initial kinetic energy which was recalculated by the modal analysis. These 
energies helped to correct the test setup by using the experimental approach for impact energy calculations [33].

The impact behaviour is also explored on foam reinforced 3D printed plastics. Kao et al. [35] tested foam reinforced 3D printed lattice structures to explore the effects on PLA material by evaluating the toughness, stiffness, jerk, displacement, energy absorption and the maximum acceleration in the structure. This type of material is called Bi-material structure (BMS) in which a 3D printed lattice was filled with a reinforcement material like foam. In this study a 3D printed PLA lattice was filled with three different types of polyurethane (PU) foams and a 3 -point bend test machine was used as a low velocity impact test machine. The specimens were manufacture according to ASTM D7264 and were supported on both the ends with as impact at the centre. The impactor mass was $1.4 \mathrm{~kg}$ equipped with integrated piezoelectric triaxial accelerometer. The drop height was around $228 \mathrm{~mm}$ giving an impact energy of $3.14 \mathrm{~J}$ required to break the samples. The foams used were FlexFoam-it 17 (FF-17), FlexFoam-it (FF-25) and Foam-it (FI-8) which created BMS specimens: BMS-FF-17, BMS-FF-25, BMS-FI-08 and pure $\mathrm{BMS}_{0}$. Total of 15 samples were tested for each configuration and the acceleration calculated extracted all the data required. The FF-17 and FF-25 reinforced samples performed better than the pure BMS. Since they were flexible foams, they increased the energy absorption of the material with less jerk in the sample. The FI-8 is a ridged foam and did not give any promising results and in turn even reduced the values compared to pure BMS. The rigidness was due to high stiffness of the material which made the sample break easily compared with the other configurations. The high-speed images also showed that the BMS-FF-17 and BMS-FF-25 took more time to break showing ductile behaviour when compared to BMS-FI-08 and pure BMS0, which showed a brittle fracture. This means that they needed more energy to break and these energy absorptions of the samples were high compared to the others. This confirmed that the foam reinforcements with good viscoelastic properties can aid more energy dissipation and crack stabilization [35].

\subsection{OBJECTIVE}

The literature review study described FFF 3D printing design and process parameters, and their impact on structural performance of the final parts. Several mechanical testing techniques were reviewed including, tensile, compressive, bending, Charpy, Izod, etc. 3D printed parts made from PLA have a brittle nature, which makes them susceptible to impact damage. At low impact energy levels, damage can arise in the subsurface through the thickness of the part and not be easily detectable. The previous research studies were limited in terms of test piece 
geometry and did not investigate low velocity impact of 3D printed plates and damage through the thickness. In this project, a pendulum impact testing apparatus along with passive InfraRed (IR) thermography and a high-speed camera were used to investigate the impact damage characteristics of PLA 3D printed plates. Two sets of experiments were performed: one to explore the damage characteristics of 3D printed PLA plates with 2 level of impact energies; and one to investigate the effect of the layer thickness with one level of impact energy. The results obtained are useful for validating the Finite Element simulations models of 3D printed parts in impact testing using impact energies and damage patterns obtained during testing. In the following sections, the test apparatus, specimen geometry and the test plan are first presented. Then, design and manufacturing parameters for production of the specimens using FFF 3D printing are explained, followed by presentation and discussion of the results for different load levels and impact locations, with finally some concluding remarks. 


\section{METHODOLOGY}

\subsection{TeSTING APPARATUS}

In the previous section, several 3D printing processes were described, and research works performed to explore and improve their mechanical behaviour were discussed. In this section, the detailed description of the testing apparatus, test plan, manufacturing of the test specimens, and the testing procedure. An impact test was performed using a low velocity impact test apparatus in this research.

In this study we conducted a low velocity impact testing. The standard method for testing a laminated plate was a drop-weight testing using the ASTM D7136. Since the drop-weight testing was expensive and required equipment was not available in the research laboratory, an in-house low velocity pendulum impact testing apparatus was designed and manufactured (Figure 1). This low velocity impact apparatus acts like a Charpy impact test machine, but it was modified to stimulate a drop-weight test. The modified design of the impact test machine was shown below.

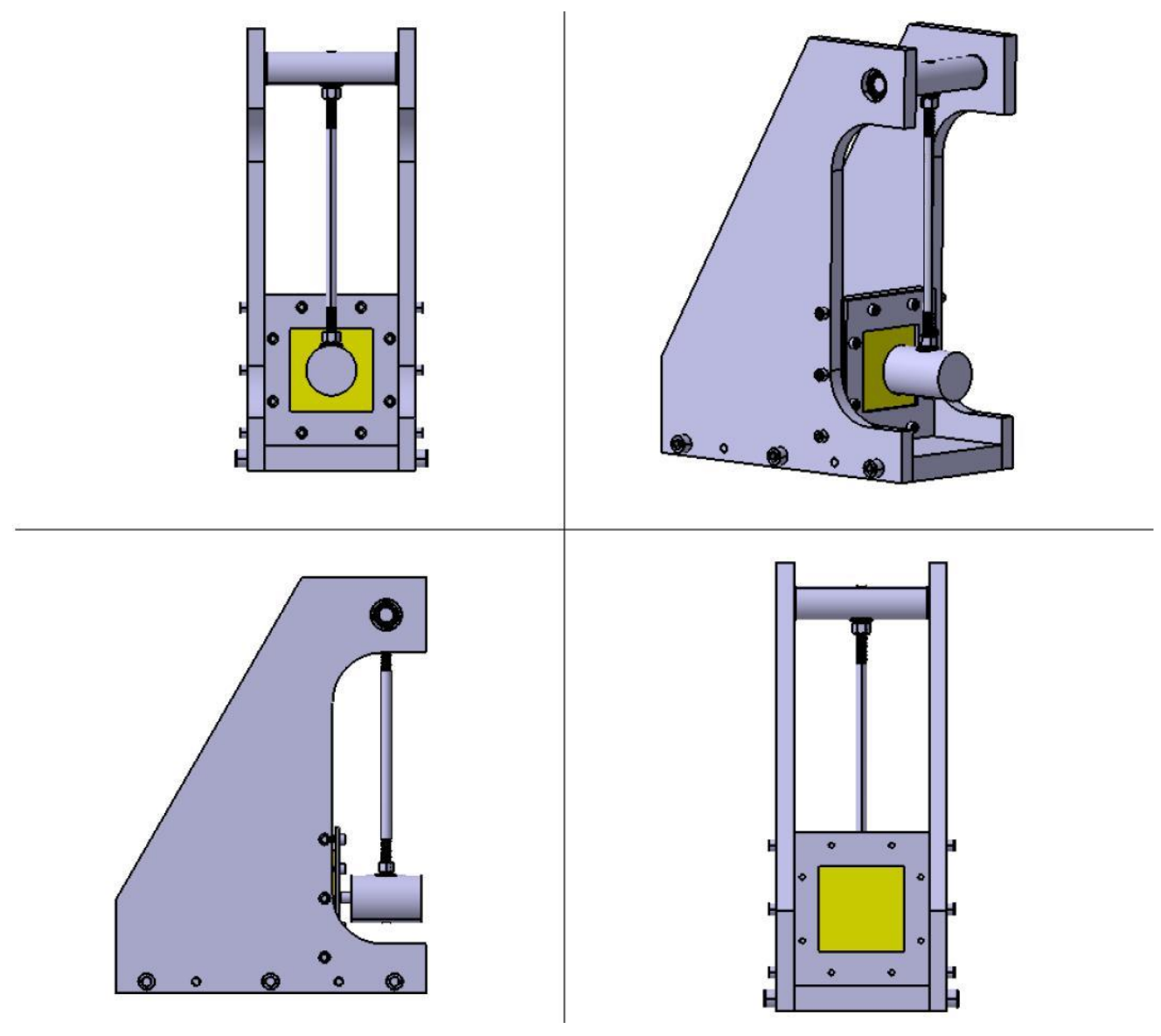

Figure 1: Modified low velocity impact test apparatus [36] 
In a Charpy impact test, the V-notched specimen was fixed on both ends and impact was applied in the centre to the opposite side of the notch. In an Izod impact test the V-notched specimen was fixed at one end and the load was applied on the free edge of the sample. In both the tests the specimen was fully fractured or broken and the difference in the height of the hammer before and after the impact gives the absorbed energy to fracture. The same principle was applied on the modified low velocity impact test machine.

The machine was a low energy or low velocity impact test machine for plastic or composite materials. It works on the pendulum and energy conservation principle mentioned for Charpy and Izod impact tests. A mass was attached to the pendulum arm and released from a certain height to impact the specimen. The difference in the height of the pendulum before impact (initial energy) and after impact (rebound energy) was relative to the absorbed energy by the specimen.

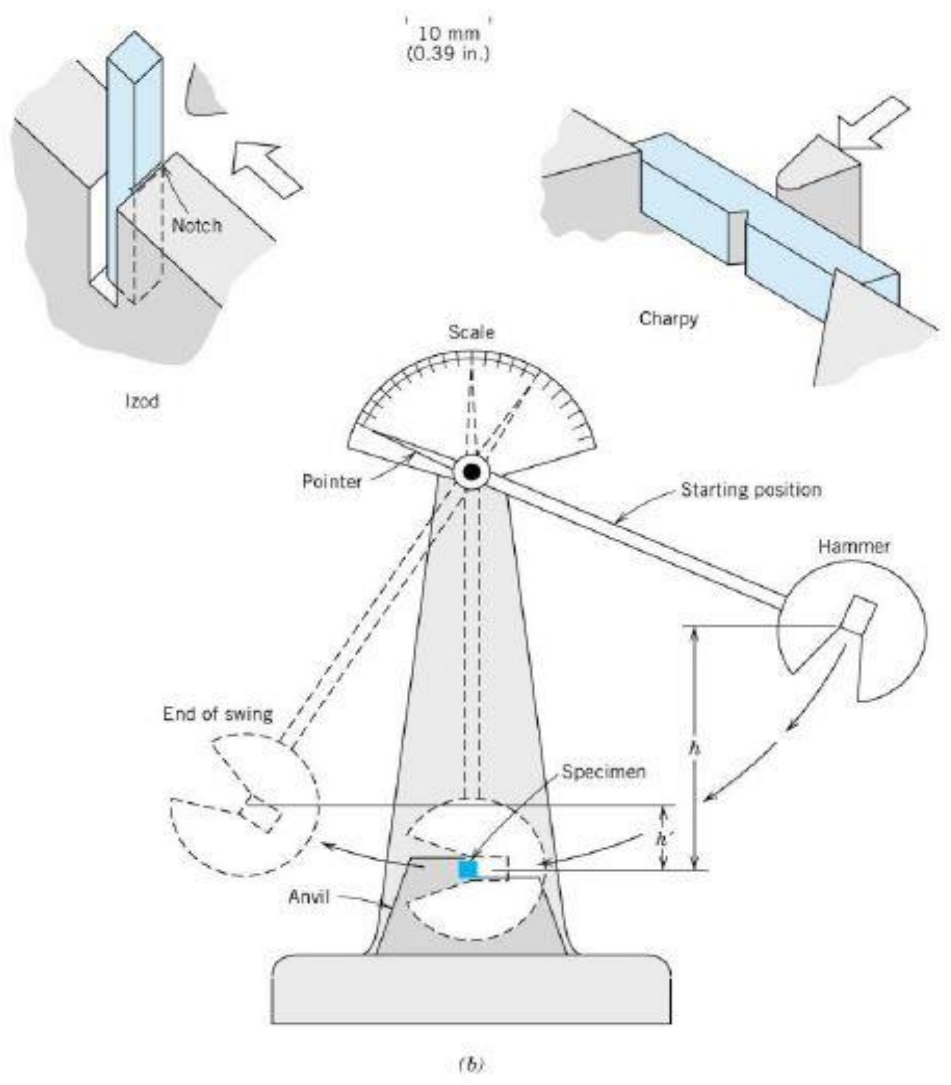

Figure 2: Standard mechanism of Charpy and Izod impact test [37]

The specimen was mounted between two plates, i.e. the support plate and the clamping plate. The test aperture has a square shape with $4.5 \times 4.5 \mathrm{in} .(114.5 \times 114.5 \mathrm{~mm})$ in dimensions. The pendulum arm is adjustable, and the impact energy was transferred by the steel hemispherical tip of $16 \mathrm{~mm}$ in diameter, and the pendulum with all the fittings weighs $4.4 \mathrm{~kg}$. Well-greased 
ball bearings are used to reduce the friction of the pendulum. The machine resembles a modified Charpy's impact test apparatus but acts like a drop-weight testing machine in which the impact was applied in a swing pendulum motion. The comparison between the drop-weight and the in-house low velocity impact was shown in Figure 3.
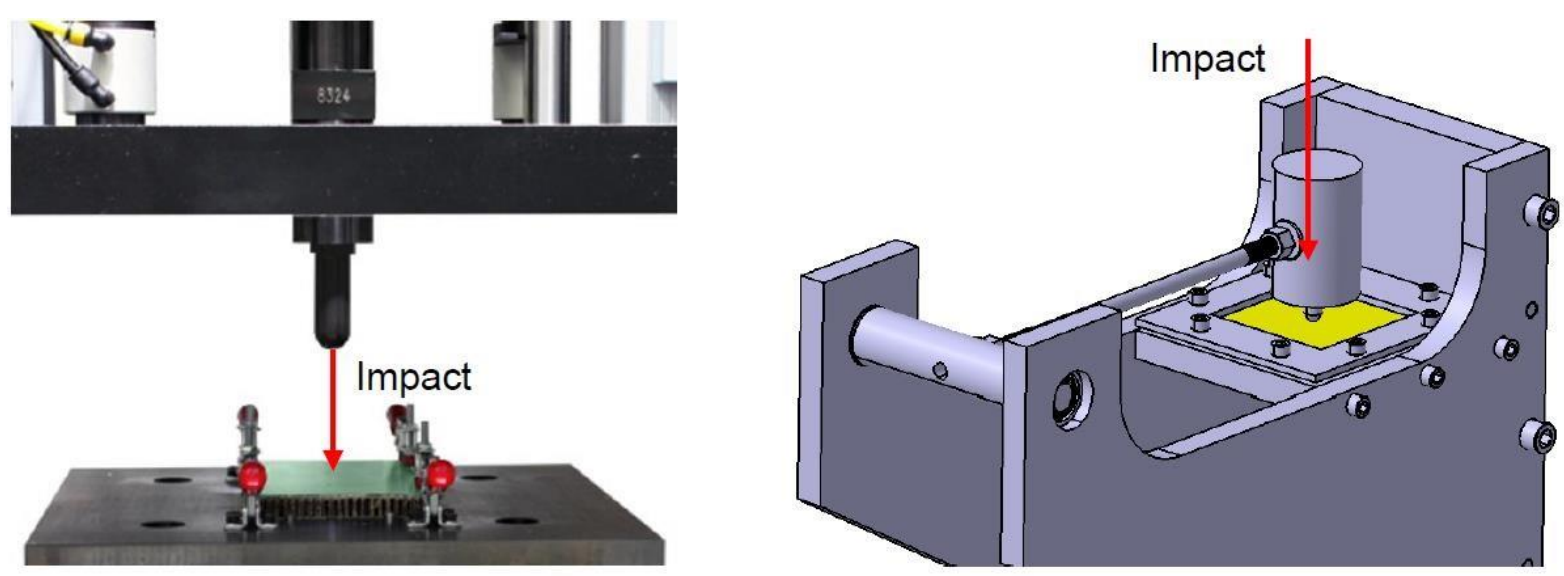

Figure 3: Impact comparison between drop weight and low velocity impact test apparatus [38]

The experimental setup was depicted in Figure 4, which showed the following: the impact test apparatus, a test specimen clamped between the plates; a high-speed camera which is of 1000 $\mathrm{Hz}$ frequency used to record a slow-motion video of the impact test, an Infrared camera which was used to record the thermal variations of the test specimen having a resolution of $320 \times 240$ pixels, temperature sensitivity of $20 \mathrm{mK}$ and a maximum recording frequency of $173 \mathrm{~Hz}$. High intensity lights were utilized to obtain a clear recording by high speed camera. The rebound angle of the pendulum was calculated using the high-speed video recording. The IR camera was place opposite to the impact test specimen and the high-speed camera was sited perpendicular to the test setup. 


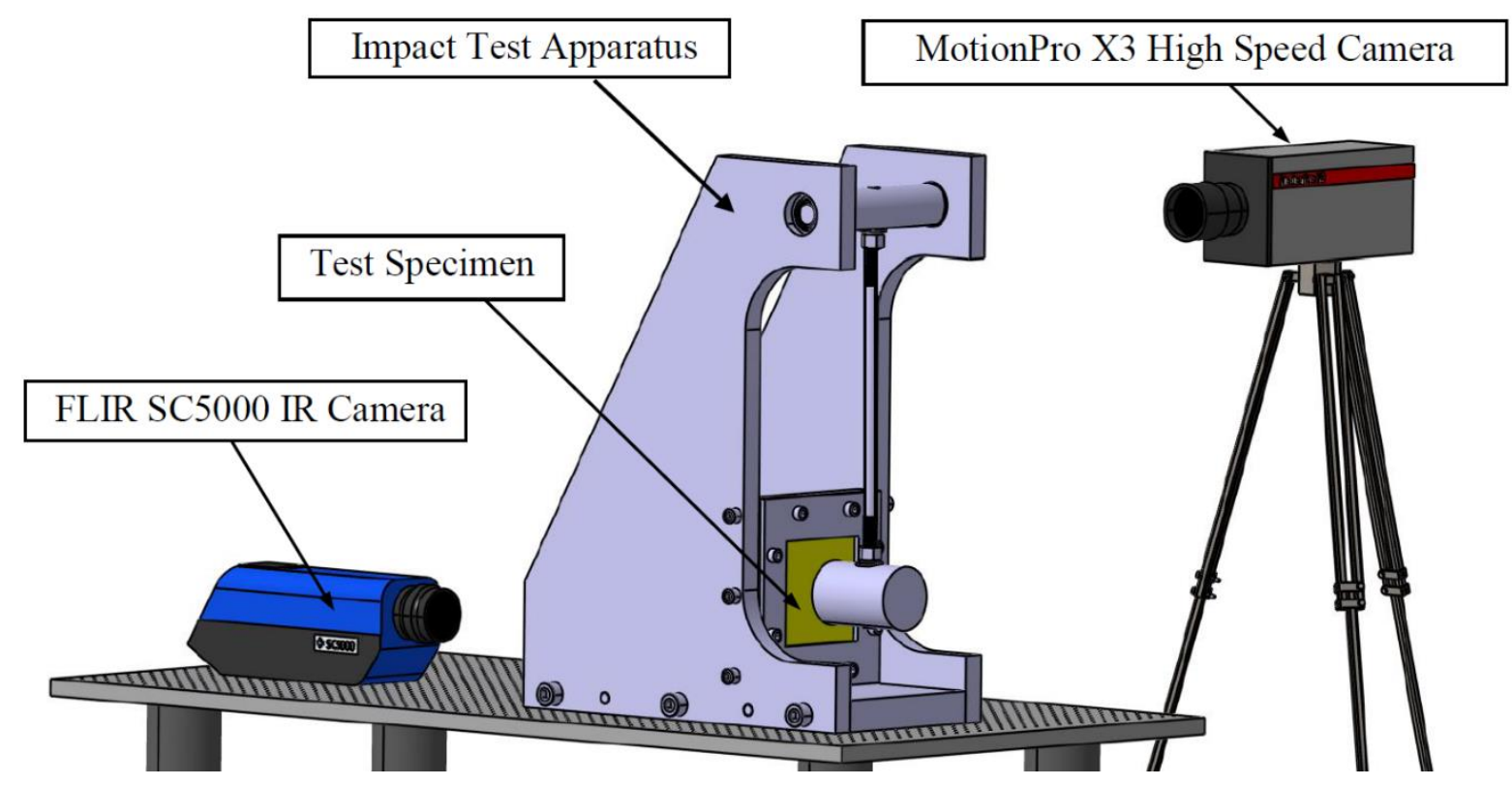

Figure 4: Experimental test setup [36]

When the pendulum was released from a height, the potential energy was converted to kinetic energy used to determine the velocity of the pendulum. The mass of the pendulum was considered as " $\mathrm{m}$ " and the length of the pendulum from the centre of the pivot to the centre of mass of the pendulum arm assembly in " $\mathrm{L}$ ". The pendulum release height, $\mathrm{H}_{1}$ was the initial height of the pendulum which determines the initial energy of the pendulum. The Drop height was calculated by the drop angle $\alpha$, as follows:

$$
\mathrm{H}_{1}=\mathrm{L} \times(1-\cos \alpha)
$$

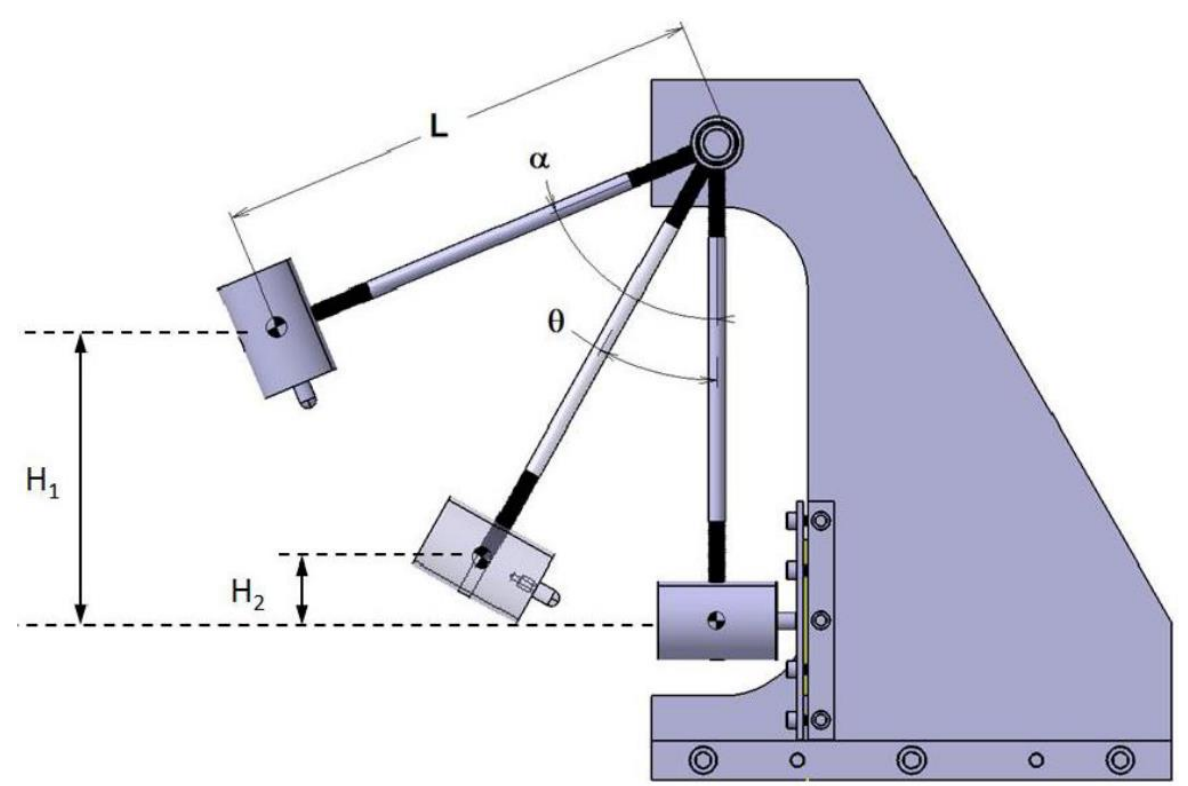

Figure 5: Pendulum impact test apparatus height setup [38] 
After the impact on the specimen, the pendulum rebounds to a height which was less than the initial one and was considered as the rebound height, $\mathrm{H}_{2}$ and the corresponding angle called the rebound angle, $\theta$.

$$
\mathrm{H}_{2}=\mathrm{L} \times(1-\cos \theta)
$$

The absorbed energy was calculated by the difference of the initial and the rebound energies of the pendulum.

$$
\text { Energy absorbed }=\mathrm{m} \times \mathrm{g} \times\left(\mathrm{H}_{1}-\mathrm{H}_{2}\right)
$$

, where the gravitational acceleration $(\mathrm{g})$ is considered as $9.81 \mathrm{~m} / \mathrm{s} 2$, and mass $(\mathrm{m})$ is $4.4 \mathrm{~kg}$.

The energies were calculated for each test specimen and compared to know the fracture mechanism of the $3 \mathrm{D}$ printed plates.

\begin{tabular}{|c|c|}
\hline SPECIFICATION & VALUE/DESCRIPTION \\
\hline Pendulum Effective Mass & $4.4 \mathrm{~kg}$ \\
\hline Distance from Pivot to centreline of impactor & $18 "(457 \mathrm{~mm})$ \\
\hline Distance from Pivot to centre of mass of the pendulum & $17.85 "(453 \mathrm{~mm})$ \\
\hline Impactor Tip diameter & $0.63 ”(16 \mathrm{~mm})$ \\
\hline Impactor Shape & Hemispherical \\
\hline Required specimen size & $4.5 " \times 4.5 "(114.3 \times 114.3 \mathrm{~mm})$ \\
\hline Cut-out window size & $3.5 " \times 3.5 "(88.9 \times 88.9 \mathrm{~mm})$ \\
\hline Maximum pendulum drop angle & 179 degrees \\
\hline Maximum impact energy & Up to 39 Joules \\
\hline
\end{tabular}

Table 1: Specifications of the Pendulum impact apparatus 


\subsection{Test Plan}

The specimens were $3 \mathrm{D}$ printed with the required dimension of $4.5 " \times 4.5$ " out of PLA plate. Since the aim of this study was to characterize the impact properties of 3D printed PLA plates, $0^{\circ}$ raster angle was selected. Impact testing was performed at two different locations of $\mathrm{P}_{1}$ and

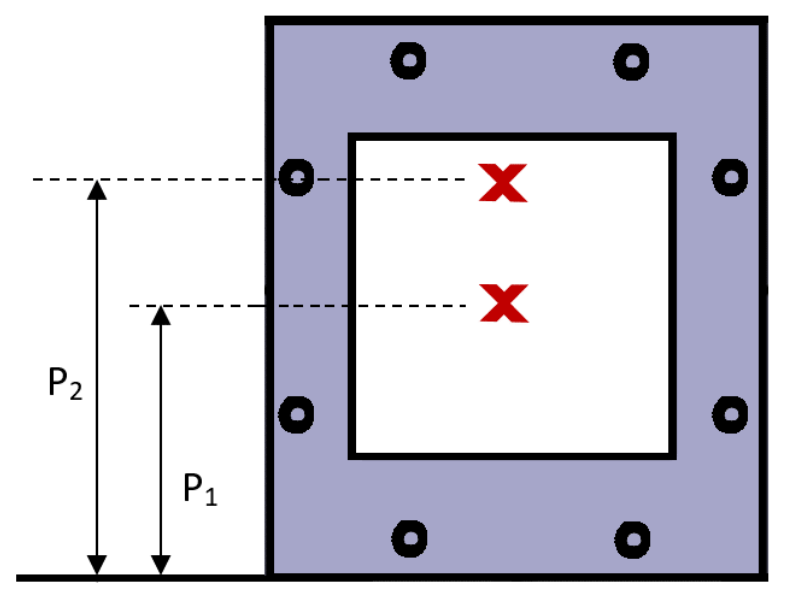

Figure 6: The test specimen impact locations [38]

The locations were labelled as:

$\mathrm{P}_{1}$ as the impact location in the centre of the specimen.

$\mathrm{P}_{2}$ as the impact location in the half of the distance between the centre and the edge of the specimen.

As the arm of the pendulum can be changed, the $\mathrm{P}_{2}$ location was adjusted by varying the arm of the pendulum. Both the thermal and slow-motion videos were recorded when the tests were performed.

In this research, two types of experiments were performed:

\subsubsection{FiXed layer Thickness (Test Plan 1)}

All the four edges of the specimen were constrained in this experiment and a layer thickness of $0.14 \mathrm{~mm}$ is selected. Each specimen was printed with 18 layers in $0^{\circ}$ orientation having an overall thickness of $2.52 \mathrm{~mm}$ (0.10 in). Each specimen was subjected to two different impact energies i.e. $1 \mathrm{~J}$ and $3 \mathrm{~J}$ and at two different locations $\mathrm{P}_{1}$ and $\mathrm{P}_{2}$ on the specimen. Three samples were used for each test configuration making a total of 12 samples for the experiment. Each test case was defined by the impact energy and the position of the impact. Table 2 gives the specifications of the test case. 
Table 2: Test plan 1 for the 3D printed PLA specimens

\begin{tabular}{|c|c|c|}
\hline Test Case ID & Energy level $(\mathrm{J})$ & Impact location \\
\hline $1 \mathrm{a}$ & 1 & $\mathrm{P}_{1}$ \\
\hline $1 \mathrm{~b}$ & 1 & $\mathrm{P}_{2}$ \\
\hline $2 \mathrm{a}$ & 3 & $\mathrm{P}_{1}$ \\
\hline $2 \mathrm{~b}$ & 3 & $\mathrm{P}_{2}$ \\
\hline
\end{tabular}

Samples with *a are considered as the impact on the specimen at $\mathrm{P}_{1}$

Samples with $* b$ are considered as the impact on the specimen at $\mathrm{P}_{2}$.

\subsubsection{DIFFERENT LAYER THICKNESS (TEST PLAN 2)}

All the four edges of the specimen were constrained in this experiment. An overall plate thickness of $2.52 \mathrm{~mm}$ was maintained while changing the layer thickness (or total number of layers) used in $3 \mathrm{D}$ printing. The energy for the impact was fixed as $3 \mathrm{~J}$ for these tests since it led to a significant change in the specimen after impact. Four types of layer thicknesses were used for printing, i.e. $0.10,0.12,0.16$, and $0.18 \mathrm{~mm}$. These were the values for a gradual increase and decrease of the fixed layer thickness $0.14 \mathrm{~mm}$ from test plan 1 by $0.02 \mathrm{~mm}$. Each test configuration was tested with 3 samples and two impact locations resulting in a total of 24 samples. Each test case was defined by layer thickness (total number of layers) and the position of the impact location. Table 3 shows test configurations.

Table 3: Test plan 2 configuration of the 3D printed PLA specimens

\begin{tabular}{|c|c|c|c|}
\hline Test Case ID & $\begin{array}{c}\text { Layer thickness mm } \\
\text { (number of layers) }\end{array}$ & $\begin{array}{c}\text { Laminate thickness } \\
(\mathrm{mm})\end{array}$ & Impact location \\
\hline $1 \mathrm{a}$ & $0.10(25)$ & 2.50 & $\mathrm{P}_{1}$ \\
\hline $1 \mathrm{~b}$ & $0.12(21)$ & 2.52 & $\mathrm{P}_{1}$ \\
\hline $1 \mathrm{c}$ & $0.16(16)$ & 2.56 & $\mathrm{P}_{1}$ \\
\hline $1 \mathrm{~d}$ & $0.18(14)$ & 2.52 & $\mathrm{P}_{1}$ \\
\hline $2 \mathrm{a}$ & $0.10(25)$ & 2.50 & $\mathrm{P}_{2}$ \\
\hline $2 \mathrm{~b}$ & $0.12(21)$ & 2.52 & $\mathrm{P}_{2}$ \\
\hline $2 \mathrm{c}$ & $0.16(16)$ & 2.56 & $\mathrm{P}_{2}$ \\
\hline $2 \mathrm{~d}$ & $0.18(14)$ & 2.52 & $\mathrm{P}_{2}$ \\
\hline
\end{tabular}

We selected three test samples for each test configuration since it can be considered as minimum number of specimens for meaningful statistical analysis, e.g. standard deviation and average. It is clear that an increase in number of samples of samples for each test will result in better statistical material values but increase materials and manufacturing cost. 


\subsection{SPECIMEN MANUFACTURING}

The specimens used in the research are 3D printed PLA plates which were impact tested. The plates were printed with fixed dimensions of $4.5 " \times 4.5 "(114.3 \times 114.3 \mathrm{~mm})$ in a square shape with an average overall thickness of $2.52 \mathrm{~mm}$. The total number of plates printed combining two test plans is 36. Every specimen was printed using Prusa i3 MK2S 3D (Figure 8) printer which was available at Facility for Research on aerospace Materials and Engineered Structures (FRAMES) lab. We used PLA material for manufacturing the specimens as the materials was widely used for rapid prototyping besides it being a biodegradable material. Grey PLA filament of $1.75 \mathrm{~mm}$ in diameter was used in Prusa for 3D printing (Figure 7).

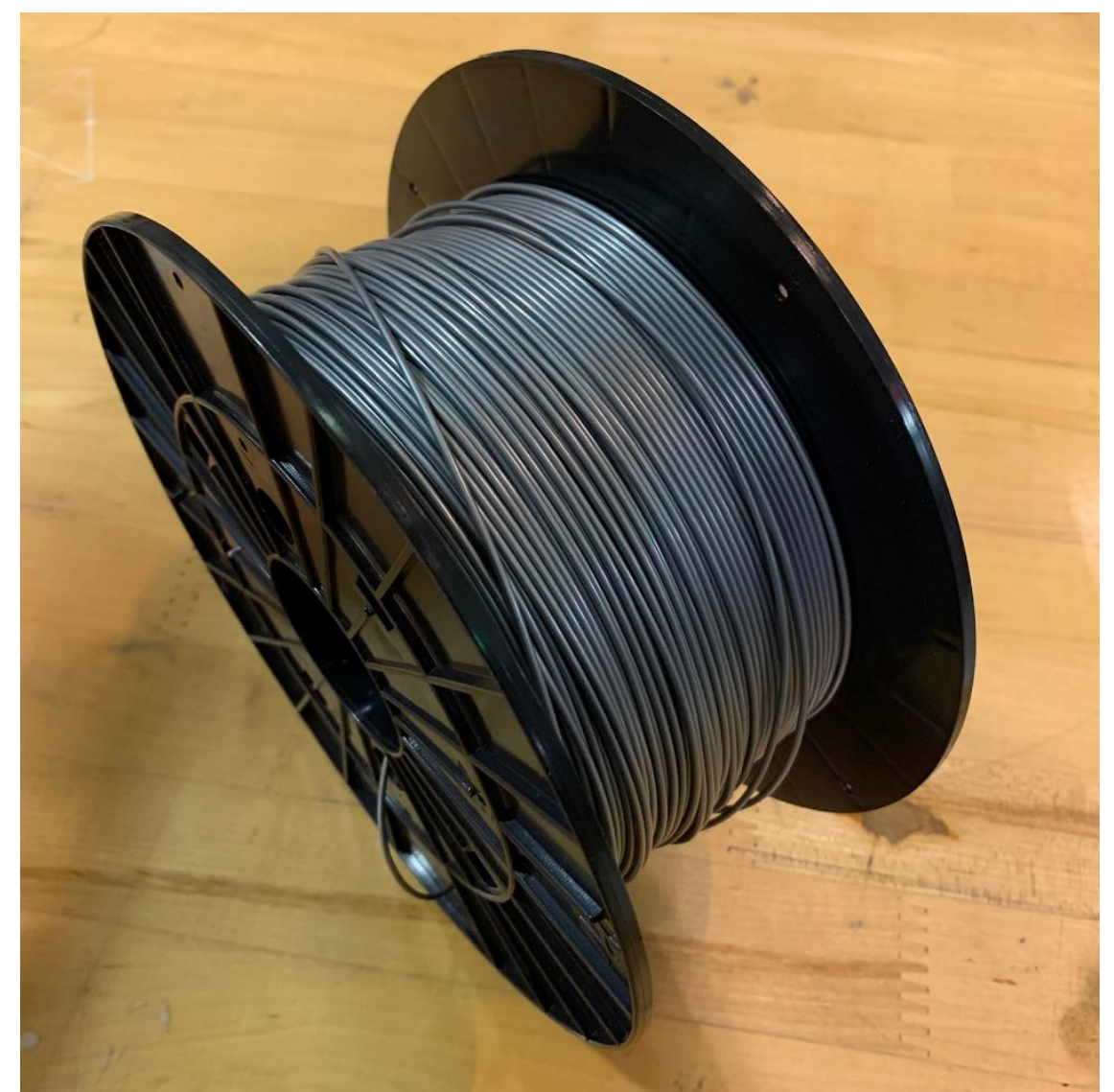

Figure 7: Spool used in 3D printing

$3 \mathrm{D}$ printing manufacturing process and design parameters impact mechanical performance of the manufactured parts. All these parameters were kept constant during manufacturing of all specimens to eliminate the effect of other external parameter. The manufacturing process and design parameters used during 3D printing were summarized in Table 4. 
Table 4: Manufacturing process and design parameters of 3D printing

\begin{tabular}{|l|c|l|c|}
\hline $\begin{array}{c}\text { Manufacturing/design } \\
\text { Parameter }\end{array}$ & Value & $\begin{array}{c}\text { Manufacturing/design } \\
\text { Parameter }\end{array}$ & Value \\
\hline Material & PLA & Bed temperature & $60^{\circ} \mathrm{C}$ \\
\hline Print direction & $\mathrm{XYZ}$ & Layer height & $0.14 \mathrm{~mm}$ \\
\hline Raster angle & $0^{\circ}$ & Printing speed & $2400 \mathrm{~mm} / \mathrm{min}$ \\
\hline Filament diameter & $1.75 \mathrm{~mm}$ & Cooling & No fan cooling \\
\hline Nozzle diameter & $0.4 \mathrm{~mm}$ & infill & $100 \%$ \\
\hline Nozzle temperature & $215^{\circ} \mathrm{C}$ & \multicolumn{3}{|l|}{} \\
\hline
\end{tabular}

The process of 3D printing starts with designing the 3D model in a CAD software. Then, the file needs to be converted into STL used in slicing software. In this project, CATIA V5 was used for modelling and Simlify3D software was used for slicing and setting manufacturing process and design parameters. The output of the slicing software was a GCODE file that commands the $3 \mathrm{D}$ printer to move in the required trajectories and extrude materials. In the beginning, the nozzle and the build plate were pre-heated to the set temperatures (see Table 4). In addition, there was a probe attached to the $3 \mathrm{D}$ printing head that calibrates the levelness of the build plate before the start of the actual print by checking nine specified points. The total printing time for specimen varies with total number of layers and changes between three and five hours.

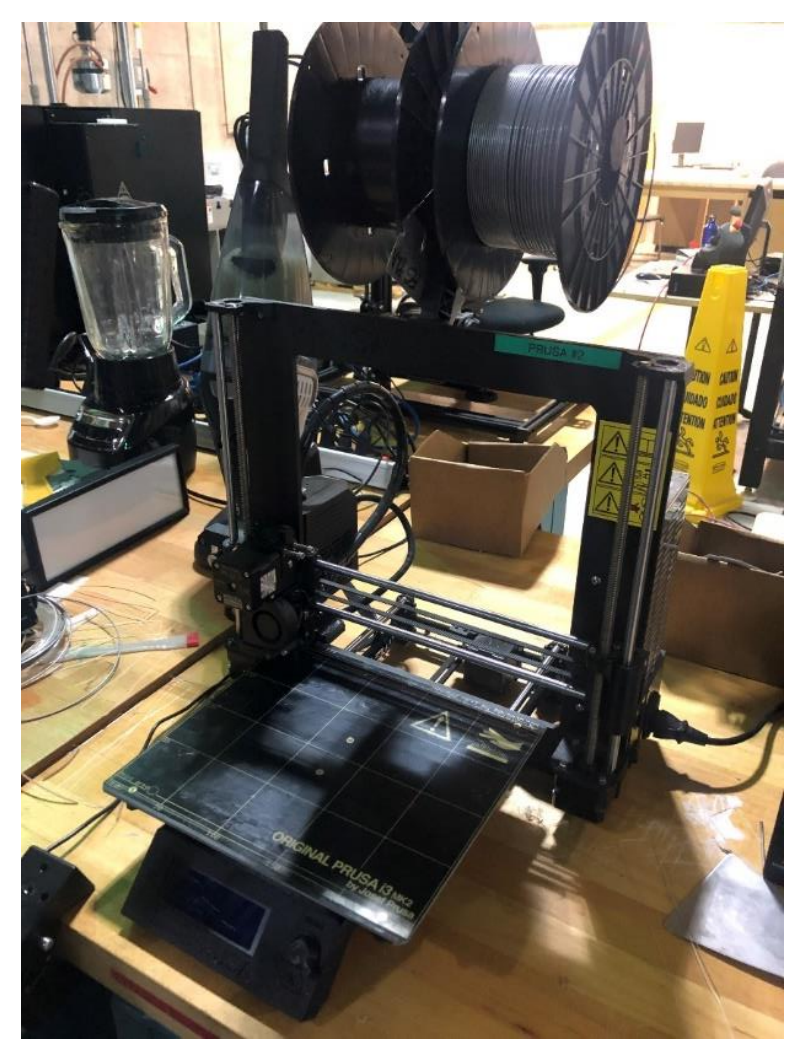

Figure 8: Prusa i3 MK2S 3D printer 


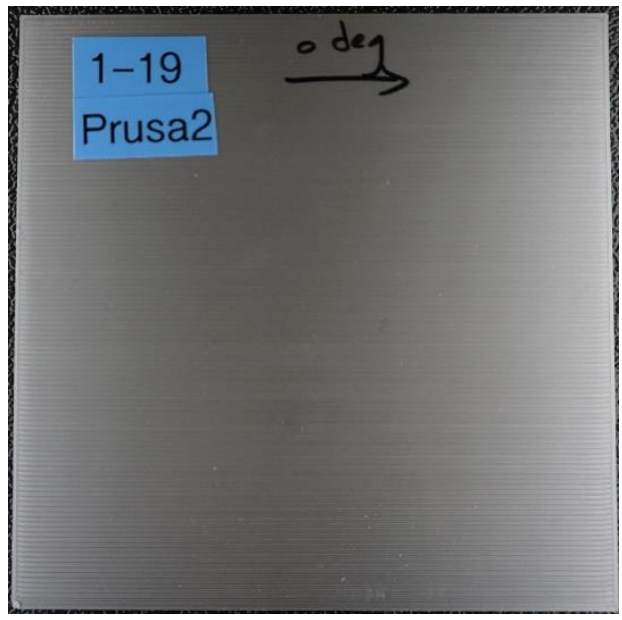

Figure 9: 3D printed PLA plate before testing

\subsection{TESTING PROCEDURE}

As discussed, a low velocity impact test apparatus was used for impact testing of the 3D printed PLA plates. The testing procedure per the ASTM D7136 was followed, which was a procedure for drop-weight impact test. The specimens were printed and stored at room temperature. Each specimen was labelled with the test case ID and were marked with location of impacts before testing.

The FLIR SC5000 IR camera (Figure 10) was used to record the thermal response of the test specimen during and after the impact which was placed to rear side of the square aperture. When an impact load was applied to the test plate, the energy was transferred to it through the impactor, resulting in a thermal change and temperature variation in the specimen that can be picked up by the IR camera. The test specimen absorbs energy leading to crack, damage or delamination in the layers seen as hot spots in the IR imaging. This was helpful since some of the damages in the specimen were not visible to the naked eye. By recording the thermal response before, during, and after the test, all the damages can be captured in a non-destructive way.

The IR camera has a resolution of $320 \times 240$ pixels and a temperature sensitivity of $20 \mathrm{mK}$. The recording of the impact was at a frame rate of 173 per second allowing an accurate damage development. The FLIR camera was operated using the Altair software recommended by FLIR for processing results. 


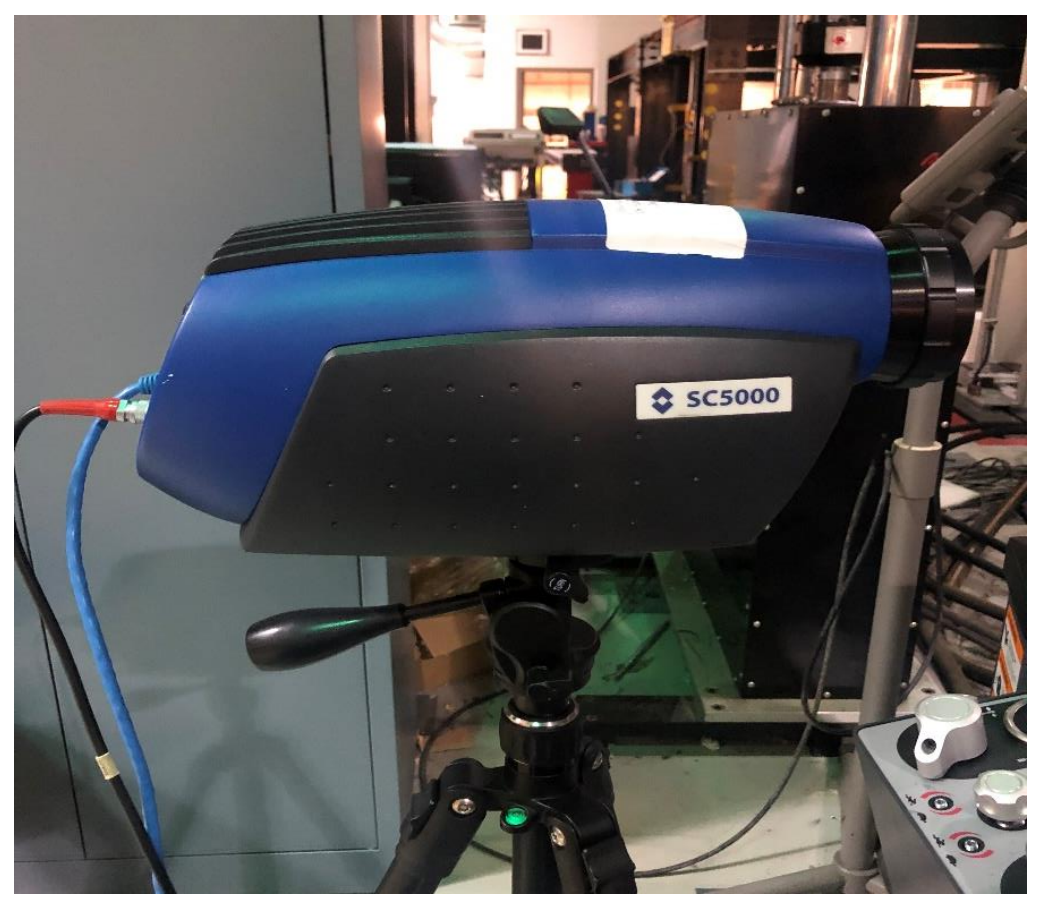

Figure 10: IR camera FLIR SC5000

A high-speed camera was used in the experiments to record the motion of the pendulum and to find the rebound angle. Using this angle, the height of the pendulum and in turn the rebound and absorbed energies of the test case can be obtained. The high-speed camera was placed at the side of the pendulum aligned with the pivot, which helps capturing the rebound angle accurately.

The high-speed camera used was MotionPro X3 (Figure 11), which can record a video up to $1040 \mathrm{~Hz}$ in frequency. The IDT MotionPro x64 software was used to record and get the data from the camera for the video post-processing. Considering the lighting environment, a frequency of $300 \mathrm{~Hz}$ was used to record the motion of a pendulum arm. Figure 11 showed the camera used for the video recording. 


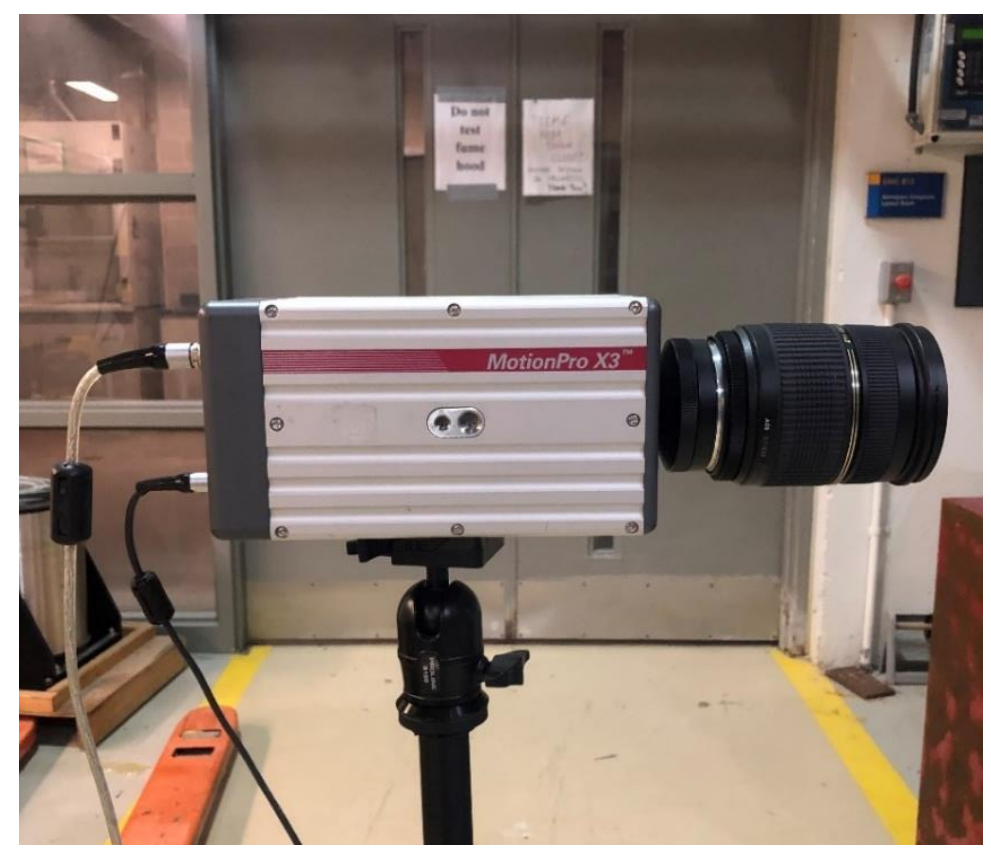

Figure 11: High-speed camera MotionPro X3

To get high quality videos with high frequency rates, high intensity lights (Figure 12) were used during testing. They help the camera to capture a clear and bright video, so that the pendulum release and rebound angles can be capture accurately.

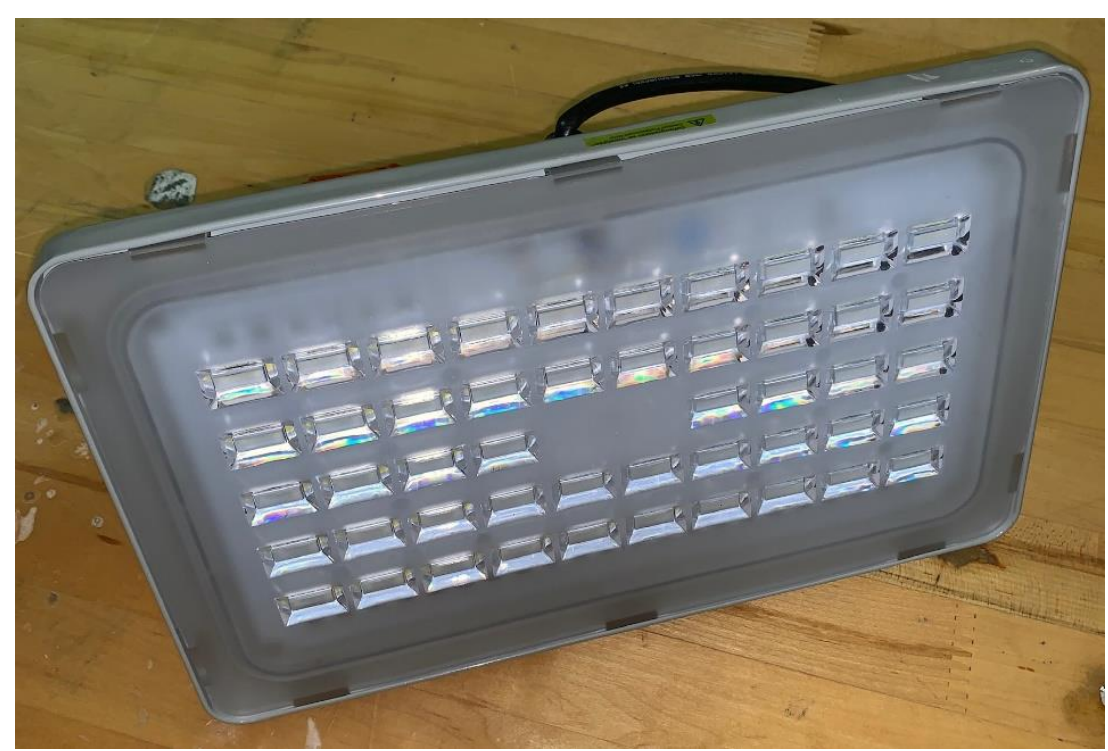

Figure 12: High intensity light 
The camera gave a live recording, so that Iconico screen protractor software was used to set the release angle. In addition, a recorded video after the test was captured, used to measure the rebound angle using the same software. The software provided two indicators: one is at zerodegree angle (pendulum rest position), and the other was used to measure the initial and rebound angle.

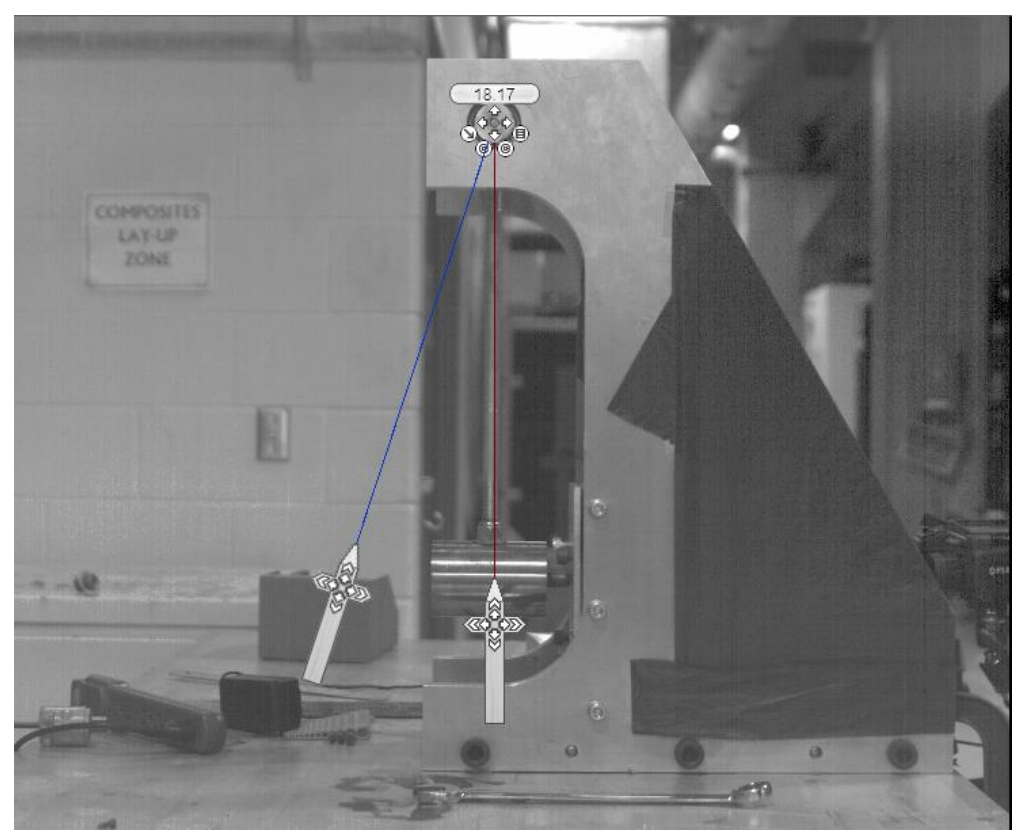

Figure 13: Screen protractor on the live recording

A test specimen was inserted between the clamp and the support plates of the pendulum apparatus. Then, a required energy was given to the pendulum for the impact by lifting it to a certain release angle (height). The IR video and high-speed video capturing, and the impact on the test specimen were performed simultaneously to obtain results. The results were presented in section 4 and the effect of the impact energy and the location, and layer thickness (total number of layers) were discussed. 


\section{RESULTS AND DISCUSSION}

In the previous sections, the specimen manufacturing, testing apparatus, and the testing procedures were explained. As mentioned two test plans were explored in this study: fixed layer thickness with two levels of energy, and varying layer thickness (total number of layers) with fixed level of energy. In this section, the results of the two test plans are presented.

\subsection{Test Plan 1}

To obtain the upper energy levels for impact, extra specimens were printed and tested at $4 \mathrm{~J}$ and $5 \mathrm{~J}$ of energy. The test for $5 \mathrm{~J}$ energy impact showed a complete breakage of the specimen into separate pieces in a circular pattern (Figure 14a). Testing was repeated for $4 \mathrm{~J}$ energy and the result was the same catastrophic failure with the breakage (Figure 14b). As a result, the impact energy was lowered to $3 \mathrm{~J}$, which showed a reasonable failure with cracking and not a complete breakage. Therefore, $3 \mathrm{~J}$ impact energy was chosen as the upper bound and $1 \mathrm{~J}$ as the lower level for testing.

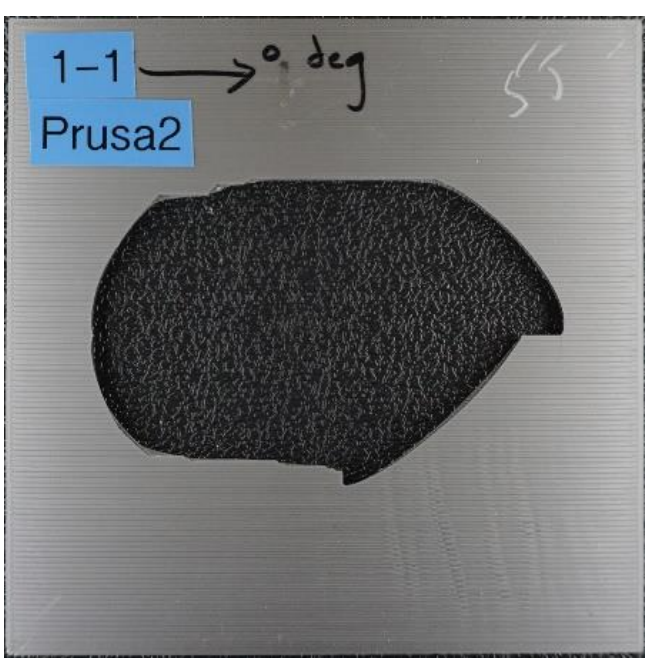

(a)

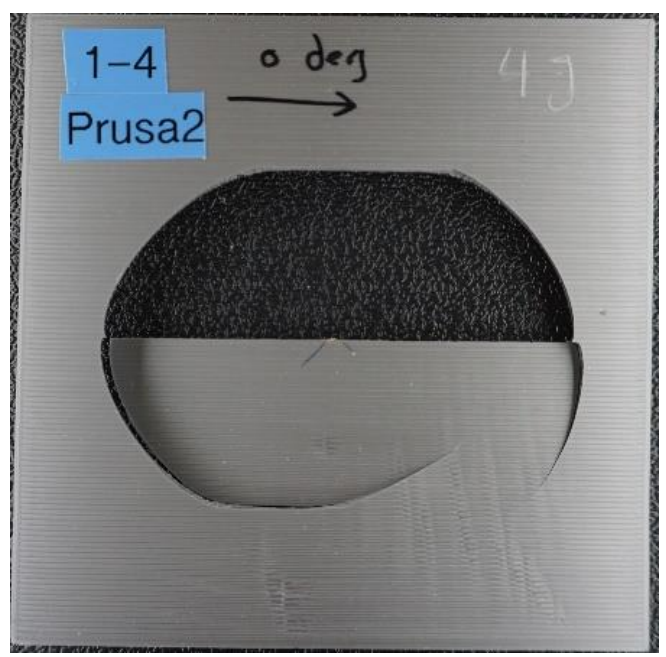

(b)

Figure 14: Specimens after testing (a) 5J energy level (b) 4J energy level

The experiment was commenced with $1 \mathrm{~J}$ of impact energy on the 3D printed samples at two different impact locations. The samples were clamped between the plates with $0^{\circ}$ orientation horizontally, and the impact locations were marked on the sample which can be seen in Figure $15 \mathrm{a}$ and $15 \mathrm{c}$. Three samples were tested for each position and the damage was a localized crack which cannot be observed by the naked eye for all three specimens (Figure 15 a). The thermal images captured a crack at the impact location along the extrudates $\left(0^{\circ}\right.$ orientation, horizontal). The length of the cracks was different for two impact locations which is discussed later. Figure 
15 showed the specimens after impact and thermal images captured for $\mathrm{P}_{1}$ and $\mathrm{P}_{2}$ impact locations, respectively.

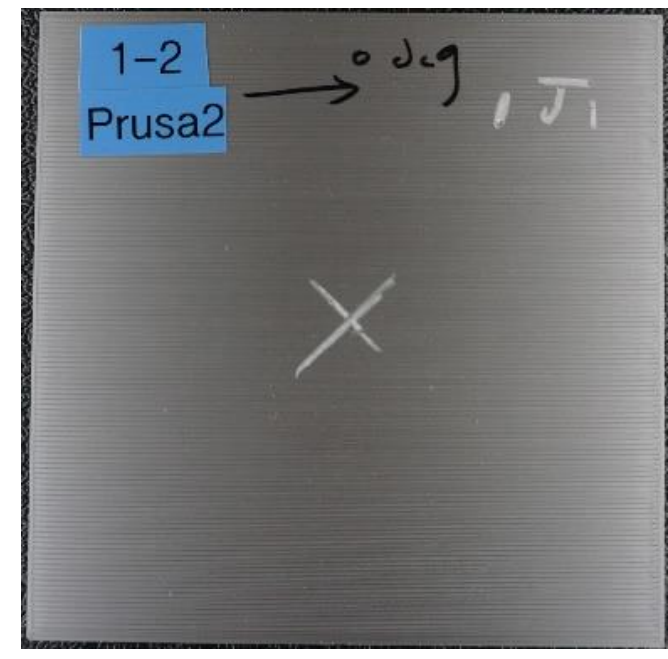

(a)

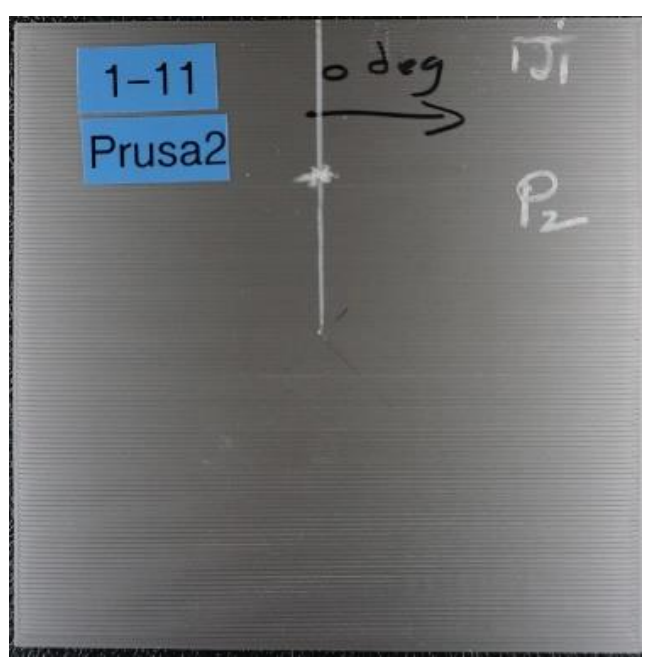

(c)

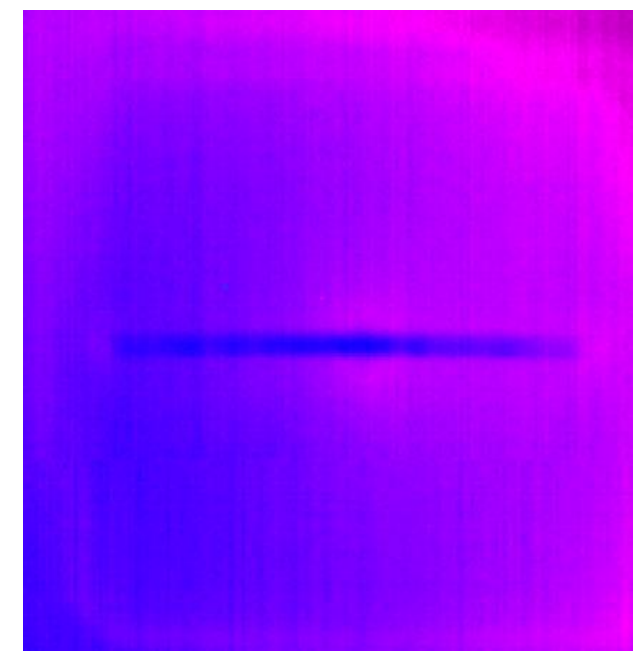

(b)

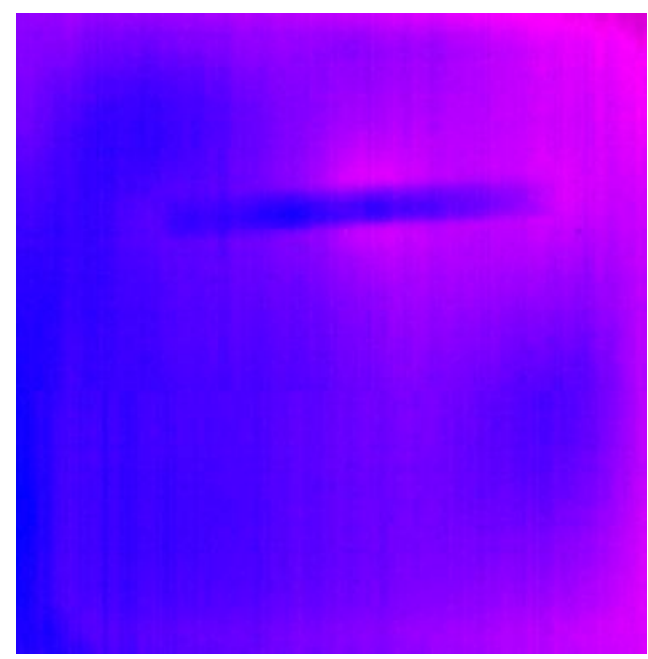

(d)

Figure 15: Specimens at $1 \mathrm{~J}$ energy level (a) specimen after impact at $P_{1}$ location, (b) thermal imaging for $P_{1}$ location, (c) specimen after impact at $P_{2}$ location, (d) thermal imaging for $P_{2}$ location.

Then, samples were placed horizontally ( $0^{\circ}$ orientation) and were impacted with $3 \mathrm{~J}$ of energy at the marked locations $P_{1}$ and $P_{2}$. Unlike previous case, the damage in the specimens due to 3 $\mathrm{J}$ impact energy was visible to the naked eye. The damage pattern, crack length, and extent were different for the two locations. At $\mathrm{P}_{1}$ location, the crack was along the extrudates, like the damage observed for $1 \mathrm{~J}$ energy. In addition, a crack along $90^{\circ}$ direction combined with a semicircular crack starting from the end of the $0^{\circ}$ crack was observed. The damage for $\mathrm{P}_{2}$ impact location was more extensive than $\mathrm{P}_{1}$ location. It showed multiple cracks along horizontal and vertical directions with some angled once creating circular patterns. Considering the hot spots 
shown in the Figure $16 \mathrm{~b}$ and $16 \mathrm{~d}$, it can be stated that for lower impact energy the cracks were only along the extrudates, while for higher level of energy the cracks were along and across the extrudates. The specimens after testing and the thermal images for the $3 \mathrm{~J}$ impact energy at $\mathrm{P}_{1}$ and $\mathrm{P}_{2}$ locations were shown in Figure 16.

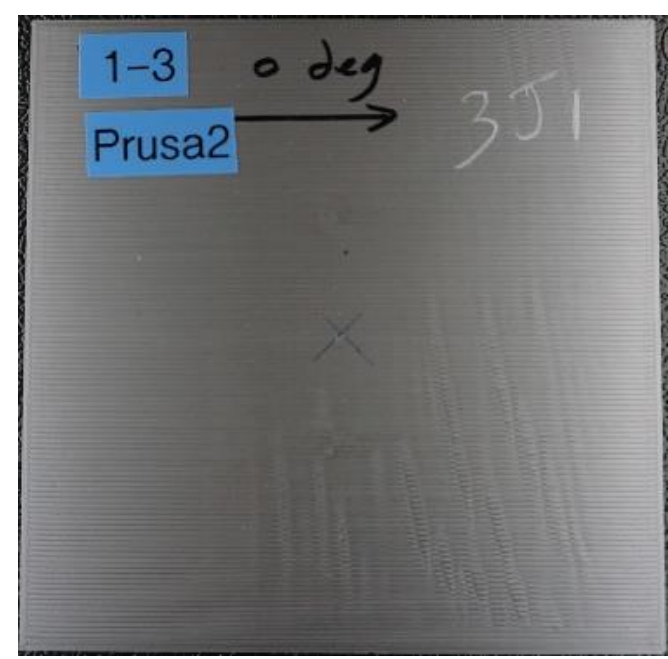

(a)

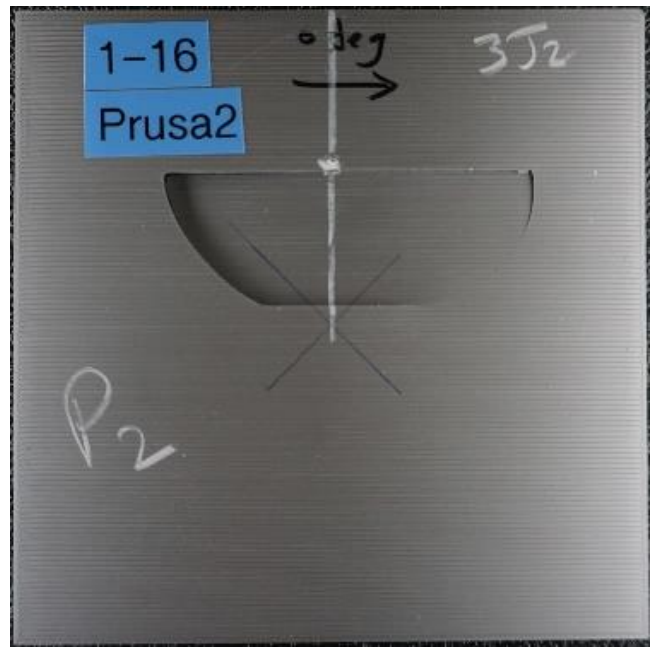

(c)

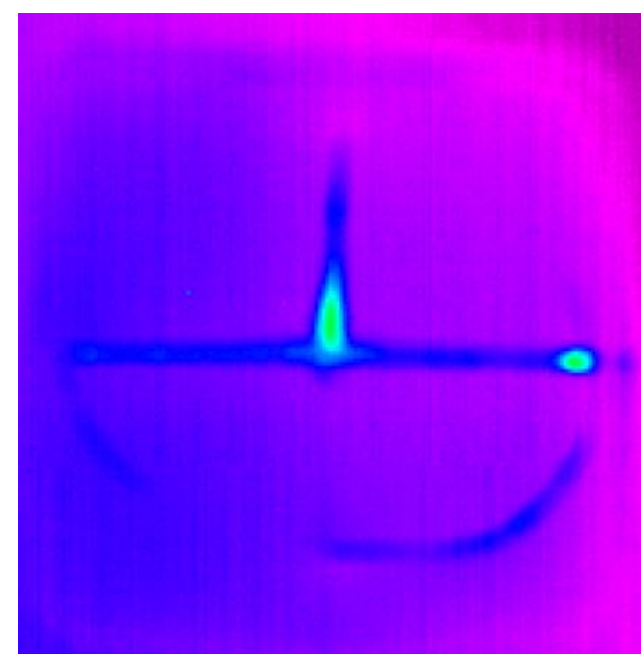

(b)

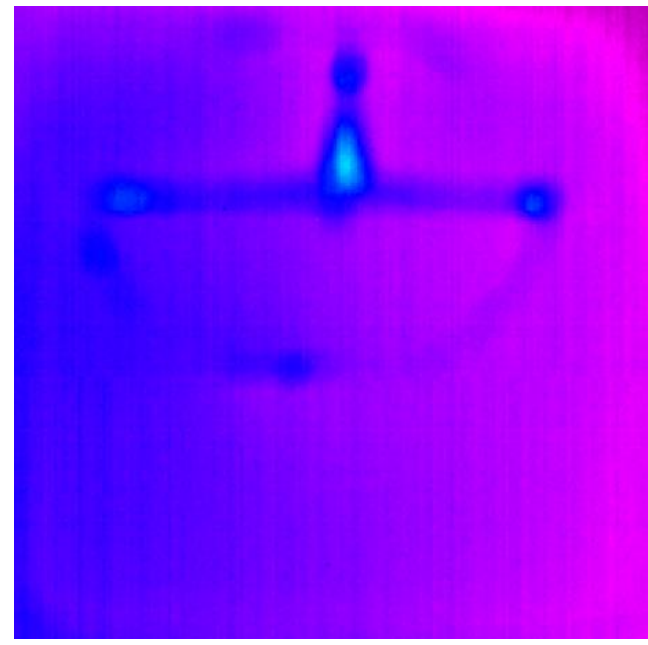

(d)

Figure 16: Specimens at $3 \mathrm{~J}$ energy level (a) specimen after impact at $P_{1}$ location, (b) thermal imaging for $P_{1}$ location, (c) specimen after impact at $P_{2}$ location, (d) thermal imaging for $P_{2}$ location.

As discussed, the impactor energy is transferred to the specimens during the impact, in which the absorbed energy results in the damage or the cracks of the test specimens. The energy absorbed indicates the extent of the damage observed during the impact test. If the energy is fully absorbed, then it will shatter the test specimen, but if it does not, then the specimen absorbs some energy with cracks and transfers some momentum to the impactor causing a 
rebound angle in the pendulum. The absorbed energy is the difference between the total applied energy and the rebound energy (equation 1):

$$
\mathrm{E}(\text { absorbed })=\mathrm{E}(\text { total })-\mathrm{E}(\text { rebound })
$$

In this study, for each specimen, release and rebound angles were recorded which in turn gives the impact and rebound energies, respectively. For one specimen, the calculations are explained in detail below to show how the release angle $(\alpha)$ and rebound angle $(\theta)$ can be used to get the absorbed energy value.

For $1 \mathrm{~J}$ of impact energy with an impactor mass of $4.4 \mathrm{Kg}$ and acceleration due to gravity (g) as $9.807 \mathrm{~m} / \mathrm{s} 2$, the release height can be obtained from equation (2):

$$
\begin{gathered}
\mathrm{E}(\text { total })=\mathrm{mgH}_{1} \\
\mathrm{H}_{1}=0.0231 \mathrm{~m}
\end{gathered}
$$

From,

$$
\begin{gathered}
\mathrm{H}_{1}=\mathrm{L}(1-\operatorname{Cos} \alpha) \\
\alpha=\operatorname{Cos}^{-1}\left[1-\left(\mathrm{H}_{1} / \mathrm{L}\right)\right]
\end{gathered}
$$

, where $\mathrm{L}$ is $0.457 \mathrm{~m}$ for $\mathrm{P}_{1}$ location and $0.428 \mathrm{~m}$ for $\mathrm{P}_{2}$ location. As a result, the release angle can be calculated as,

$$
\alpha=18.32^{\circ}
$$

For the first sample in the test case ID 1a, the rebound angle was measured at $\theta=14^{\circ}$ from high-speed videos analysed by the screen protractor software, the rebound height $\mathrm{H}_{2}$ can be calculated as:

$$
\mathrm{H}_{2}=\mathrm{L}(1-\operatorname{Cos} \theta)
$$

$\mathrm{H}_{2}$ can be used in equation 4 to find the rebound energy

$$
\begin{gathered}
\mathrm{E}^{*}(\text { rebound })=\mathrm{mgH}_{2} \\
\mathrm{E}^{*}(\text { rebound })=0.585 \mathrm{~J}
\end{gathered}
$$

Knowing the total and rebound energies, the absorbed energy can be calculated using equation 1 ,

The absorbed energy for sample 1 of the test case ID 1a is: $\mathrm{E}$ (absorbed) $=1-0.585=0.415 \mathrm{~J}$ 
The same procedure was followed for all the samples and rebound, and absorbed energies are calculated and presented in Table 5 and average absorbed energy percentages were provided in Table 6. The standard deviation and margin of error of each test configuration were provided in Table 7. Absorbed energy percentages with error bars for all test specimens are plotted in Figure 17.

Table 5: Rebound energy calculations for each specimen

\begin{tabular}{|c|c|c|c|c|c|c|c|c|c|}
\hline \multirow{2}{*}{$\begin{array}{c}\text { Test } \\
\text { case } \\
\text { ID }\end{array}$} & \multirow{2}{*}{$\begin{array}{c}\text { Impact } \\
\text { energy } \\
(\mathrm{J})\end{array}$} & \multirow[b]{2}{*}{$\begin{array}{l}\text { Impact } \\
\text { location }\end{array}$} & \multirow{2}{*}{$\begin{array}{l}\text { Impact } \\
\text { angle } \alpha \\
\left(^{\circ}\right)\end{array}$} & \multicolumn{3}{|c|}{ Rebound angle $\theta\left(^{\circ}\right)$} & \multicolumn{3}{|c|}{ Rebound Energy $(\mathrm{J})$} \\
\hline & & & & $\begin{array}{c}\text { Sample } \\
\# 1\end{array}$ & $\begin{array}{c}\text { Sample } \\
\# 2\end{array}$ & $\begin{array}{c}\text { Sample } \\
\text { \#3 }\end{array}$ & $\begin{array}{c}\text { Sample } \\
\# 1\end{array}$ & $\begin{array}{c}\text { Sample } \\
\# 2\end{array}$ & $\begin{array}{c}\text { Sample } \\
\# 3\end{array}$ \\
\hline $1 \mathrm{a}$ & 1 & $\mathrm{D}$ & 18.32 & 14.0 & 13.6 & 14.1 & 0.585 & 0.552 & 0.595 \\
\hline $1 \mathrm{~b}$ & 1 & & 18.94 & 15.6 & 15.7 & 15 & 0.680 & 0.689 & 0.646 \\
\hline $2 a$ & 3 & $\mathrm{P}_{1}$ & .02 & 20.0 & 19.8 & 24.0 & 1.189 & 1.165 & 1.704 \\
\hline $2 b$ & 3 & $\mathrm{P}_{2}$ & 33.12 & 5.0 & 6.0 & 5.8 & 0.070 & 0.101 & 0.094 \\
\hline
\end{tabular}

Table 6: Rebound and Absorbed energies for each specimen

\begin{tabular}{|c|c|c|c|c|c|c|c|c|c|}
\hline \multirow{2}{*}{$\begin{array}{c}\text { Test } \\
\text { case } \\
\text { ID }\end{array}$} & \multicolumn{3}{|c|}{ Rebound Energy $(\mathrm{J})$} & \multirow{2}{*}{$\begin{array}{c}\text { Average } \\
\text { rebound } \\
\text { energy } \\
(\mathrm{J})\end{array}$} & \multicolumn{3}{|c|}{ Absorbed Energy (J) } & \multirow{2}{*}{$\begin{array}{c}\text { Average } \\
\text { absorbed } \\
\text { energy } \\
(\mathrm{J})\end{array}$} & \multirow{2}{*}{$\begin{array}{c}\text { Absorbed } \\
\text { energy } \\
\text { percentage }\end{array}$} \\
\hline & $\begin{array}{c}\text { Sample } \\
\# 1\end{array}$ & $\begin{array}{c}\text { Sample } \\
\# 2\end{array}$ & $\begin{array}{c}\text { Sample } \\
\# 3\end{array}$ & & $\begin{array}{c}\text { Sample } \\
\# 1\end{array}$ & $\begin{array}{c}\text { Sample } \\
\# 2\end{array}$ & $\begin{array}{c}\text { Sample } \\
\# 3\end{array}$ & & \\
\hline $1 \mathrm{a}$ & 0.585 & 552 & 595 & 0.577 & 0.415 & 0.448 & 0.406 & 0.432 & 42.3 \\
\hline $1 b$ & 0.680 & 0.689 & 0.646 & 0.672 & 0.320 & 0.311 & 0.353 & 0.3 & 32 \\
\hline $2 a$ & 1.189 & 1.165 & 1.704 & 1.353 & 1.811 & 1.835 & 1.296 & 1.647 & 54.9 \\
\hline $2 b$ & 0.070 & 0.101 & 0.094 & 0.088 & 2.930 & 2.899 & 2.912 & 2.912 & 97.1 \\
\hline
\end{tabular}

Table 7: Standard deviation and margin of error for each test configuration

\begin{tabular}{|c|c|c|c|}
\hline Test case ID & $\begin{array}{c}\text { Absorbed energy } \\
\text { percentage }\end{array}$ & $\begin{array}{c}\text { Standard } \\
\text { deviation }\end{array}$ & $\begin{array}{c}\text { Margin of error } \\
(\%)\end{array}$ \\
\hline $1 \mathrm{a}$ & 42.3 & 1.80 & 2.60 \\
\hline $1 \mathrm{~b}$ & 32.8 & 1.85 & 2.75 \\
\hline $2 \mathrm{a}$ & 54.9 & 8.28 & 12.30 \\
\hline $2 \mathrm{~b}$ & 97.1 & 0.41 & 0.61 \\
\hline
\end{tabular}

In the below two graphs, the bar represents the average absorbed energy percentage and the error bars show the standard deviation of the absorbed energy of 3 specimens in each configuration. It can be observed that the lower level of impact energy had the lower absorbed energy percent for both the impact locations and vice versa with low margin of error which can be observed from the graph. The highest absorbed energy percentage was obtained for $\mathrm{P}_{2}$ impact location for $3 \mathrm{~J}$ energy with $97.1 \%$ and the lowest one was also obtained for $\mathrm{P}_{2}$ location at $1 \mathrm{~J}$ energy with $32.8 \%$. The specimen impacted at $\mathrm{P}_{1}$ location with $3 \mathrm{~J}$ energy had a high error percentage compared to $\mathrm{P}_{2}$ location which can be noted. 


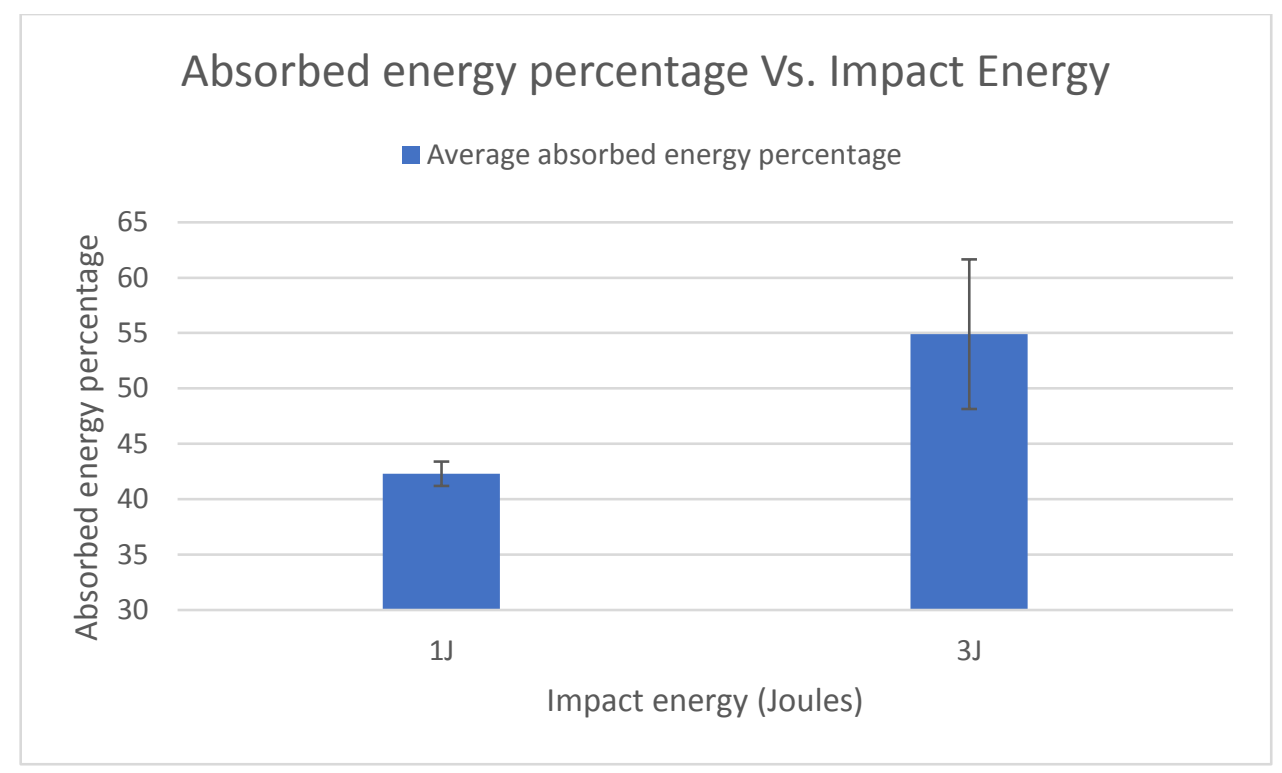

Figure 17: Absorbed energy percentage versus impact energy at $P_{1}$ location

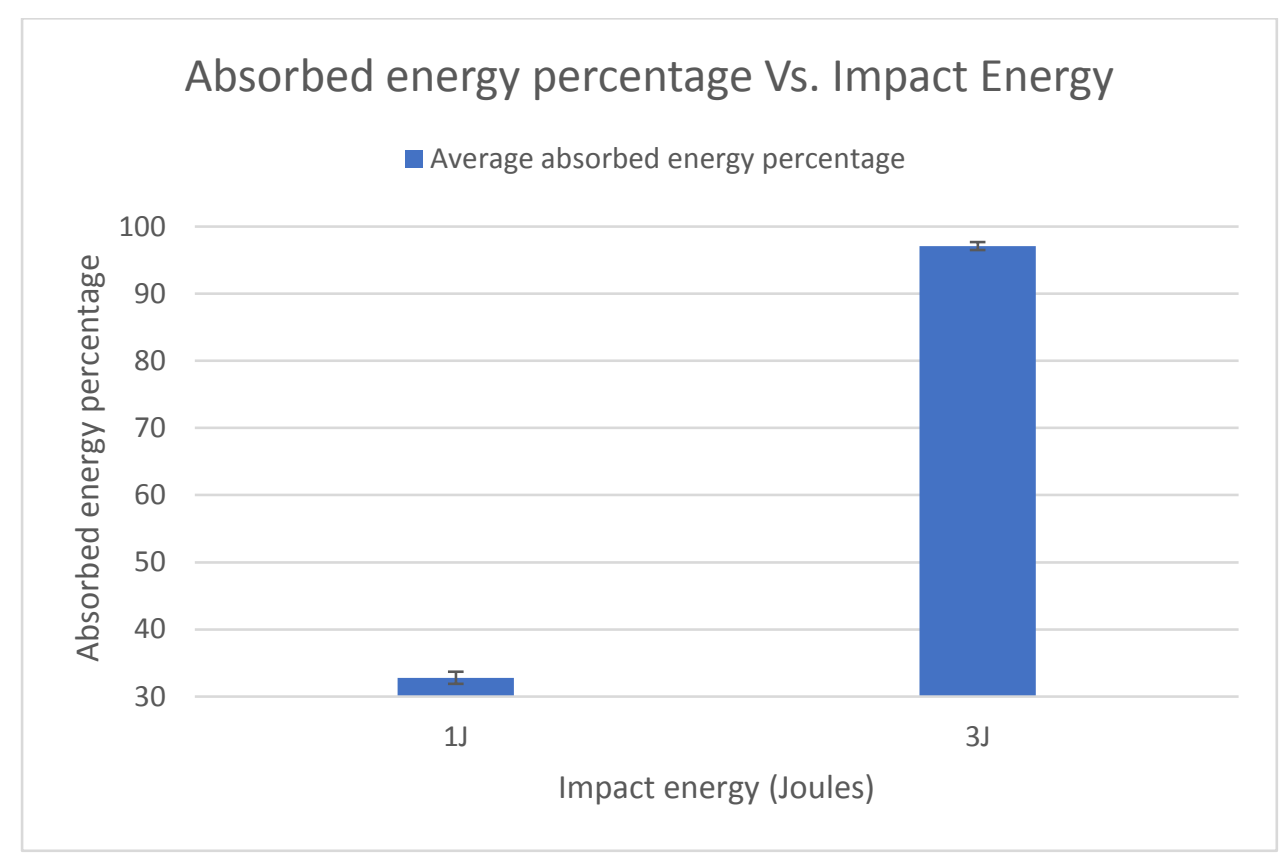

Figure 18: Absorbed energy percentage versus impact energy at $P_{2}$ location

The thermal images show that the crack length for $1 \mathrm{~J}$ impact energy at $\mathrm{P}_{2}$ location is shorter compared to the one for $\mathrm{P}_{1}$ impact location. This can be correlated to the absorbed energy values in Table 6 as well, the specimens with shorter crack length have the lower absorbed energy compared to the longer ones. This trend is reverse for $3 \mathrm{~J}$ impact energy, where the damage due to an impact at $\mathrm{P}_{2}$ location was more pronounced that the one due to $\mathrm{P}_{1}$ impact per IR images. Like the previous case, more extensive damage corresponds to higher absorbed energy indicated in Table 6. 
Figure 19 shows the horizontal, vertical, and inclined cracks in an IR image for a specimen subjected to $3 \mathrm{~J}$ impact at $\mathrm{P}_{2}$. The bright red and green spots are the hotspots generally seen at the ends of the horizontal cracks where the crack directions changes. These hot spots are the thermal variations caused by energy dissipation of the test specimen during impact. The cracks change their directions at the ends of the horizontal crack and travel at $45^{\circ}$ creating a circular shape damage pattern.

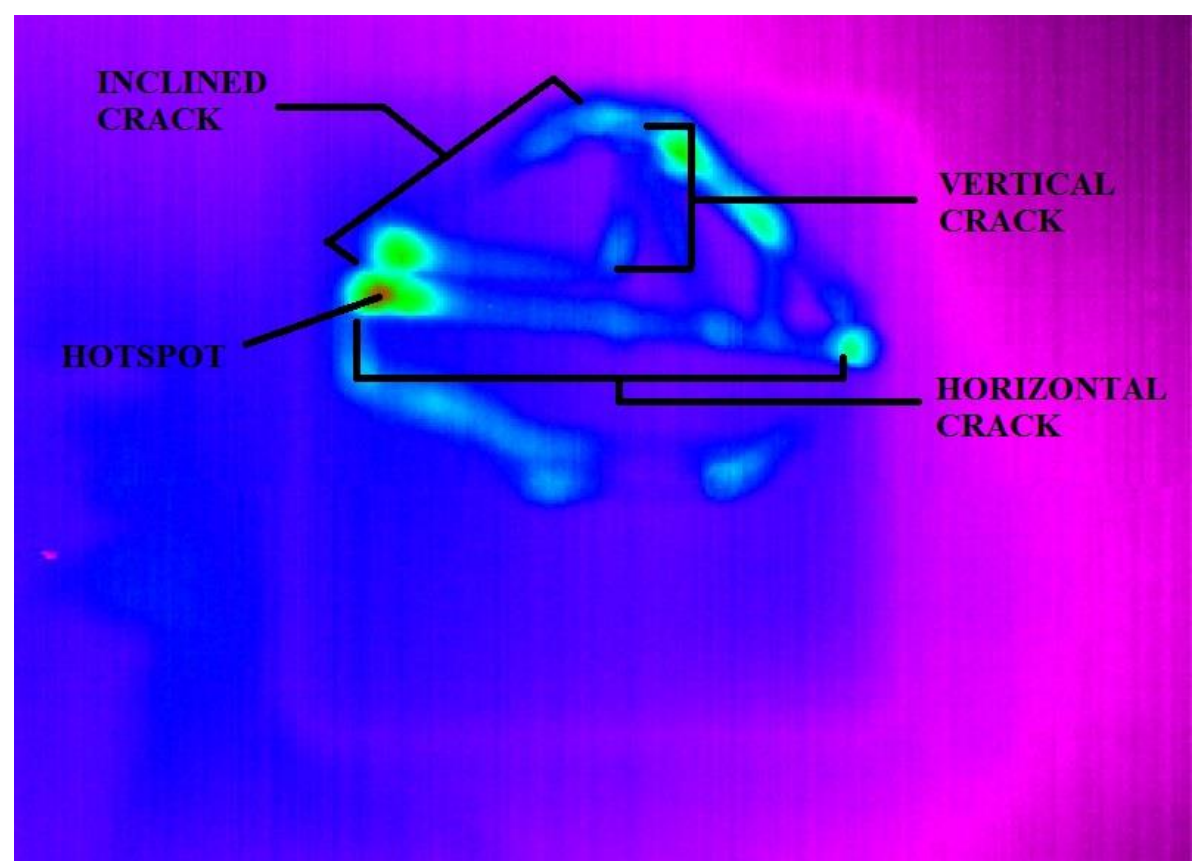

Figure 19: Damage of a test specimen subjected to $3 \mathrm{~J}$ impact at $\mathbf{P}_{\mathbf{2}}$

Per Table 6 , it can be seen that at $1 \mathrm{~J}$ impact energy the absorbed energy is more for $\mathrm{P}_{1}$ location, while this is the reverse for $3 \mathrm{~J}$ energy. The fracture along the orientation of the extrudates is in the interface between them and needs less energy than the cracks formed transversely to the extrudates. When a crack changes its direction to $90^{\circ}$ and $45^{\circ}$ angles, it dissipates more energy. The change of the directions is considered as a mixed style cracking in which it is an intermediate for tensile and in-plane shear cracking. As the crack approaches the clamped edges, the change in the crack behaviour due to the tensile and the shear stresses can be seen as mixed crack behaviour. The thermal images also show the damaged area highlighted with a significant temperature difference when the crack propagates across the extrudates. The hot spots appear at both ends of the horizontal crack, where it changes its direction from $0^{\circ}$ to $90^{\circ}$ or $45^{\circ}$ substantiating that more energy dissipation for mixed mode fracture. 
As mentioned, more energy absorption was observed for $\mathrm{P}_{1}$ impact location for $1 \mathrm{~J}$ energy than the $\mathrm{P}_{2}$ location, and it is the reverse for the $3 \mathrm{~J}$ impact energy. This is due to the clamping forces and the area available for crack propagation. At $\mathrm{P}_{2}$ location, the impact location is closer to the clamped edges, and the area for crack propagation is comparatively less causing the crack to be smaller at $\mathrm{P}_{2}$ location then the $\mathrm{P}_{1}$ location. At low energy impact the crack in the plate was caused by the bending of the plate. When $3 \mathrm{~J}$ impact energy is applied, the crack propagation at $\mathrm{P}_{1}$ location is more compared to $\mathrm{P}_{2}$ location with no complete damage or shatter, but the crack has propagated through larger area without breaking. At higher impact energy the crack was caused due to bending and the shear force in the plate caused by the impactor and the clamped edges. But at $\mathrm{P}_{2}$ location the area is less, and near to clamped edges also influence the crack propagation. The crack grew over the limited area which made the specimen to shatter. All these results obtained validates the results from the table 5 and table 6 given above, where the absorbed energy for $3 \mathrm{~J}$ is more than $1 \mathrm{~J}$ energy impact at both the locations.

\subsection{TeST Plan 2}

In the test plan \#1, the experiments were performed with two different energies and specimen had the same layer thickness of $0.14 \mathrm{~mm}$ (18 layers total). The effect of impact energies and the crack behaviour were explored in detail. The higher impact energy ( $3 \mathrm{~J}$ ) induced more extensive damage and was selected for the second parts of tests. As discussed in Section 3.2.2, the layer thickness (total number of layers) was varied, while keeping the specimen thickness constant at approximately $2.52 \mathrm{~mm}$.

It was planned to keep the experimental test set-up unchanged; however, the FLIR SC5000 camera was not available and was replace by a FLIR T450SC. As usual this camera was placed to the rear side of the square aperture equipped by using a clamp mount articulated arm. The IR camera had a resolution of $320 \times 240$ and a temperature sensitivity of $30 \mathrm{mK}$. The recording frame rate of 30 per second which was good enough for a recording a damage. This camera was operated by FLIR ResearchIR software which was recommended by FLIR for processing results. 
As mentioned in Section 3.2.2, the layer thicknesses were varied from $0.10 \mathrm{~mm}$ to $0.18 \mathrm{~mm}$ by $0.02 \mathrm{~mm}$ leaving $0.14 \mathrm{~mm}$ thickness as it was already tested in Section 4.1. Since the specimen thickness is kept unchanged, the total number of layers were varying from 25 to 14 . For each configuration, three specimens were tested, and the average values were calculated for comparison purposes. Each test specimen showed a different type of crack behaviour, which is explained in detail below.

The test was commenced with $\mathrm{P}_{1}$ impact location with 25-layer specimens and $3 \mathrm{~J}$ impact energy. Only one specimen which is having the severe damage is represented below and the remaining ones are listed in the appendix B. The damage is seen clearly visible and the cracks are horizontal and vertical. There is a horizontal crack in the middle along the extrudates in every specimen, but two samples have a vertical crack as well which are formed after the horizontal crack. The absorbed energy for (1a-3) specimen is the highest among the three. This can be identified by seeing more visible horizontal and vertical cracks in the specimen.

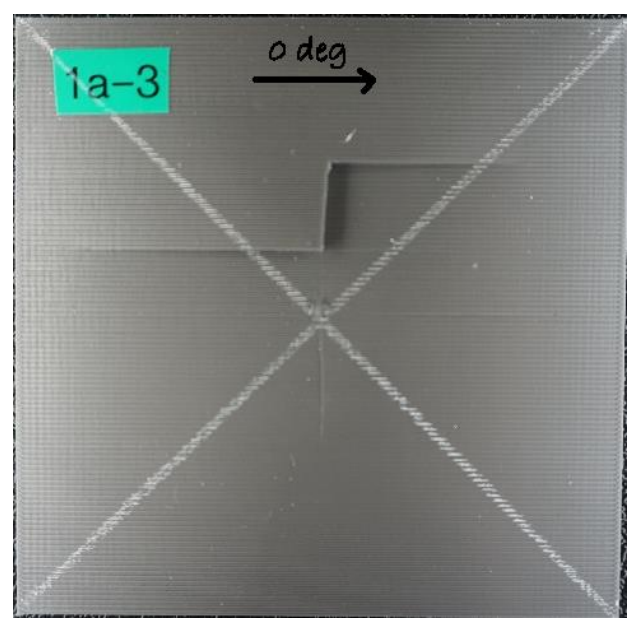

(a)

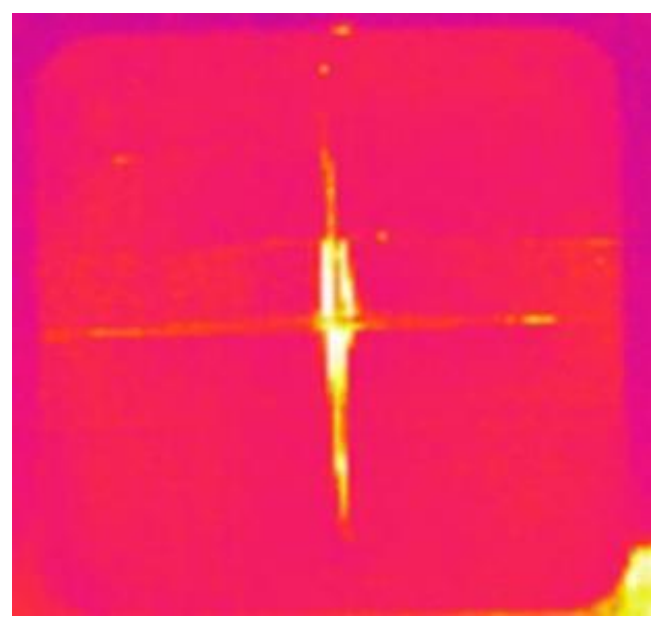

(b)

Figure 20: Specimens with $P_{1}$ impact location and 25 layers (a) specimen after testing; (b) thermal image captured during the test

The 25-layer specimens are followed by 21-layer specimens which are tested at the same location $\mathrm{P}_{1}$. The cracks are not very severe compared to 25-layer specimens. All three specimen shows similar pattern of damage with a horizontal crack and a vertical crack in the middle. As mentioned more energy absorption leads to more cracks, which made one specimen to have an extra horizontal crack close to the top clamped edge (Figure 21), while less energy was absorbed for the other specimen that did not show a vertical crack (Appendix B Figure 39). 


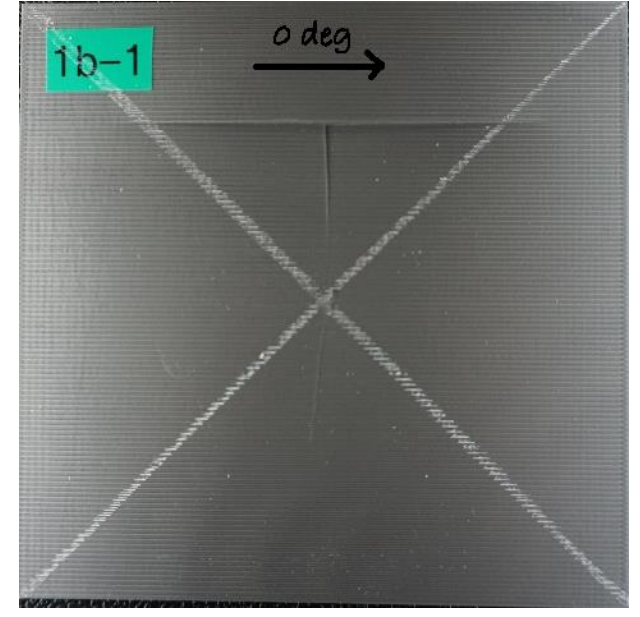

(a)

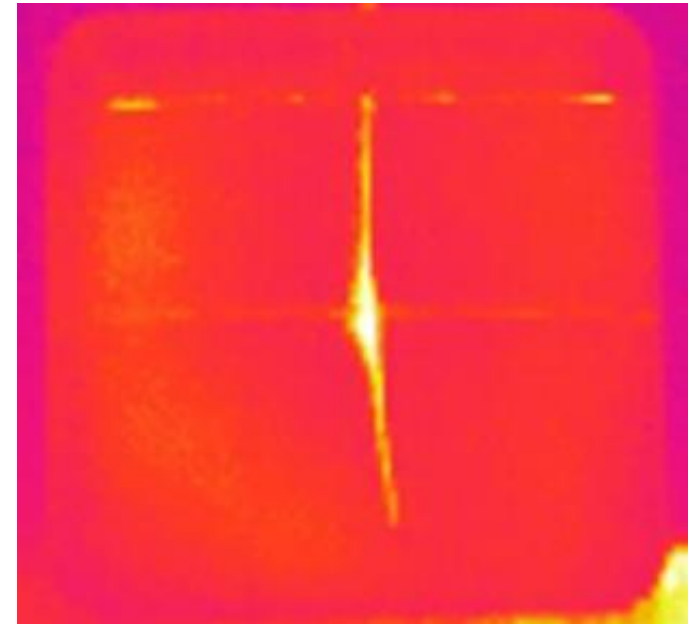

(b)

Figure 21: Specimens with $P_{1}$ impact location and 21 layers (a) specimen after testing; (b) thermal image captured during the test

The next set of specimens tested had 16 layers that showed severe cracks when compared to the others. These specimens showed different types of cracks which were different among themselves. The damage in one specimen (1C-2) is not visible to the naked eye (Figure 22a) and can be only observed in the thermal image (Figure 22b). The other two specimens had severe damage with multiple horizontal cracks and a long vertical crack in the middle respectively. Both specimens (1C-1 and $1 \mathrm{C}-3$ ) absorbed almost the same percentage of energy, but the cracks for 1C-3 were more extensive (Figure 23).

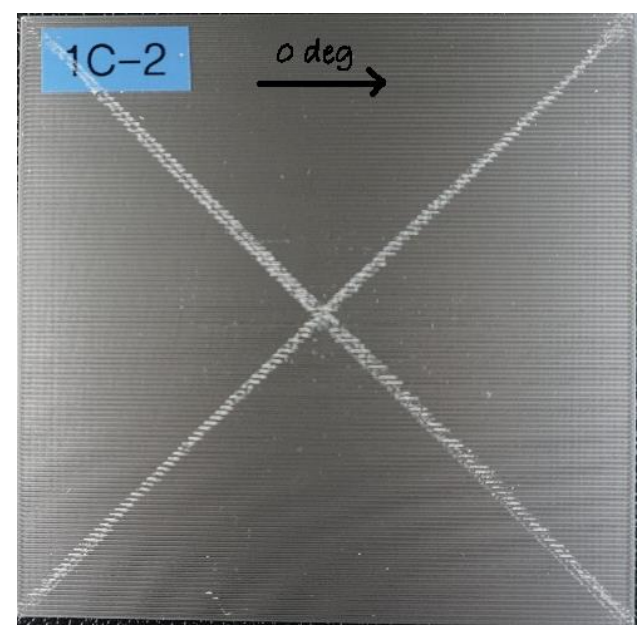

(a)

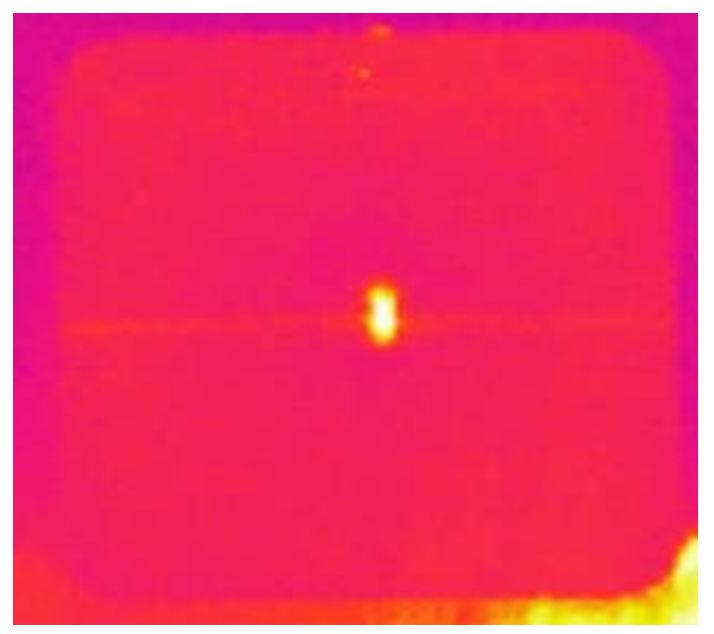

(b)

Figure 22: Specimens with $P_{1}$ impact location and 16 layers (a) specimen after testing; (b) thermal image captured during the test 


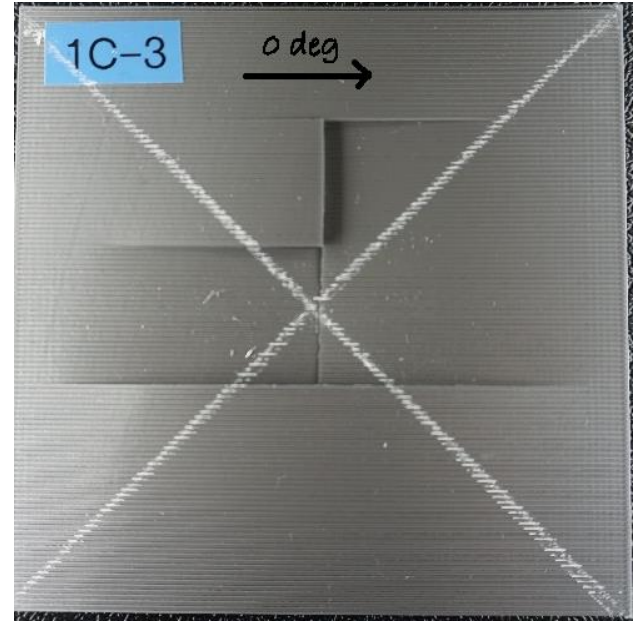

(a)

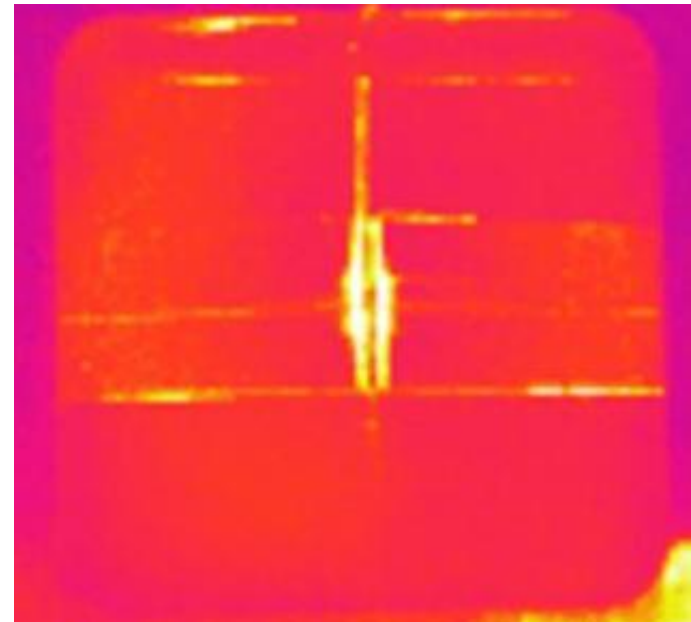

(b)

Figure 23: Specimens with $P_{1}$ impact location and 16 layers (a) specimen after testing; (b) thermal image captured during the test

The 14-layer specimens have almost the same type of crack behaviour as 16-layer specimens and absorbed energy percentage. Multiple horizontal cracks on top and bottom, and a vertical crack followed by it were formed in the specimens, which was the damage pattern for all three.

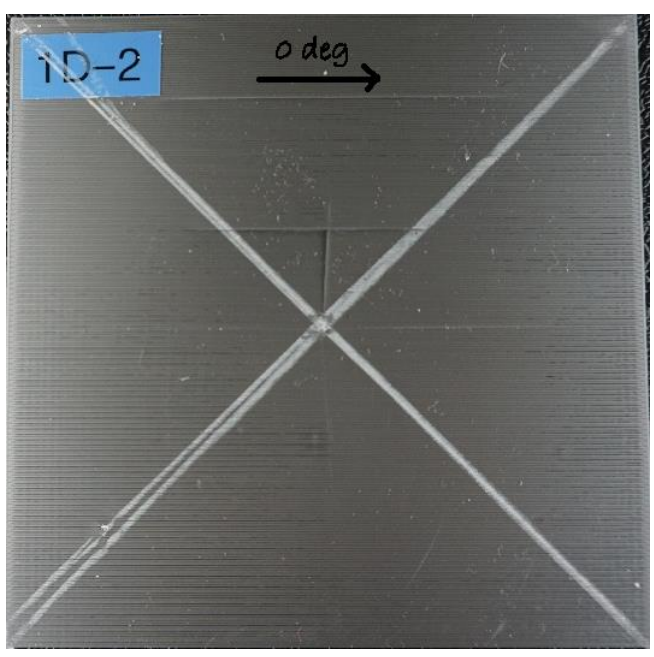

(a)

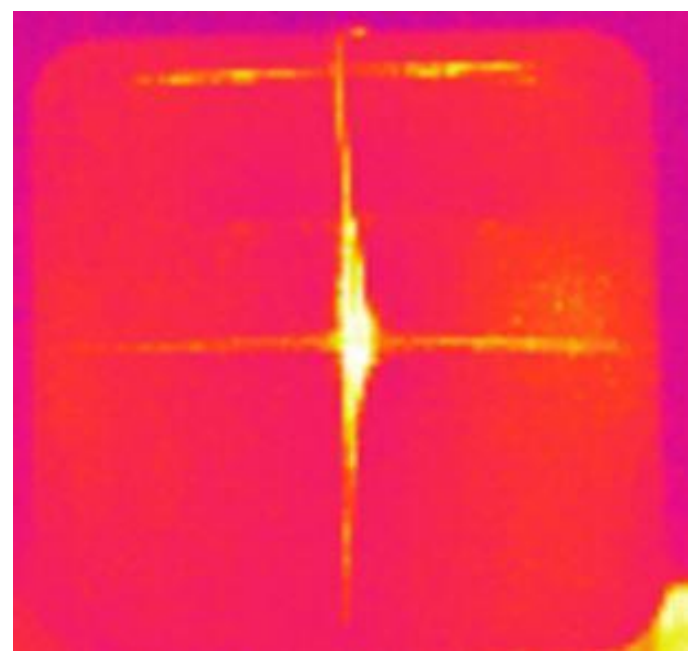

(b)

Figure 24: Specimens with $P_{1}$ impact location and 14 layers (a) specimen after testing; (b) thermal image captured during the test

The rebound energies and absorbed energies with their average values and the absorbed energy percentage for $\mathrm{P}_{1}$ impact location are calculated following the procedure described in Section 4.1 provided in Tables 8 and 9. The standard deviation and margin of error values for each test configuration was provided in Table 10. 
If we observe the values in the table 9, the energy absorption percentage is lower for high layer thickness and higher for low layer thickness. The individual energy absorption values in the table showed a different pattern of the fracture behaviour but when you compare the average percentage absorbed values we can see a trend of increasing behaviour with respect to the layer thickness in $\mathrm{P}_{1}$ location.

Table 8: Rebound energy calculations for each specimen configuration at $\mathbf{P}_{\mathbf{1}}$

\begin{tabular}{|c|c|c|c|c|c|c|c|c|c|}
\hline \multirow{2}{*}{$\begin{array}{c}\text { Test } \\
\text { case } \\
\text { ID }\end{array}$} & \multirow{2}{*}{$\begin{array}{c}\text { Impact } \\
\text { energy } \\
\text { (J) }\end{array}$} & \multirow[b]{2}{*}{$\begin{array}{l}\text { Impact } \\
\text { location }\end{array}$} & \multirow{2}{*}{$\begin{array}{l}\text { Impact } \\
\text { angle } \alpha \\
\left(^{\circ}\right)\end{array}$} & \multicolumn{3}{|c|}{ Rebound angle $\theta\left(^{\circ}\right)$} & \multicolumn{3}{|c|}{ Rebound Energy $(\mathrm{J})$} \\
\hline & & & & $\begin{array}{c}\text { Sample } \\
\# 1\end{array}$ & $\begin{array}{c}\text { Sample } \\
\# 2\end{array}$ & $\begin{array}{c}\text { Sample } \\
\# 3\end{array}$ & $\begin{array}{c}\text { Sample } \\
\# 1\end{array}$ & $\begin{array}{c}\text { Sample } \\
\# 2\end{array}$ & $\begin{array}{c}\text { Sample } \\
\# 3\end{array}$ \\
\hline $1 \mathrm{a}$ & \multirow{4}{*}{3} & & \multirow{4}{*}{32.02} & 22.20 & 20.66 & 18.78 & 1.462 & 1.268 & 1.050 \\
\hline $1 \mathrm{~b}$ & & & & 16.00 & 17.40 & 19.45 & 0.764 & 0.902 & 1.125 \\
\hline $1 \mathrm{c}$ & & & & 14.02 & 22.12 & 14.11 & 0.587 & 1.451 & 0.595 \\
\hline $1 d$ & & & & 16.13 & 17.31 & 15.24 & 0.776 & 0.893 & 0.693 \\
\hline
\end{tabular}

Table 9: Rebound and absorbed energies for each specimen configuration at $\mathbf{P}_{\mathbf{1}}$

\begin{tabular}{|c|c|c|c|c|c|c|c|c|c|}
\hline \multirow{2}{*}{$\begin{array}{l}\text { Test } \\
\text { case } \\
\text { ID }\end{array}$} & \multicolumn{3}{|c|}{ Rebound Energy $(\mathrm{J})$} & \multirow{2}{*}{$\begin{array}{c}\text { Average } \\
\text { rebound } \\
\text { energy } \\
(\mathrm{J})\end{array}$} & \multicolumn{3}{|c|}{ Absorbed Energy $(\mathrm{J})$} & \multirow{2}{*}{$\begin{array}{c}\text { Average } \\
\text { absorbed } \\
\text { energy } \\
(\mathrm{J})\end{array}$} & \multirow{2}{*}{$\begin{array}{c}\text { Absorbed } \\
\text { energy } \\
\text { percentage }\end{array}$} \\
\hline & $\begin{array}{c}\text { Sample } \\
\# 1\end{array}$ & $\begin{array}{c}\text { Sample } \\
\# 2\end{array}$ & $\begin{array}{c}\text { Sample } \\
\# 3\end{array}$ & & $\begin{array}{c}\text { Sample } \\
\# 1\end{array}$ & $\begin{array}{c}\text { Sample } \\
\# 2\end{array}$ & $\begin{array}{c}\text { Sample } \\
\# 3\end{array}$ & & \\
\hline $1 \mathrm{a}$ & 1.462 & 1.268 & 1.050 & 1.260 & 1.538 & 1.732 & 1.950 & 1.740 & 58.00 \\
\hline $1 b$ & 0.764 & 0.902 & 1.125 & 0.930 & 2.236 & 2.098 & 1.875 & 2.070 & 69.00 \\
\hline $1 \mathrm{c}$ & 0.587 & 1.451 & 0.595 & 0.877 & 2.413 & 1.549 & 2.405 & 2.123 & 70.76 \\
\hline $1 \mathrm{~d}$ & 0.776 & 0.893 & 0.693 & 0.787 & 2.224 & 2.107 & 2.307 & 2.213 & 73.76 \\
\hline
\end{tabular}

Table 10: Standard deviation and Margin of error for each test configuration at $\mathbf{P}_{\mathbf{1}}$

\begin{tabular}{|c|c|c|c|}
\hline Test case ID & $\begin{array}{c}\text { Absorbed energy } \\
\text { percentage }\end{array}$ & $\begin{array}{c}\text { Standard } \\
\text { deviation }\end{array}$ & $\begin{array}{c}\text { Margin of error } \\
(\%)\end{array}$ \\
\hline 1a & 58.00 & 5.61 & 8.36 \\
\hline $1 \mathrm{~b}$ & 69.00 & 4.95 & 7.38 \\
\hline $1 \mathrm{c}$ & 70.76 & 13.51 & 20.12 \\
\hline $1 \mathrm{~d}$ & 73.76 & 2.73 & 4.07 \\
\hline
\end{tabular}

The graph (Figure 25) also showed that, When the layer thickness is increased (number of layers decreased), the absorbed energy percentage also increases, which shows that a specimen with a greater number of layers absorbs less energy. Less margin of error is observed in 0.18 $\mathrm{mm}$ layer thickness specimens and highest was observed on $0.16 \mathrm{~mm}$ layer thickness specimens which was taken into consideration. 


\section{Absorbed energy percentage Vs. Layer thickness}

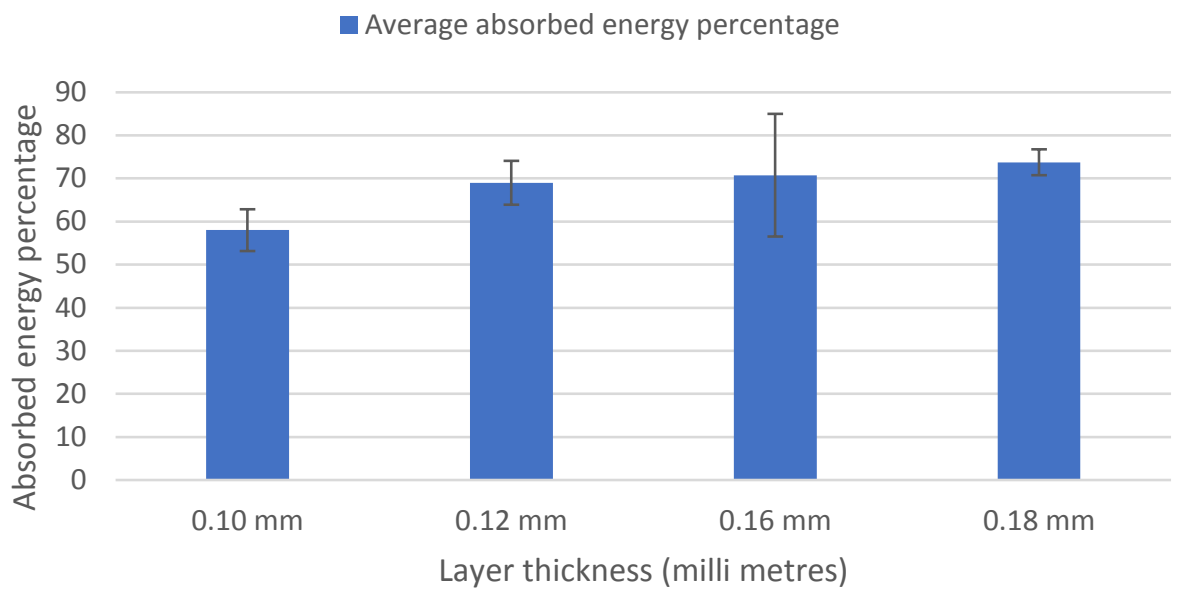

Figure 25: Absorbed energy percentage versus layer thickness at $\mathbf{P}_{1}$ location

This testing was continued on the next set of specimens for a different impact location, $\mathrm{P}_{2}$ position. Almost all specimens experienced a higher extent of damage than the specimens tested at $\mathrm{P}_{1}$ location. Here, results are presented following the same procedure used for $\mathrm{P}_{1}$ impact location. 25-layer specimens were tested first, which showed a higher extent of damage, approximately $15 \%$ increase in absorption energy than the case of $\mathrm{P}_{1}$ was observed. All specimens showed a horizontal crack at the impact location followed by an extra vertical crack for 2 of the sample. One of the specimens shattered at the impact location, which resulted in a high energy absorption (Figure 26).

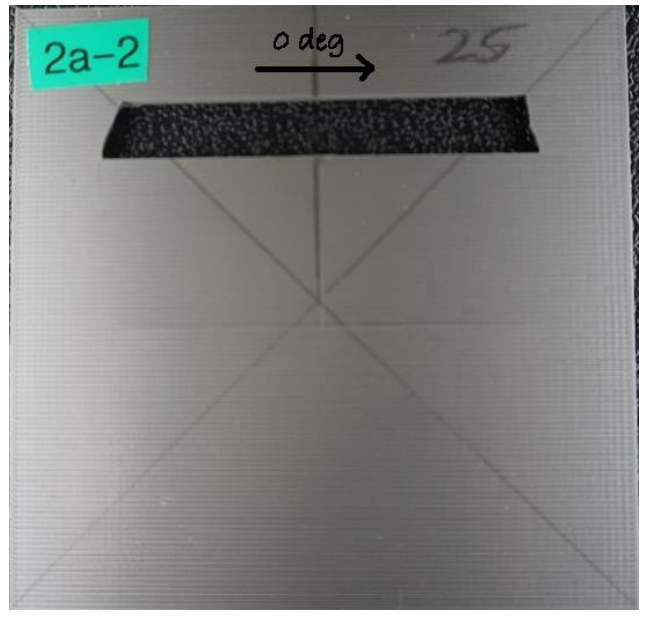

(a)

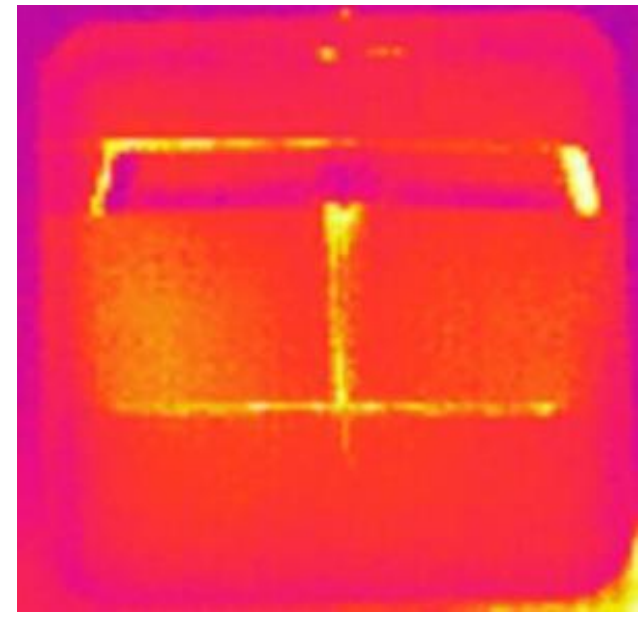

(b)

Figure 26: Specimens with $P_{2}$ impact location and 25 layers (a) specimen after testing; (b) thermal image captured during the test 
The next set of tests were completed for the 21-layers specimens, which had the highest energy absorption rate in the samples. The crack behaviour is similar between specimens that can be observed during inspection. Specimens showed multiple horizontal cracks and a vertical crack in the middle. The horizontal cracks were close to the clamped edges, but one specimen had a horizontal crack at the end of the downward vertical crack (Appendix B Figure 46) and another one had a shattered piece at the impact location (Figure 27)

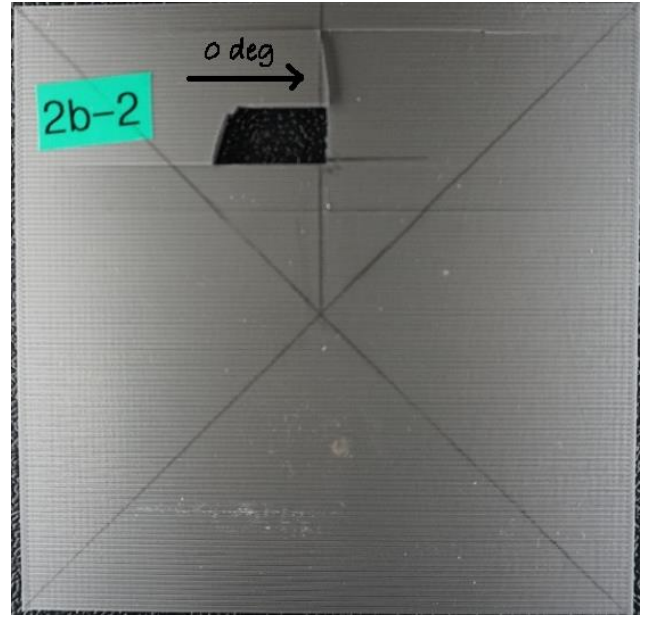

(a)

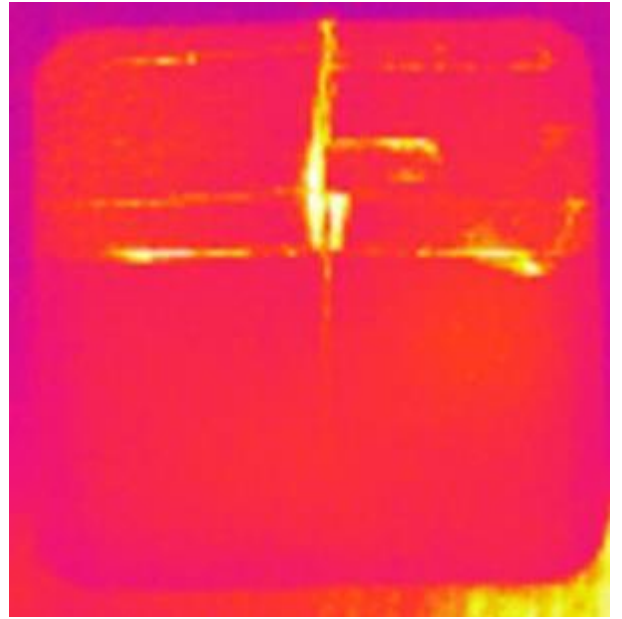

(b)

Figure 27: Specimens with $\mathbf{P}_{2}$ impact location and 21 layers (a) specimen after testing; (b) thermal image captured during the test

For the coupons with 16 layers, the damage can be seen clearly with horizontal and vertical cracks at the impact locations. As mentioned, the $\mathrm{P}_{2}$ location damages were severe and even made a broken damage in the impact location (Figure 28).

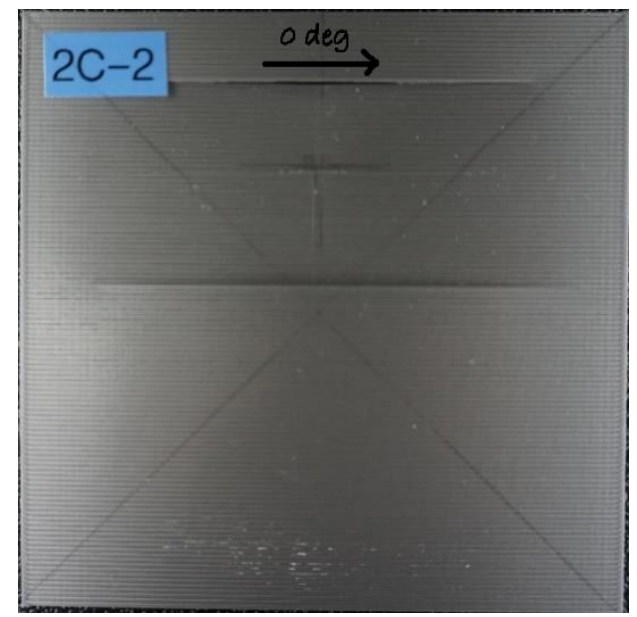

(a)

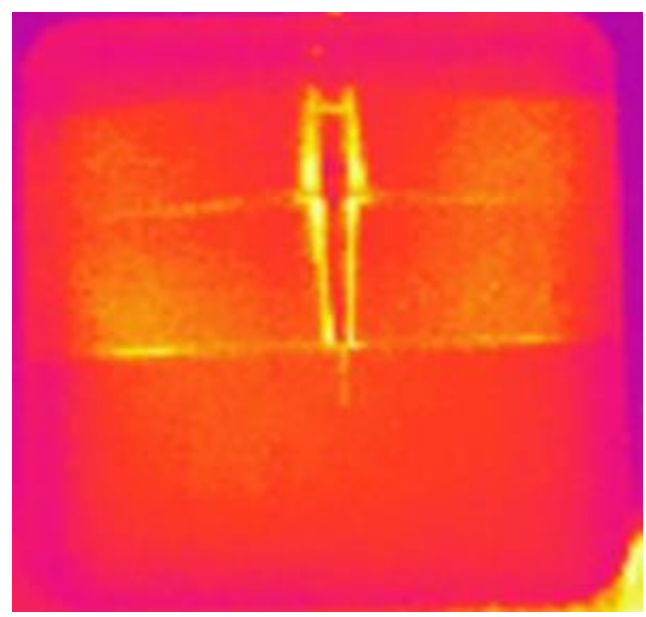

(b)

Figure 28: Specimens with $P_{2}$ impact location and 16 layers (a) specimen after testing; (b) thermal image captured during the test 
One specimen did not show a severe damage and only 2 horizontal cracks were observed at the impact location and the clamped edge (Figure 29). This difference can be related to the clamping forces between the plates and the specimen.

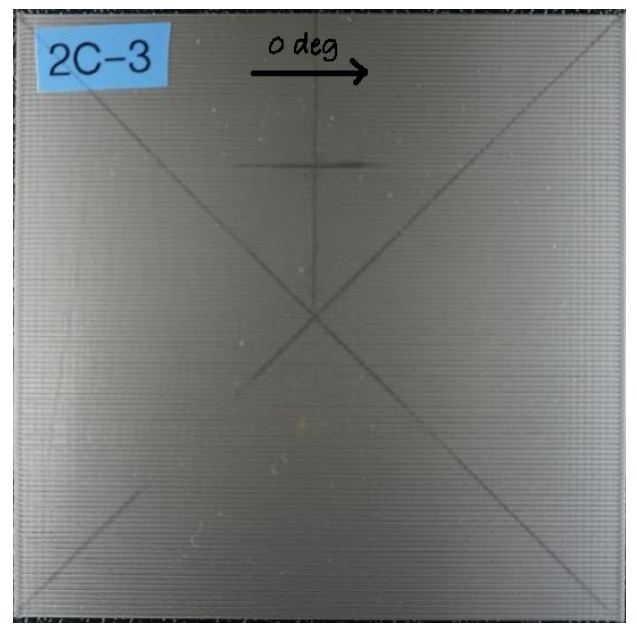

(a)

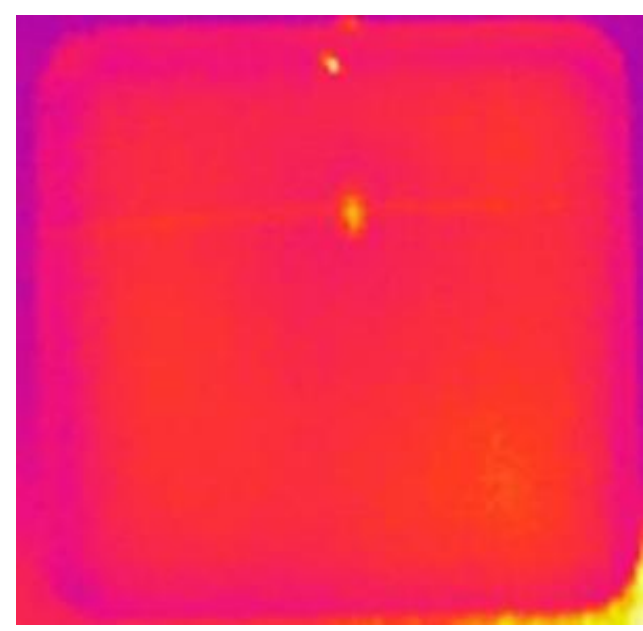

(b)

Figure 29: Specimens with $P_{2}$ impact location and 16 layers (a) specimen after testing; (b) thermal image captured during the test

The 14-layer specimens were the last set tested in this study. These specimens showed a similar behaviour like $\mathrm{P}_{2}$ impact location specimens of multiple horizontal cracks at the impact location with a vertical crack passing through the plate centre. We can also observe that there was a shatter in the test specimen (Figure 30).

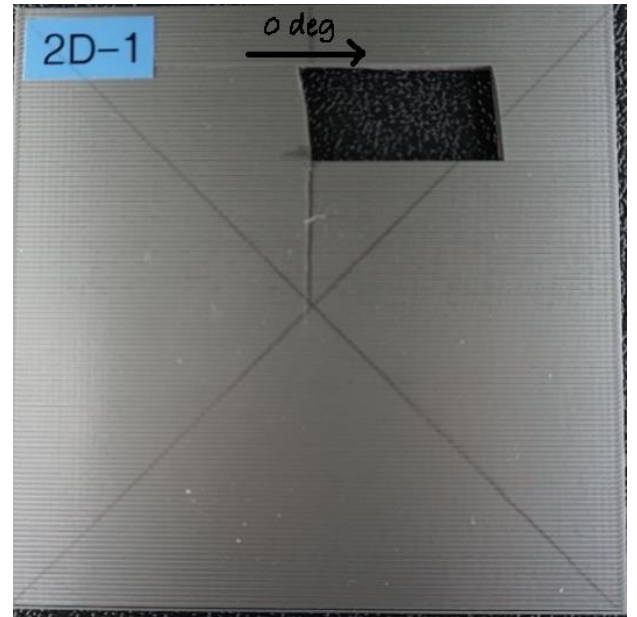

(a)

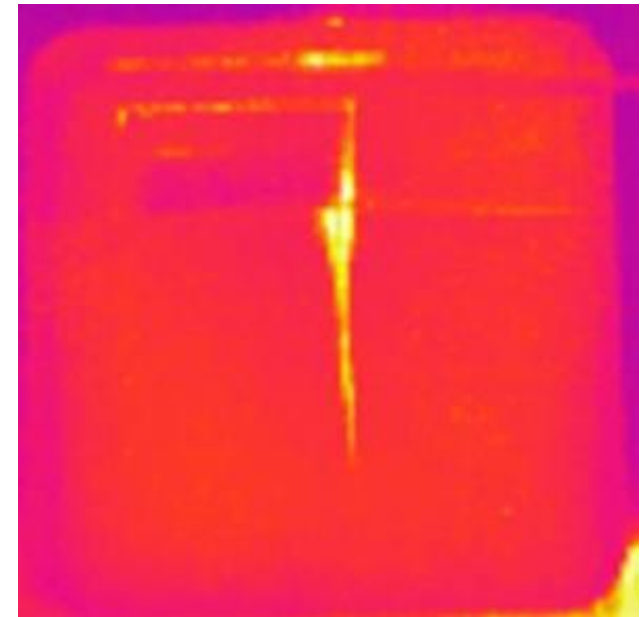

(b)

Figure 30: Specimens with $P_{2}$ impact location and 14 layers (a) specimen after testing; (b) thermal image captured during the test 
The rebound and absorbed energies with their average values, and absorbed energy percentage for $\mathrm{P}_{2}$ impact location are calculated following the procedure described earlier for test plan \#1 (Section 4.1) and are listed in Tables 11 and 12. Table 13 gives the standard deviation and margin of error details for each test configuration.

Table 11: Rebound energy calculations for each specimen configuration at $\mathbf{P}_{2}$

\begin{tabular}{|c|c|c|c|c|c|c|c|c|c|}
\hline \multirow{2}{*}{$\begin{array}{c}\text { Test } \\
\text { case } \\
\text { ID }\end{array}$} & \multirow{2}{*}{$\begin{array}{c}\text { Impact } \\
\text { energy } \\
(\mathrm{J})\end{array}$} & \multirow[b]{2}{*}{$\begin{array}{l}\text { Impact } \\
\text { location }\end{array}$} & \multirow{2}{*}{$\begin{array}{c}\text { Impact } \\
\text { angle } \alpha \\
\left({ }^{\circ}\right)\end{array}$} & \multicolumn{3}{|c|}{ Rebound angle $\theta\left(^{\circ}\right)$} & \multicolumn{3}{|c|}{ Rebound Energy $(\mathrm{J})$} \\
\hline & & & & $\begin{array}{c}\text { Sample } \\
\# 1\end{array}$ & $\begin{array}{c}\text { Sample } \\
\# 2\end{array}$ & $\begin{array}{c}\text { Sample } \\
\# 3\end{array}$ & $\begin{array}{c}\text { Sample } \\
\# 1\end{array}$ & $\begin{array}{c}\text { Sample } \\
\# 2\end{array}$ & $\begin{array}{c}\text { Sample } \\
\# 3\end{array}$ \\
\hline $2 a$ & & & \multirow{4}{*}{33.12} & 14.95 & 15.32 & 18.95 & 0.625 & 0.656 & 1.001 \\
\hline $2 b$ & & & & 13.49 & 12 & 9 & 0.510 & 0.425 & 0 \\
\hline $2 \mathrm{c}$ & & & & 18.20 & 19.75 & 14.40 & 0.924 & 1.086 & 0.580 \\
\hline $2 d$ & & & & 13.67 & 18.11 & 19.00 & 0.523 & 0.915 & 1.006 \\
\hline
\end{tabular}

Table 12: Rebound and absorbed energies for each specimen configuration at $\mathbf{P}_{\mathbf{2}}$

\begin{tabular}{|c|c|c|c|c|c|c|c|c|c|}
\hline \multirow{2}{*}{$\begin{array}{c}\text { Test } \\
\text { case }\end{array}$} & \multicolumn{3}{|c|}{ Rebound Energy (J) } & Average & \multicolumn{2}{|c|}{ Absorbed Energy (J) } & Average \\
\cline { 7 - 10 } ID & $\begin{array}{c}\text { Sample } \\
\# 1\end{array}$ & $\begin{array}{c}\text { Sample } \\
\# 2\end{array}$ & $\begin{array}{c}\text { Sample } \\
\# 3\end{array}$ & $\begin{array}{c}\text { Enebound } \\
\text { Energy }\end{array}$ & $\begin{array}{c}\text { Sample } \\
\# 1\end{array}$ & $\begin{array}{c}\text { Sample } \\
\# 2\end{array}$ & $\begin{array}{c}\text { Sample } \\
\# 3\end{array}$ & $\begin{array}{c}\text { absorbed } \\
\text { energy } \\
(\mathrm{J})\end{array}$ & $\begin{array}{c}\text { Absorbed } \\
\text { energy } \\
\text { percentage }\end{array}$ \\
\hline 2a & 0.625 & 0.656 & 1.001 & 0.760 & 2.375 & 2.344 & 1.999 & 2.240 & 74.66 \\
\hline 2b & 0.510 & 0.425 & 0.430 & 0.455 & 2.490 & 2.575 & 2.570 & 2.545 & 84.83 \\
\hline 2c & 0.924 & 1.086 & 0.580 & 0.863 & 2.076 & 1.914 & 2.420 & 2.137 & 71.23 \\
\hline 2d & 0.523 & 0.915 & 1.006 & 0.814 & 2.477 & 2.085 & 1.994 & 2.186 & 72.86 \\
\hline
\end{tabular}

Table 13: Standard deviation and margin of error for each test configuration at $\mathbf{P}_{\mathbf{2}}$

\begin{tabular}{|c|c|c|c|}
\hline Test case ID & $\begin{array}{c}\text { Absorbed energy } \\
\text { percentage }\end{array}$ & $\begin{array}{c}\text { Standard } \\
\text { deviation }\end{array}$ & $\begin{array}{c}\text { Margin of error } \\
(\%)\end{array}$ \\
\hline $2 \mathrm{a}$ & 74.66 & 5.67 & 8.45 \\
\hline $2 \mathrm{~b}$ & 84.83 & 1.29 & 1.93 \\
\hline $2 \mathrm{c}$ & 71.23 & 7.03 & 10.47 \\
\hline $2 \mathrm{~d}$ & 72.86 & 6.98 & 10.40 \\
\hline
\end{tabular}

The average values with error bars are illustrated in Figure 31. As before, it can be observed that, the blue bars represent the average absorbed percentage and the error bars are the deviation on three samples tested for each configuration. The specimens with $0.12 \mathrm{~mm}$ layer thickness has less error and other specimens were showing almost same error percentage which can be observed from the graph (figure 31) and Table (13). 
It can be observed that the average absorbed energy percentage increases with an increase in layer thickness for $\mathrm{P}_{1}$ impact location. On the other hand, for $\mathrm{P}_{2}$ impact location, the absorbed energy percentage first increases and then decreases with an increase in layer thickness. If we compare the $\mathrm{P}_{1}$ values and $\mathrm{P}_{2}$ values, the $\mathrm{P}_{2}$ values are always greater than $\mathrm{P}_{1}$ values which shows that the damage is intense at $\mathrm{P}_{2}$ compared to $\mathrm{P}_{1}$.

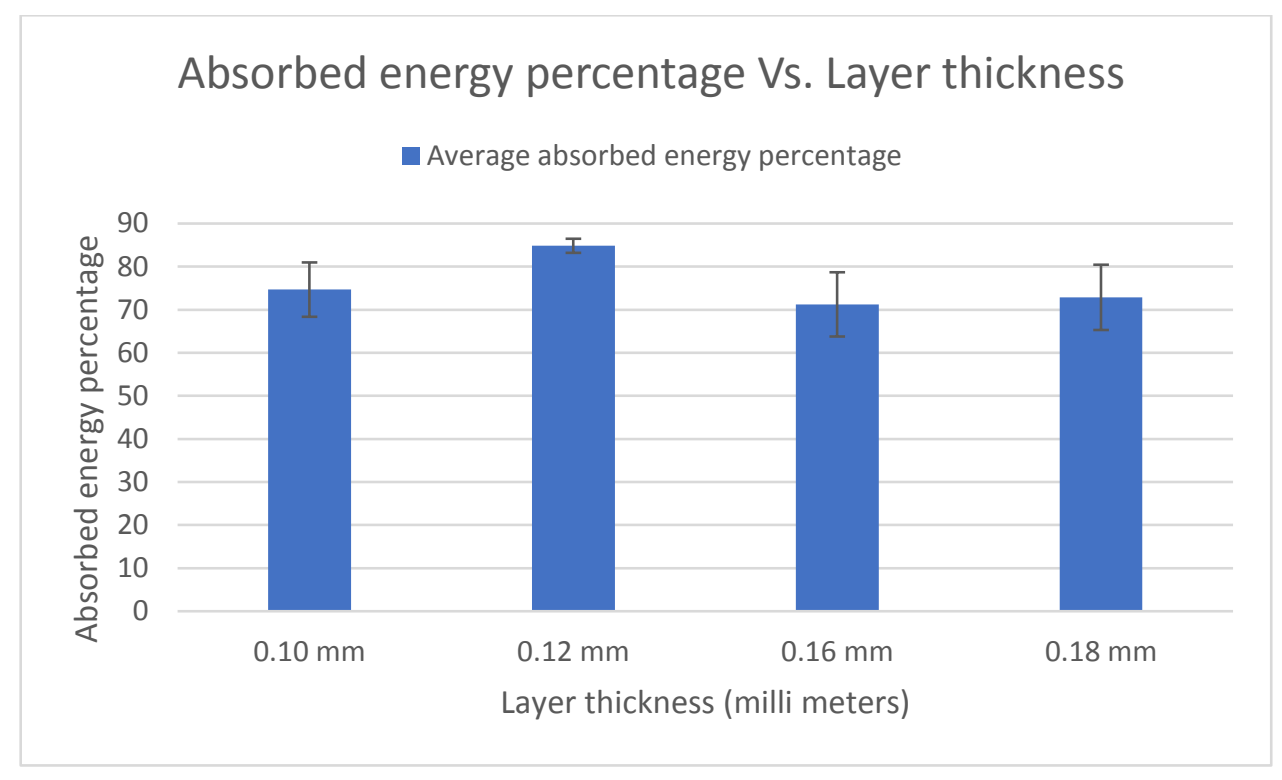

Figure 31: Absorbed energy percentage versus layer thickness at $P_{2}$ location

The study also showed that the horizontal cracks were almost along the extrudates of the specimen which absorbs less energy (Appendix Figures 36, 39, 44, 49) but when the vertical cracks were formed breaking the extrudates (Appendix B) in the transverse direction absorbed more energy. Furthermore, number of cracks are associated with the absorbed energy i.e. more cracks are formed when high energy is absorbed. In addition, if cracks are formed on both sides of the impact location, the absorbed energy percentage is more compared to the case with cracks only on one side. The highest energy absorbed specimens had a shattered piece at the impact location. For $\mathrm{P}_{2}$ impact location, damages were more severe and at least one specimen for each set had a shattered or broken piece. There was also a large variation between specimens in each set $(0.1,0.16$, and $0.18 \mathrm{~mm}$ in layer thickness) that can be explained by the clamping forces in the test set-up. Since specimens were clamped between two metal plates, the force acting on the places affect the fracture mechanism and the absorbed energy. These errors need to be taken care of during the test. The same filament material, and manufacturing process and design parameters were used in test plan \#1 and \#2. As a result, specimens with $0.14 \mathrm{~mm}$ in layer thickness can be combined with the results of test plan \#2 (Table 14). 
Table 14: Comparison of Absorbed energy percentages between $P_{1}$ and $P_{2}$ impact locations

\begin{tabular}{|c|c|c|}
\hline $\begin{array}{c}\text { Layer thickness } \\
(\mathbf{m m})\end{array}$ & $\begin{array}{c}\text { Absorbed energy } \\
\text { percentage at } \mathbf{P}_{\mathbf{1}}\end{array}$ & $\begin{array}{c}\text { Absorbed energy } \\
\text { percentage at } \mathbf{P}_{\mathbf{2}}\end{array}$ \\
\hline 0.10 & 58 & 74.66 \\
\hline 0.12 & 69 & 84.83 \\
\hline 0.14 & 54.9 & 97.10 \\
\hline 0.16 & 70.76 & 71.23 \\
\hline 0.18 & 73.76 & 72.86 \\
\hline
\end{tabular}

Considering Table 14, there is no consistent trend and relation between layer thickness and absorbed energy percentage. For $\mathrm{P}_{1}$ impact location, there is almost an increase in absorbed energy percentage with an increase in layer thickness except for specimens with $0.14 \mathrm{~mm}$ in layer thickness. For $\mathrm{P}_{2}$ impact location, first, there is an increase in absorbed energy percentage with an increase in layer thickness till $0.14 \mathrm{~mm}$ and then it decreases. Specimens with $0.14 \mathrm{~mm}$ layer thickness have the lowest absorbed energy percentage for $\mathrm{P}_{1}$ impact location and the highest value for $\mathrm{P}_{2}$ impact location. As mentioned, for all layer thicknesses, the absorbed energy percentage for $\mathrm{P}_{2}$ impact location is higher than the value for $\mathrm{P}_{1}$. In addition, specimens with a layer thickness of 0.16 and $0.18 \mathrm{~mm}$ have almost the same absorbed energy percentage for $\mathrm{P}_{1}$ and $\mathrm{P}_{2}$ impact locations. 


\section{CONCLUSIONS AND FUTURE WORK}

In this project, impact tests were performed on 3D printed PLA specimens using an in-house pendulum impact test apparatus. High-speed camera and Infra-Red (IR) thermography camera were used for obtaining the rebound angles and the damage patterns, respectively. The plates were $3 \mathrm{D}$ printed at $0^{\circ}$ orientation with a total thickness of around $0.1 \mathrm{in}(2.54 \mathrm{~mm})$. Two sets of tests were completed: 3D printed PLA plates with a layer thickness of $0.14 \mathrm{~mm}$ impacted with two levels of energies ( 1 and $3 \mathrm{~J})$ at two locations $\left(\mathrm{P}_{1}\right.$ and $\left.\mathrm{P}_{2}\right)$; and $3 \mathrm{D}$ printed plates with a varying layer thickness $(0.1,0.12,0.16,0.18 \mathrm{~mm})$ impacted with $3 \mathrm{~J}$ at two locations $\left(\mathrm{P}_{1}\right.$ and $\mathrm{P}_{2}$ ). Considering the first set of testing, the lower impact energy $(1 \mathrm{~J})$ showed cracks in between the extrudates (tensile). which dissipated more energy when impacted at the centre $\left(\mathrm{P}_{1}\right)$ than close to the clamped edges, $\mathrm{P}_{2}(42.3 \%$ versus $32.8 \%)$. At the higher impact energy ( $\left.3 \mathrm{~J}\right)$, the cracks were observed between and transverse to the extrudates (tensile and shear) and the plates showed higher absorbed energy percentage compared with $1 \mathrm{~J}$ impact energy. Unlike the case of $1 \mathrm{~J}$ impact energy, for $3 \mathrm{~J}$ impact, plates showed higher energy absorption when the impact was close to the clamped edges $\left(\mathrm{P}_{2}\right)$ compared to the impact at plate centre, $\mathrm{P}_{1}(54.9 \%$ versus $97.1 \%$ ). For the second set of tests, an increase in the total number of layers (decrease in the layer thickness) showed an increase in the impact energy absorption (from 58\% to $73.76 \%$ ) when impacted at $\mathrm{P}_{1}$ location. For $\mathrm{P}_{2}$ impact location, first, there is an increase in absorbed energy percentage with an increase in layer thickness till $0.14 \mathrm{~mm}$ and then it decreases. Specimens with $0.14 \mathrm{~mm}$ layer thickness have the lowest absorbed energy percentage for $\mathrm{P}_{1}$ impact location and the highest value for $\mathrm{P}_{2}$ impact location. As mentioned, for all layer thicknesses, the absorbed energy percentage for $\mathrm{P}_{2}$ impact location is higher than the value for $\mathrm{P}_{1}$. In addition, specimens with a layer thickness of 0.16 and $0.18 \mathrm{~mm}$ have almost the same absorbed energy percentage for $\mathrm{P}_{1}$ and $\mathrm{P}_{2}$ impact locations. Experimental results of absorbed energy percentages and crack behaviour and formation in the specimens obtained in this research can be used to validate Finite Element (FE) simulation models for impact testing of $3 \mathrm{D}$ printed plates. 
In this project, 3D printed PLA coupons with $0^{\circ}$ orientation were explored with 2 different impact energy levels and impact locations. The non-uniform trend of absorbed energy percentage with layer thickness for the case of $\mathrm{P}_{2}$ impact location needs to be explored further. The standard deviations and the error percentages showed that results are not statistically significant and this needs to be taken into account for future work. The change in the fracture mechanism and the variations in manufacturing or internal defects can be contributing factors. Other manufacturing process and design parameters can be investigated as well, e.g. cross ply and quasi-isotropic stacking sequences. In addition, the impact of nozzle temperature, bed temperature, printing speed, infill percentage, and material can be explored as well. 


\section{APPENDIX A}

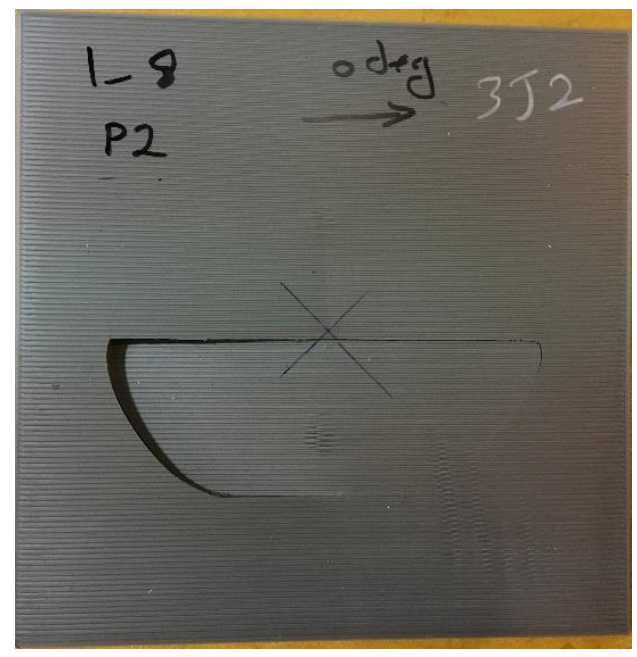

(a)

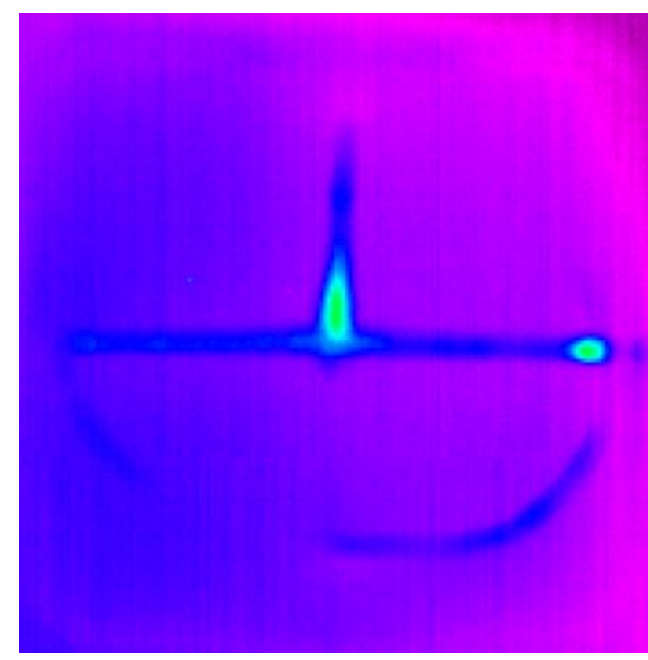

(b)

Figure 32: Specimens at $3 \mathrm{~J}$ energy level (a) specimen after impact at $P_{1}$ location, (b) thermal imaging for $\mathbf{P}_{1}$ location.

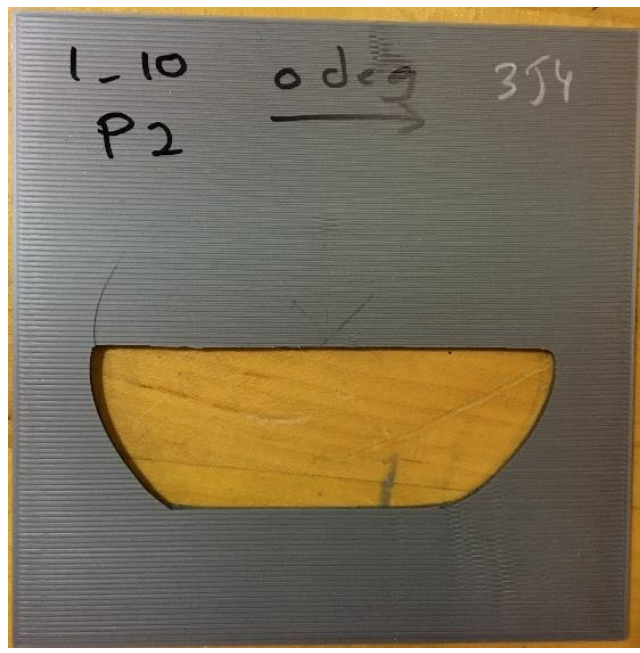

(a)

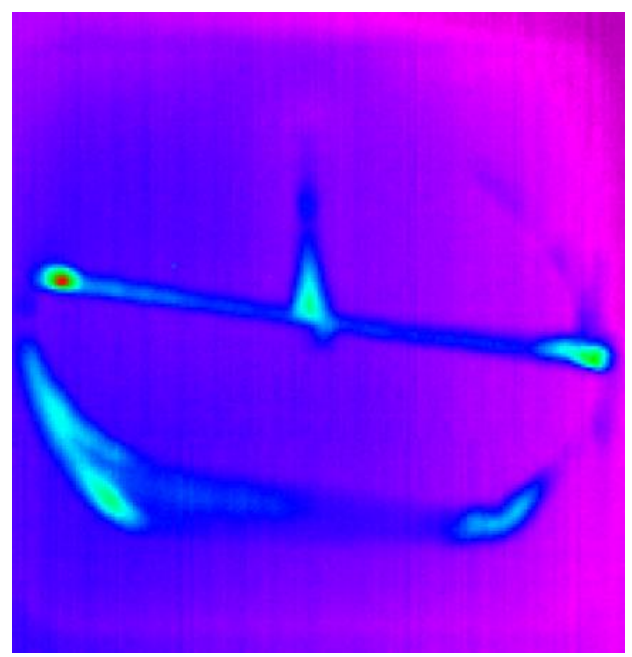

(b)

Figure 33: Specimens at $3 \mathrm{~J}$ energy level (a) specimen after impact at $P_{1}$ location, (b) thermal imaging for $\mathbf{P}_{1}$ location. 


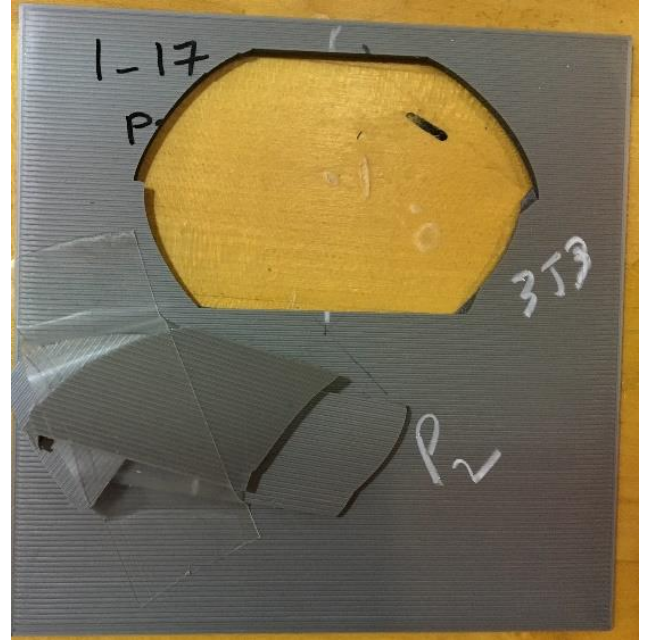

(a)

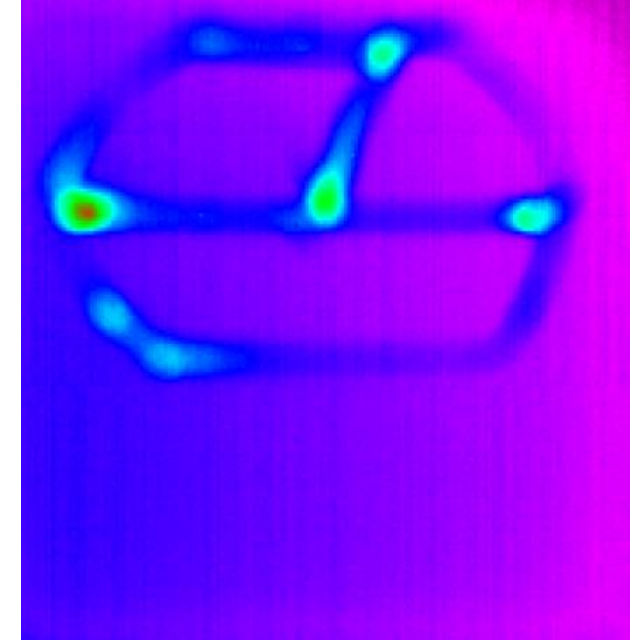

(b)

Figure 34: Specimens at $3 \mathrm{~J}$ energy level (a) specimen after impact at $P_{2}$ location, (b) thermal imaging for $P_{2}$ location.

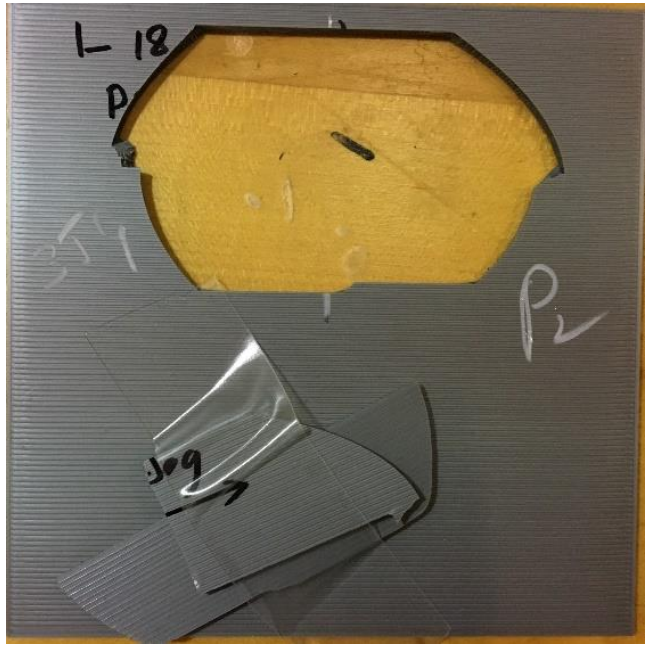

(a)

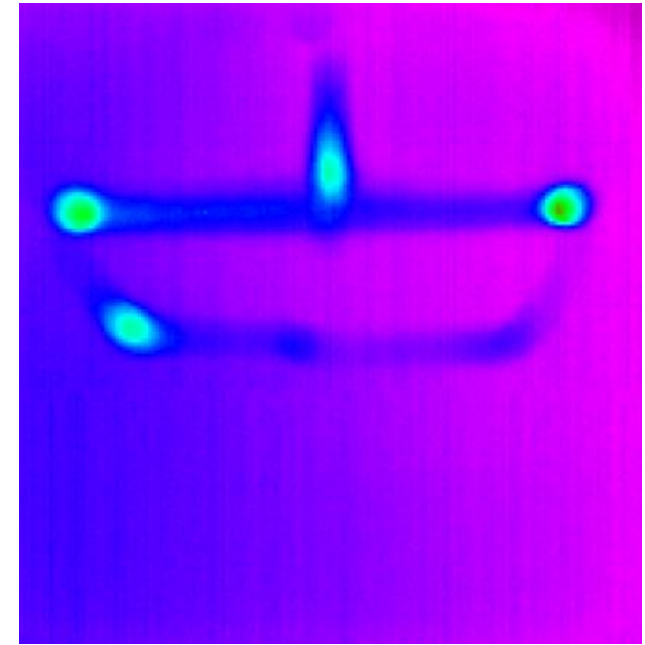

(b)

Figure 35: Specimens at 3 J energy level (a) specimen after impact at $P_{2}$ location, (b) thermal imaging for $\mathbf{P}_{2}$ location. 


\section{APPENDIX B}

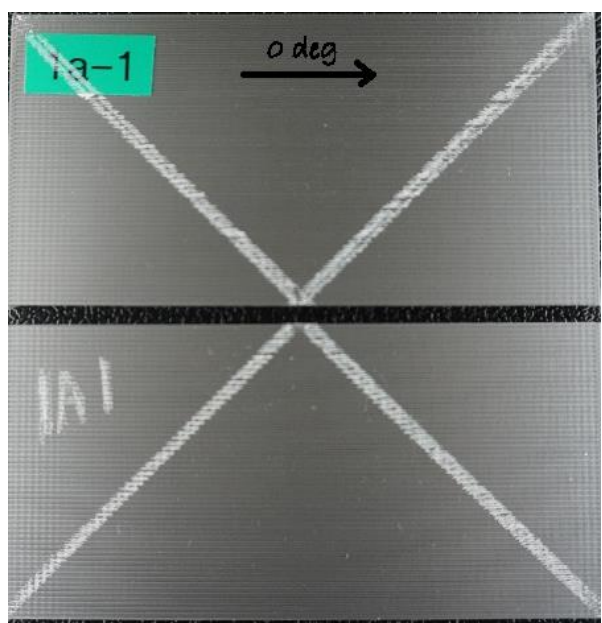

(a)

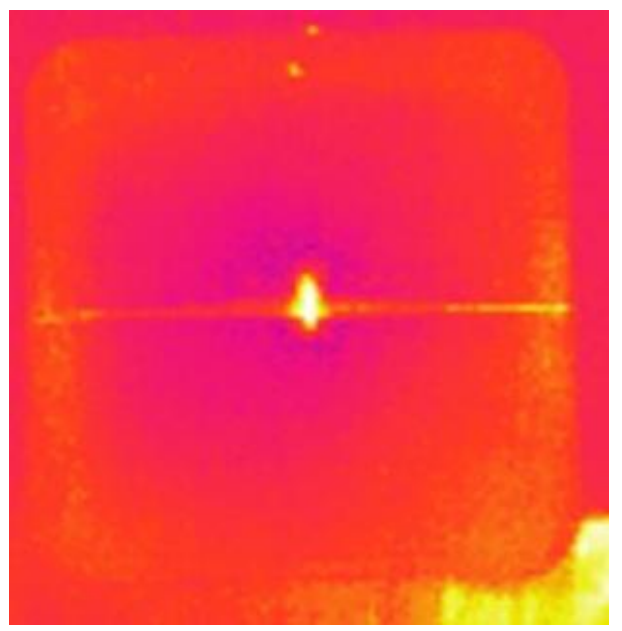

(b)

Figure 36: Specimens with $P_{1}$ impact location and 25 layers (a) specimen after testing; (b) thermal image captured during the test

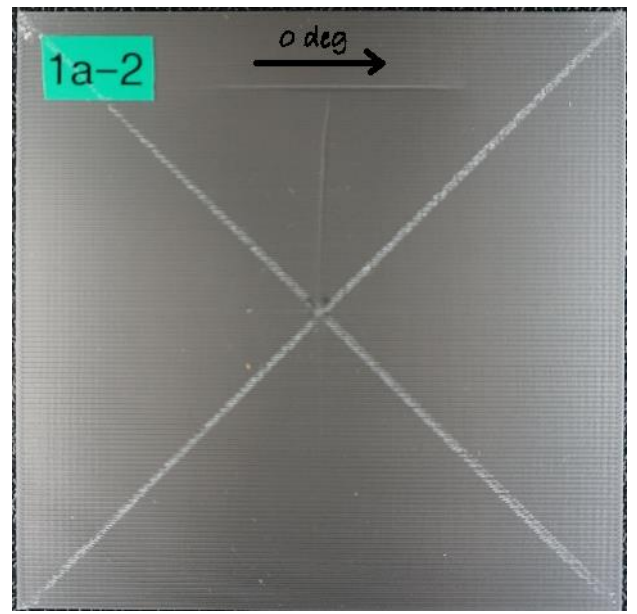

(a)

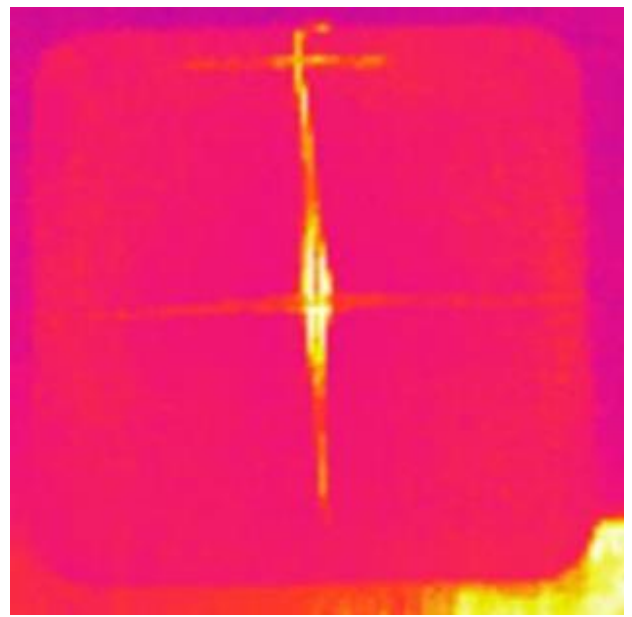

(b)

Figure 37: Specimens with $P_{1}$ impact location and 25 layers (a) specimen after testing; (b) thermal image captured during the test 


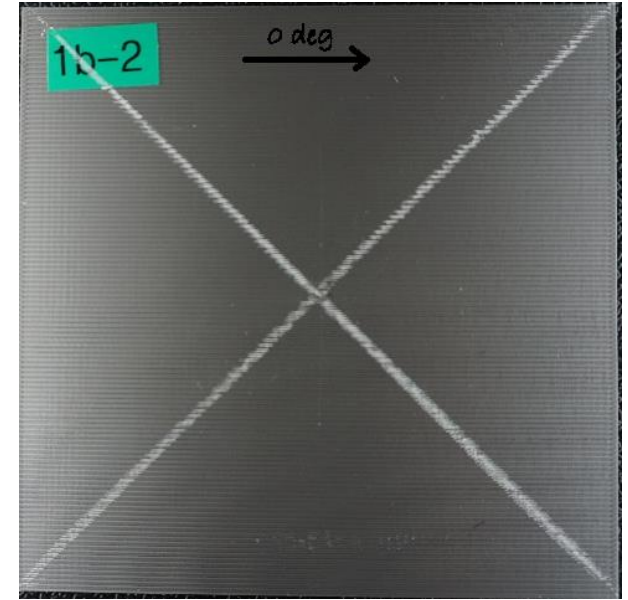

(a)

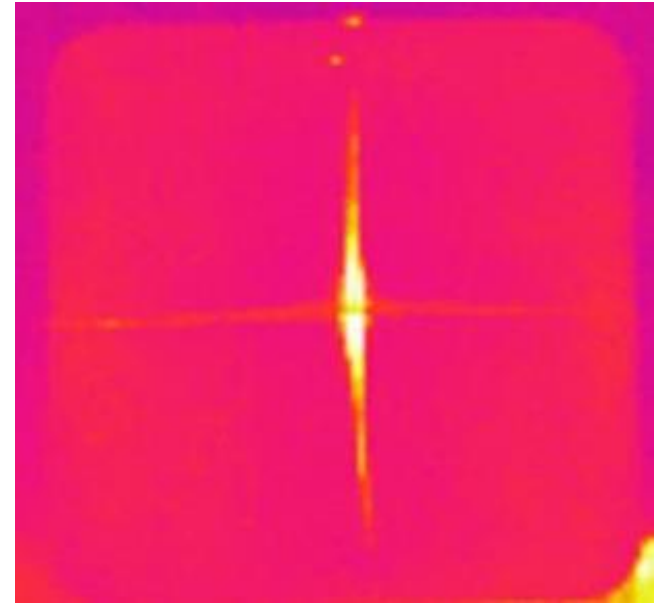

(b)

Figure 38: Specimens with $P_{1}$ impact location and 21 layers (a) specimen after testing; (b) thermal image captured during the test

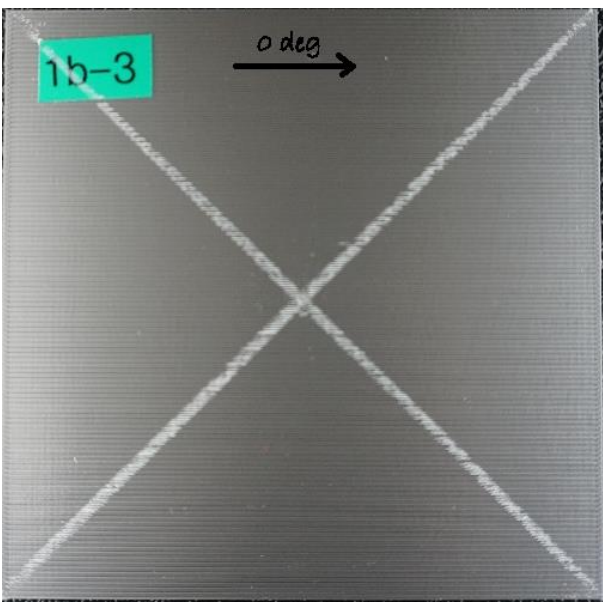

(a)

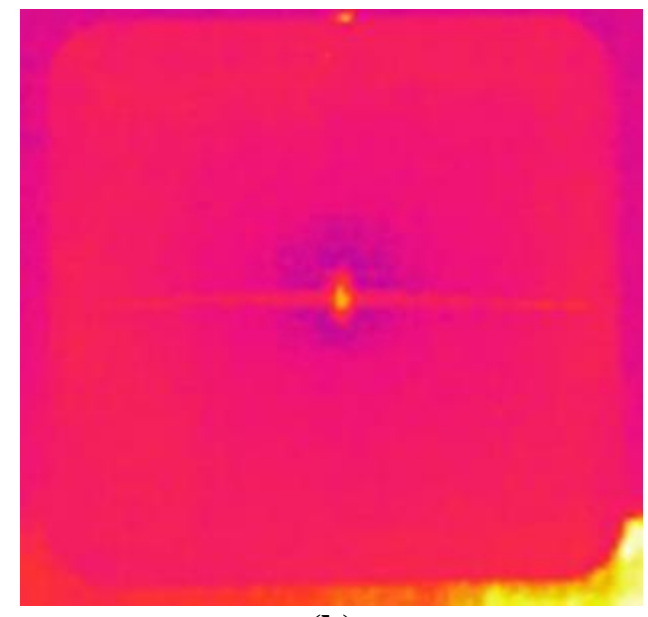

(b)

Figure 39: Specimens with $P_{1}$ impact location and 21 layers (a) specimen after testing; (b) thermal image captured during the test 


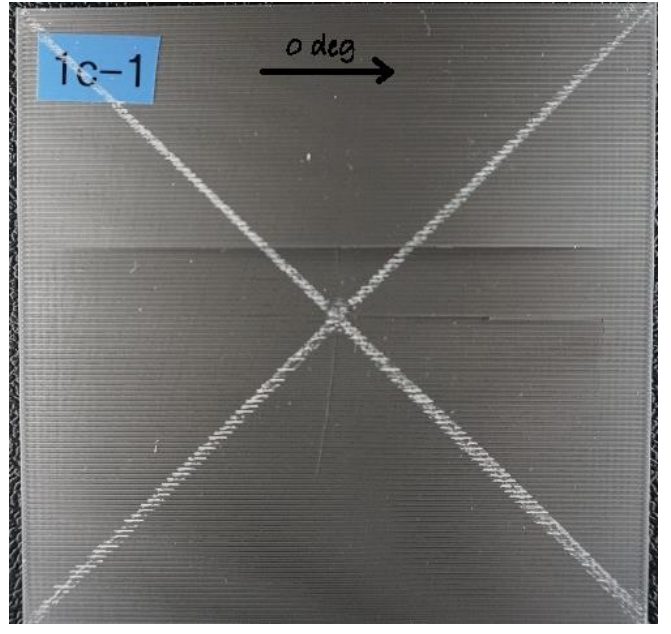

(a)

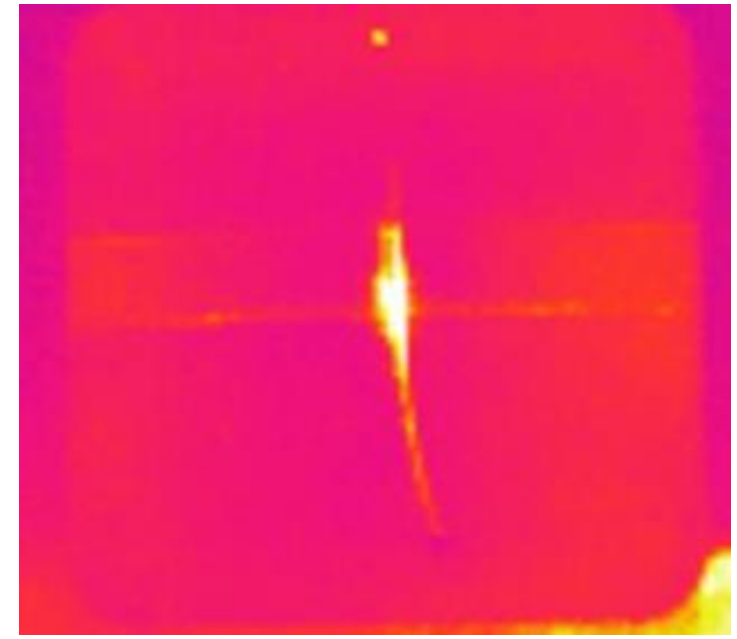

(b)

Figure 40: Specimens with $P_{1}$ impact location and 16 layers (a) specimen after testing; (b) thermal image captured during the test

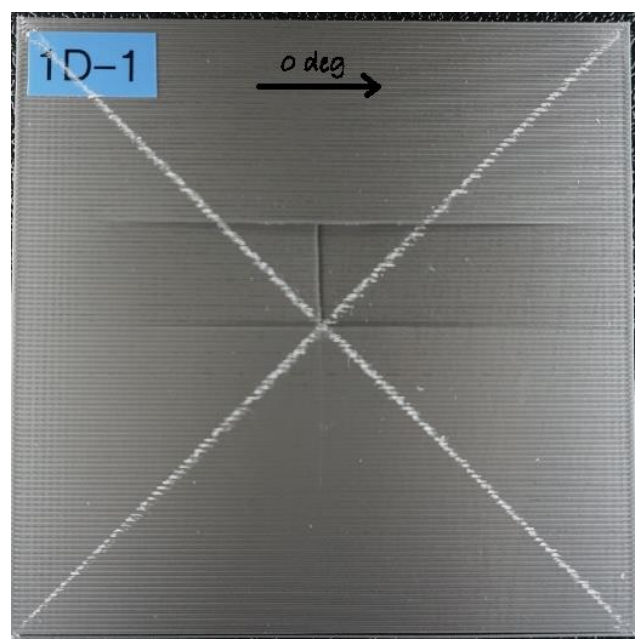

(a)

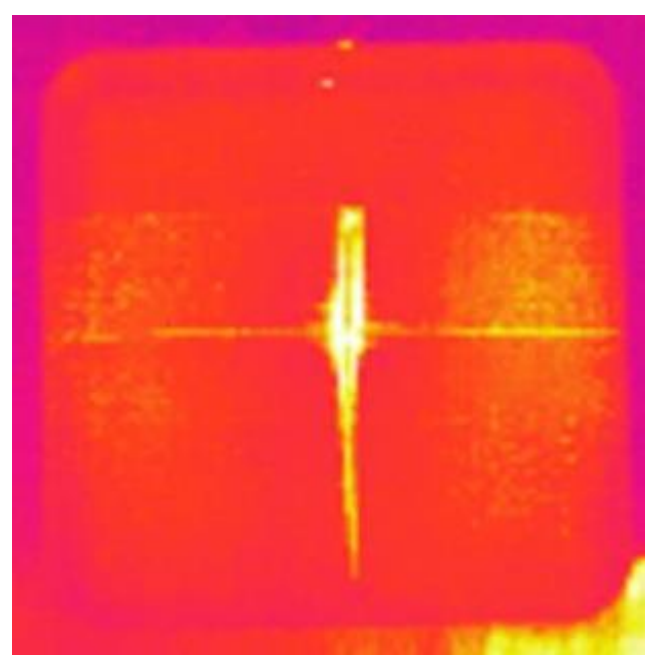

(b)

Figure 41: Specimens with $P_{1}$ impact location and 14 layers (a) specimen after testing; (b) thermal image captured during the test 


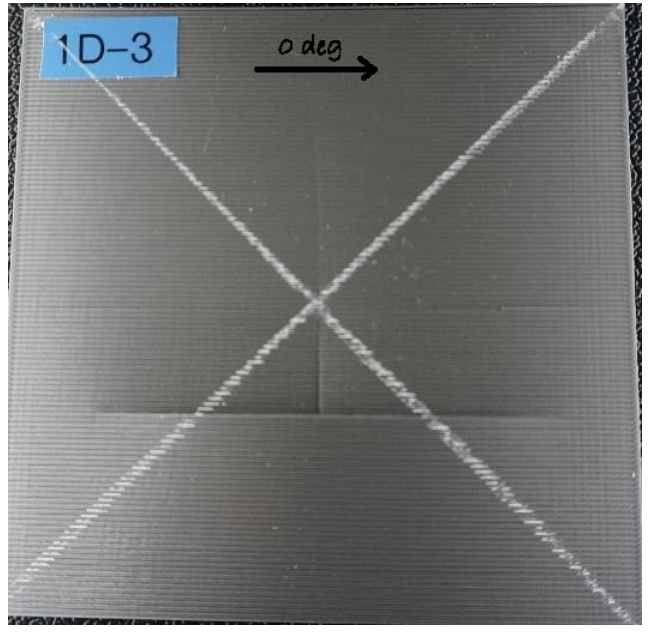

(a)

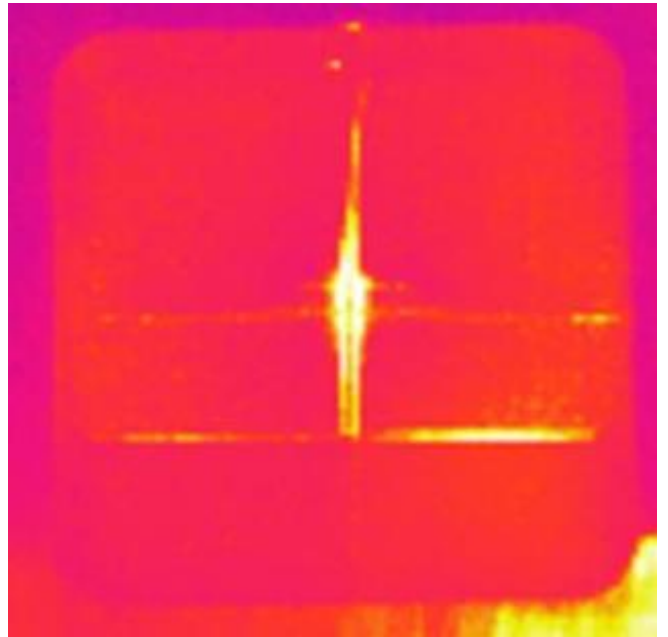

(b)

Figure 42: Specimens with $P_{1}$ impact location and 14 layers (a) specimen after testing; (b) thermal image captured during the test

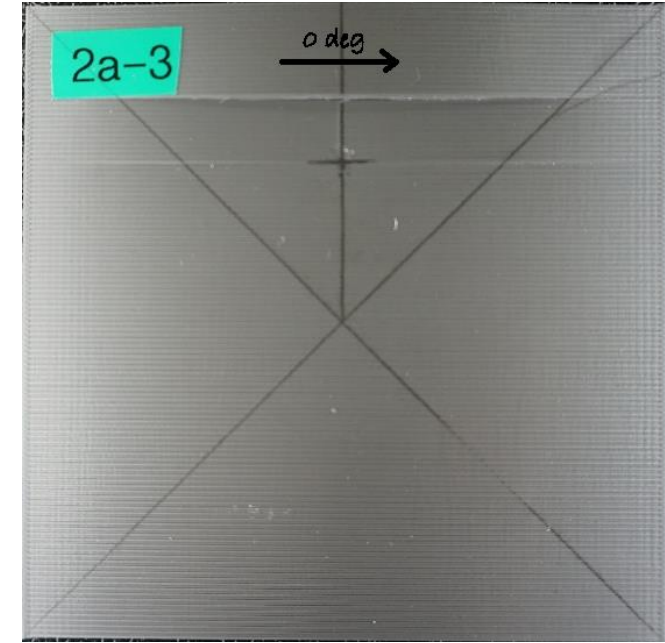

(a)

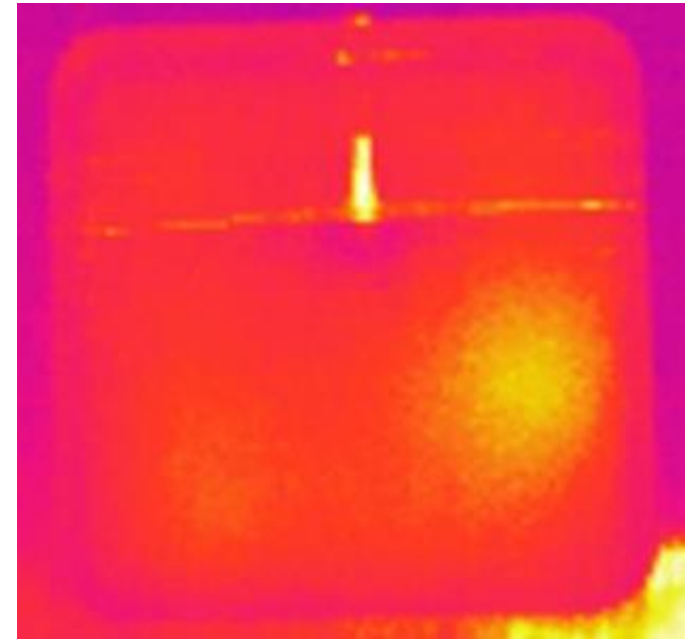

(b)

Figure 43: Specimens with $P_{2}$ impact location and 25 layers (a) specimen after testing; (b) thermal image captured during the test 


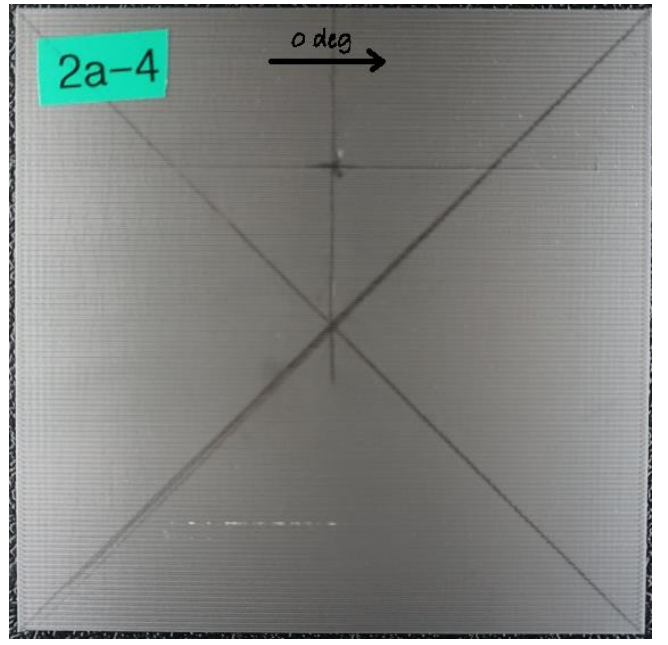

(a)

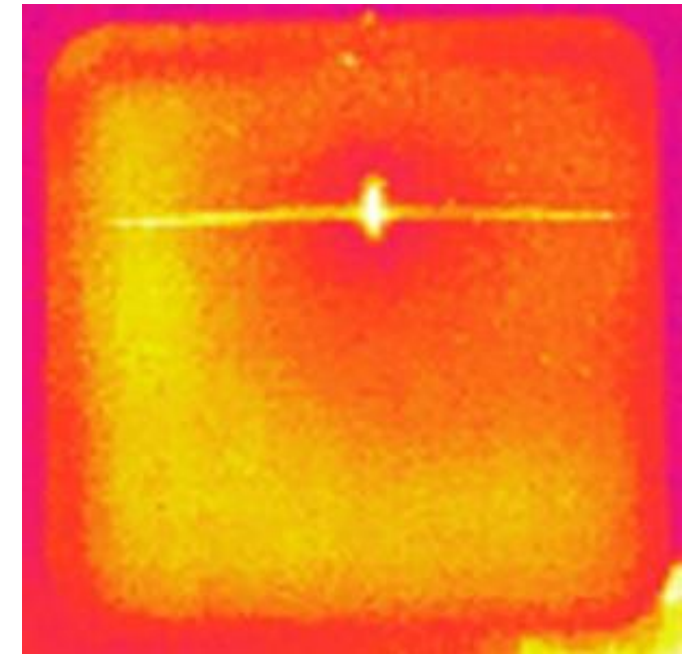

(b)

Figure 44: Specimens with $P_{2}$ impact location and 25 layers (a) specimen after testing; (b) thermal image captured during the test

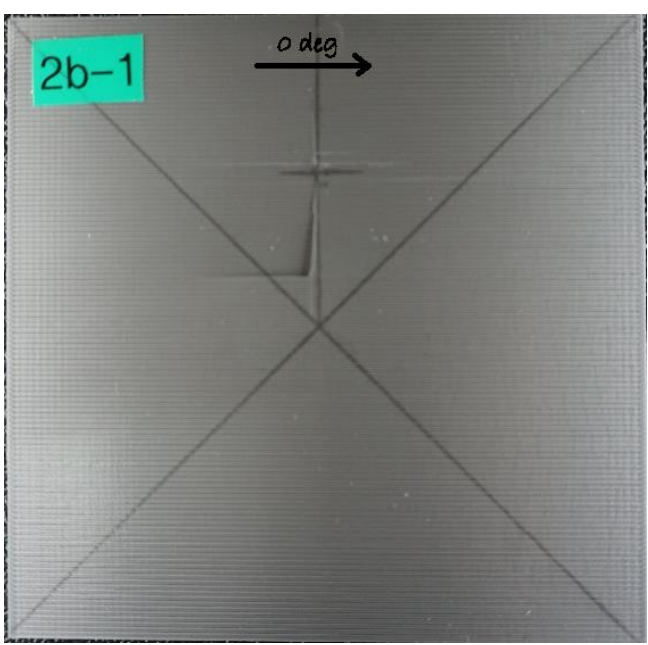

(a)

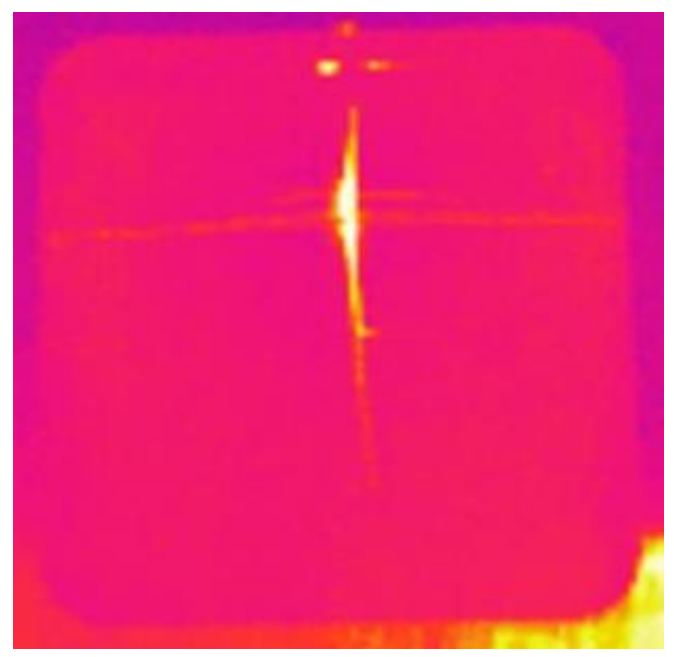

(b)

Figure 45: Specimens with $P_{2}$ impact location and 21 layers (a) specimen after testing; (b) thermal image captured during the test 


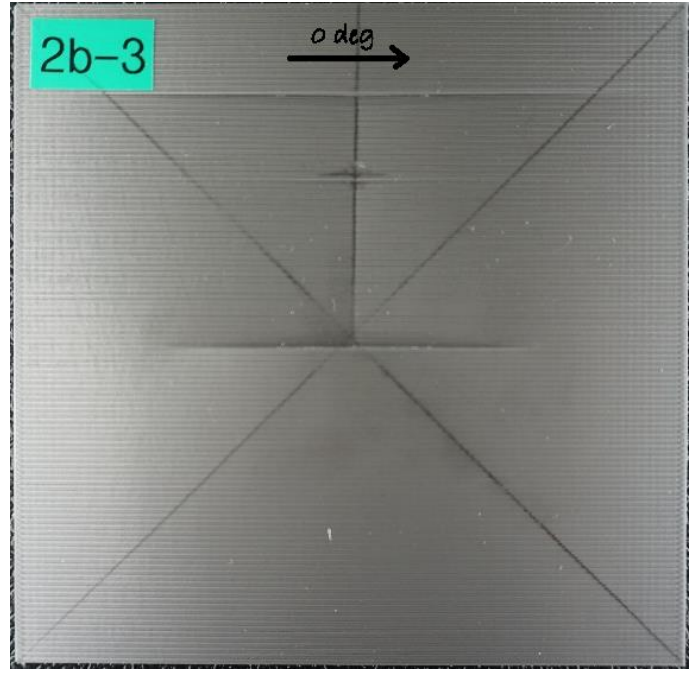

(a)

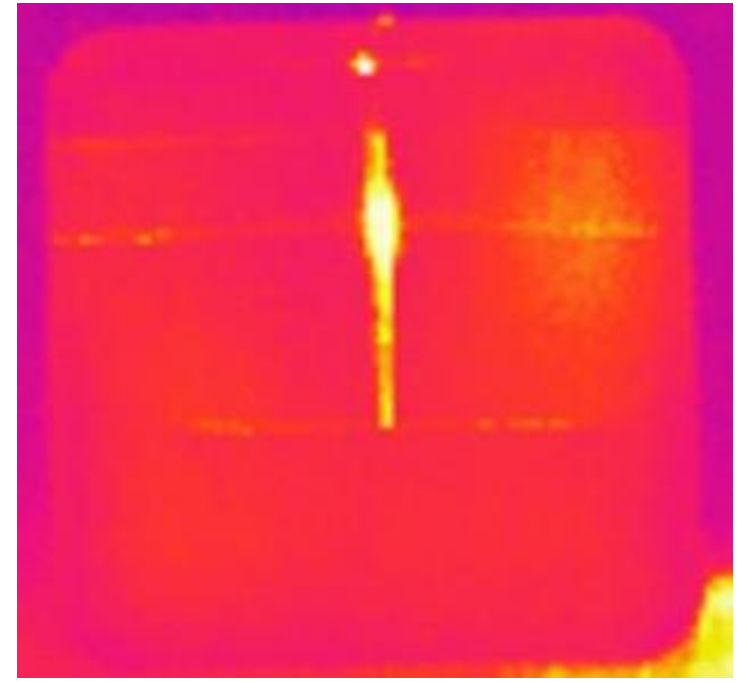

(b)

Figure 46: Specimens with $P_{2}$ impact location and 21 layers (a) specimen after testing; (b) thermal image captured during the test

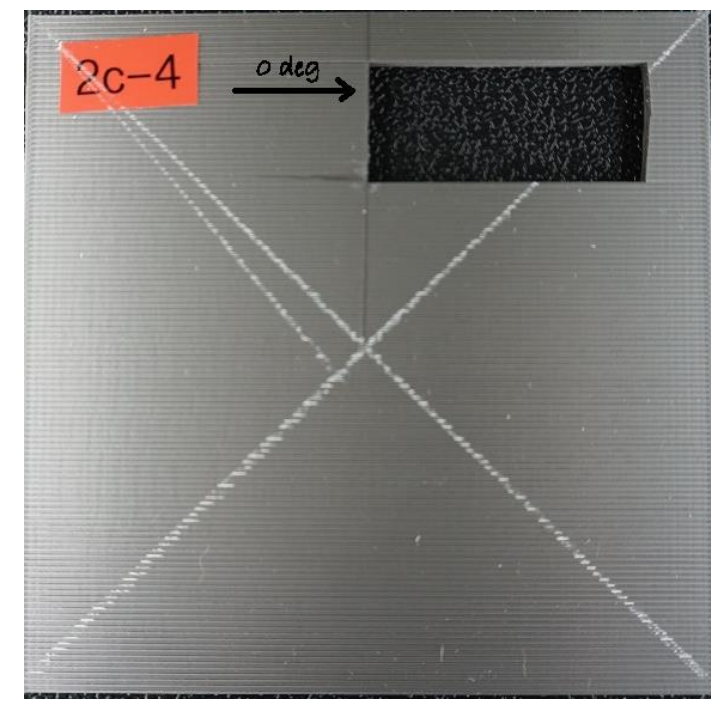

(a)

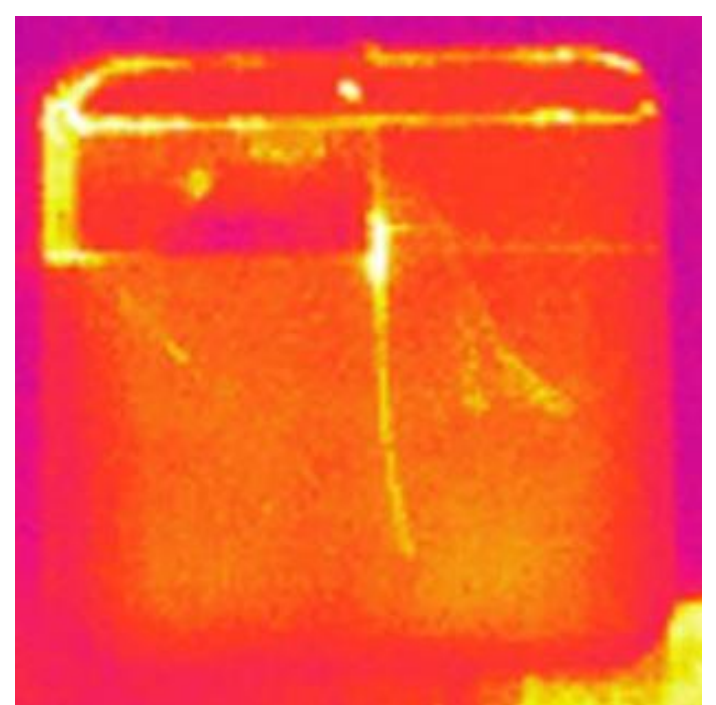

(b)

Figure 47: Specimens with $P_{2}$ impact location and 16 layers (a) specimen after testing; (b) thermal image captured during the test 


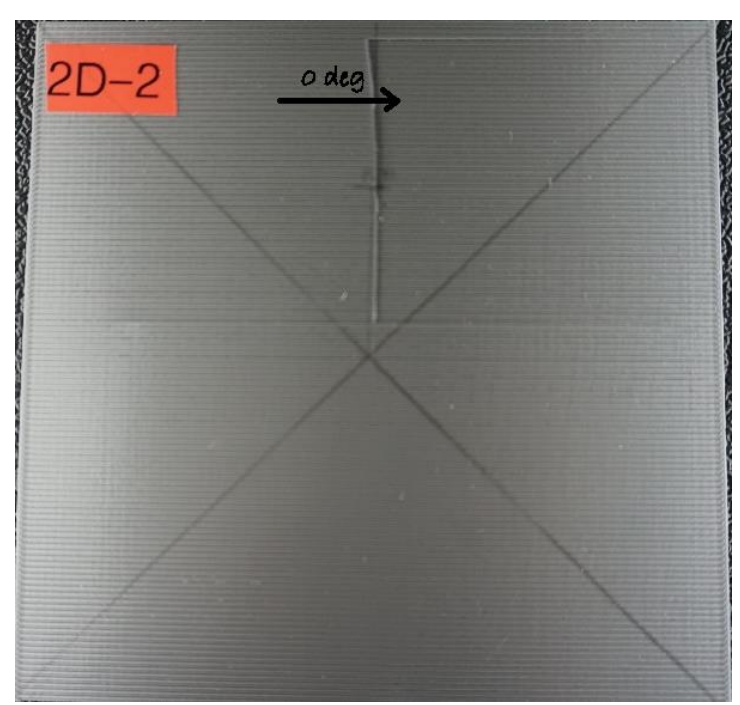

(a)

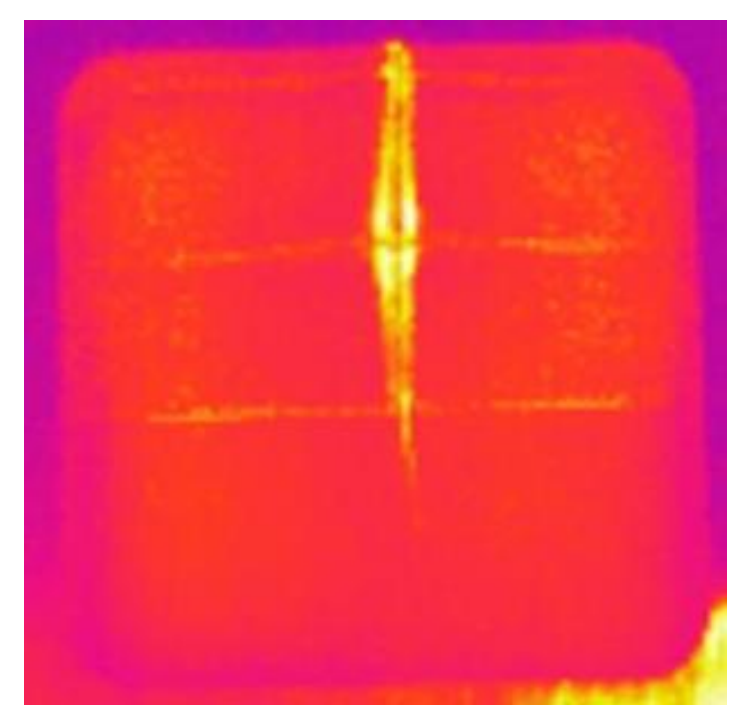

(b)

Figure 48: Specimens with $P_{2}$ impact location and 14 layers (a) specimen after testing; (b) thermal image captured during the test

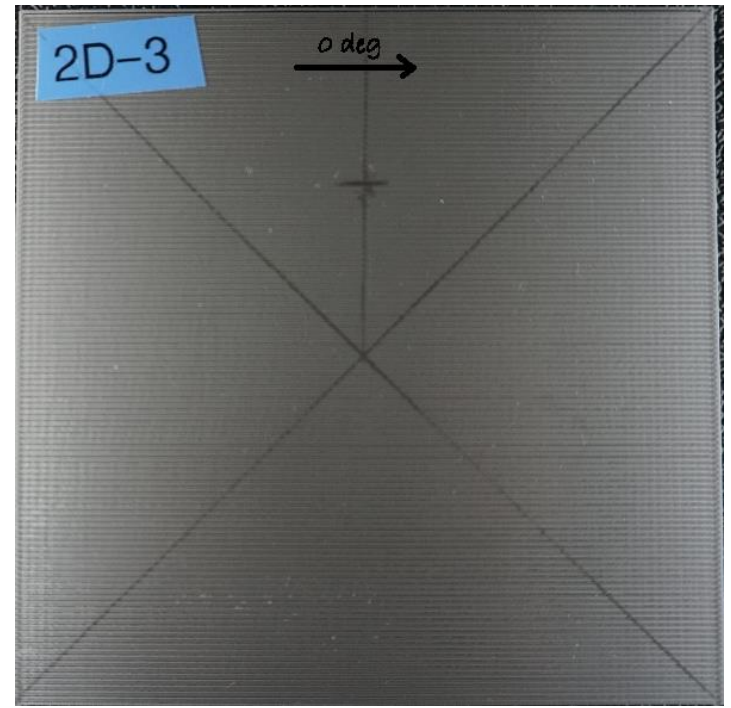

(a)

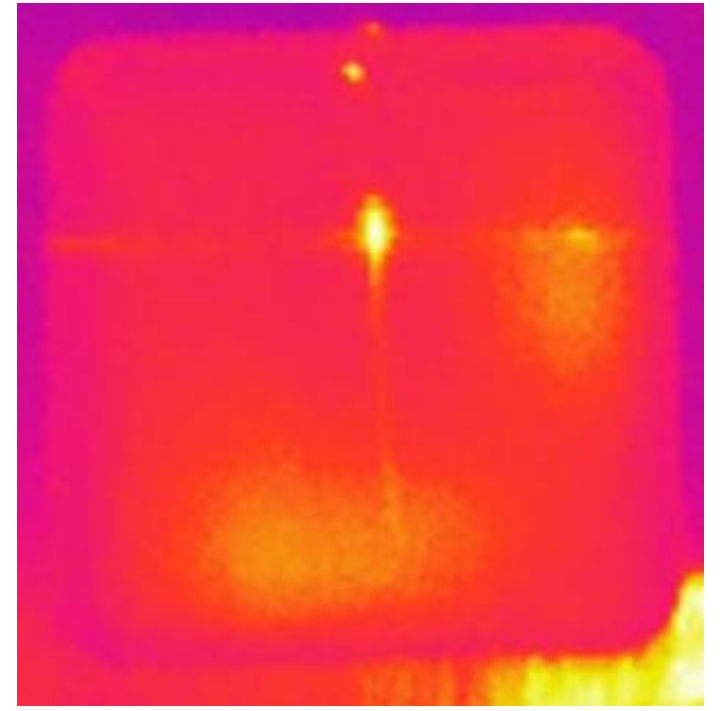

(b)

Figure 49: Specimens with $P_{2}$ impact location and 14 layers (a) specimen after testing; (b) thermal image captured during the test 


\section{REFERENCES}

1. Chin-Ching Yeh, Trend Analysis for the Market and Application Development of 3D Printing, auSMT Vol. 4 No.1 (2014).

2. Sunil C. Joshi and Abdullah A. Sheikh, 3D printing in aerospace and its long-term sustainability, virtual and physical prototyping, 2015 vol. 10, no. 4, 175-185.

3. Tuan D. Ngoa, Alireza Kashania, Gabriele Imbalzanoa, Kate T.Q. Nguyena, David Hui, Additive manufacturing (3D printing): A review of materials, methods, applications and challenges, Composites Part B 143 (2018) 172-196.

4. John Ryan C. Dizon, Alejandro H. Espera Jr., Qiyi Chen, Rigoberto C. Advincula, Mechanical characterization of 3D-printed polymers, Additive Manufacturing 20 (2018) 4467.

5. Xin Wang, Man Jiang, Zuowan Zhou, Jihua Gou, David Hui, 3D printing of polymer matrix composites: A review and prospective, Composites Part B 110 (2017) 442-458.

6. Sunpreet Singh, Seeram Ramakrishna, Rupinder Singh, Material issues in additive manufacturing: A review, Journal of Manufacturing Processes 25 (2017) 185-200.

7. Fuda Ning a, Weilong Cong a, *, Jingjing Qiu b, Junhua Wei b, Shiren Wang c, Additive manufacturing of carbon fibre reinforced thermoplastic composites using fused deposition modelling, Composites Part B 80 (2015).

8. L.G. Blok, M.L. Longana, H. Yu, B.K.S. Woods, an investigation into 3D printing of fibre reinforced thermoplastic composites, Additive Manufacturing Volume 22, August 2018, Pages 176-186.

9. Jian-Yuan Lee, Jia An, Chee Kai Chua, Fundamentals and applications of 3D printing for novel materials, Applied Materials Today 7 (2017) 120-133.

10. J.M. Chacón, M.A. Caminero, E. García-Plaza, P.J. Núñez, Additive manufacturing of PLA structures using fused deposition modelling: Effect of process parameters on mechanical properties and their optimal selection, Materials and Design 124 (2017) 143-157.

11. Christian Lubombo, Michel A. Huneault, Effect of infill patterns on the mechanical performance of lightweight 3D printed cellular PLA parts, Materials Today Communications 17 (2018) 214-228.

12. A. A. Ahmed, L. Susmel, Additively manufactured PLA under static loading: strength/cracking behaviour vs. deposition angle, Procedia Structural integrity 3 (2017) 498507.

13. Chun-Ying Lee and Chung-Yin Liu, the influence of forced-air cooling on a 3D printed PLA part manufactured by fused filament fabrication, Additive Manufacturing 25 (2019) 196-203.

14. Juraj Beniak, Peter Križan, Miloš Matúš, Michal Šajgalí, Experimental testing of PLA biodegradable thermoplastic in the frame of 3D printing FDM technology, MATEC Web of Conferences 157, 06001 (2018).

15. Marzio Grasso, Lyes Azzouz, Paula Ruiz-Hincapie, Mauro Zarrelli, Guogang Ren, "Effect of temperature on the mechanical properties of 3D-printed PLA tensile specimens", Rapid Prototyping Journal, Vol. 24 Issue: 8, pp.1337-1346 (2018).

16. Shilpesh R. Rajpurohit, Harshit K. Dave, "Effect of process parameters on tensile strength of FDM printed PLA part", Rapid Prototyping Journal, Vol. 24 Issue: 8, pp.1317-1324 (2018).

17. Giovanni Gomez-Gras, Ramón Jerez-Mesa, J. Antonio Travieso-Rodriguez, Jordi LlumaFuentes, Fatigue performance of fused filament fabrication PLA specimens, Materials and Design 140 (2018) 278-285.

18. Ashu Garg, Anirban Bhattacharya, An insight to the failure of FDM parts under tensile loading: finite element analysis and experimental study, International Journal of Mechanical Sciences 120 (2017) 225-236.

19. Mst Faujiya Afrose, S.H. Masood1, Mostafa Nikzad and Pio Iovenitti, Effects of Build Orientations on Tensile Properties of PLA Material Processed by FDM, Advanced Materials Research (2014):1662-8985, Vols. 1044-1045, pp 31-34. 
20. Y. Song, Y. Li, W. Song, K. Yee, K.-Y. Lee, V.L. Tagarielli, Measurements of the mechanical response of unidirectional 3D-printed PLA, Materials and Design 123 (2017) 154-164.

21. Fuda Ning, Weilong Cong, Jingjing Qiu, Junhua Wei, Shiren Wang, Additive manufacturing of carbon fibre reinforced thermoplastic composites using fused deposition modelling, Composites Part B 80 (2015) 369-378.

22. Fuda Ning, Weilong Cong, Yingbin Hu and Hui Wang, Additive manufacturing of carbon fiber-reinforced plastic composites using fused deposition modeling: Effects of process parameters on tensile properties, Journal of Composite Materials (2017), Vol. 51(4) 451-462.

23. Chuncheng Yang, Xiaoyong Tian, Tengfei Liu, Yi Cao, Dichen Li, (2017) "3D printing for continuous fiber reinforced thermoplastic composites: mechanism and performance", Rapid Prototyping Journal, Vol. 23 Issue: 1, pp.209-215.

24. L.G. Blok $\square$, M.L. Longana, H. Yu, B.K.S. Woods, an investigation into 3D printing of fibre reinforced thermoplastic composites, Additive Manufacturing 22 (2018) 176-186.

25. Wenzheng Wu, Peng Geng, Guiwei Li, Di Zhao, Haibo Zhang and Ji Zhao, Influence of Layer Thickness and Raster Angle on the Mechanical Properties of 3D-Printed PEEK and a Comparative Mechanical Study between PEEK and ABS, Materials 2015, 8, 5834-5846.

26. Rafael Thiago Luiz Ferreira, Igor Cardoso Amatte, Thiago Assis Dutra, Daniel Bürger, Experimental characterization and micrography of 3D printed PLA and PLA reinforced with short carbon fibres, Composites Part B 124 (2017) 88-100.

27. Lu Wang, William M. Gramlich, Douglas J. Gardner, Improving the impact strength of Poly(lactic acid) (PLA) in fused layer modeling (FLM), Polymer 114 (2017) 242-248.

28. A. Tsouknidas, M. Pantazopoulos, I. Katsoulis, D. Fasnakis, S. Maropoulos, N. Michailidis, Impact absorption capacity of 3D-printed components fabricated by fused deposition modelling, Materials and Design 102 (2016) 41-44.

29. David A. Roberson, Angel R. Torrado Perez, Corey M. Shemelya, Armando Rivera, Eric MacDonald, Ryan B. Wicker, Comparison of stress concentrator fabrication for 3D printed polymeric Izod impact test specimens, Additive Manufacturing 7 (2015) 1-11.

30. Benjamin Bax, Jorg Mussig Impact and tensile properties of PLA/Cordenka and PLA/flax composites, Composites Science and Technology 68 (2008) 1601-1607.

31. M.A. Caminero, J.M. Chacón, I. García-Moreno, G.P. Rodrígue, Impact damage resistance of 3D printed continuous fibre reinforced thermoplastic composites using fused deposition modelling, Composites Part B 148 (2018) 93-103.

32. Julien Gardan, Ali Makke, Naman Rech, Improving the fracture toughness of 3D printed thermoplastic polymers by fused deposition modelling, Int J Fract (2018) 210:1-15.

33. E. Panettieri, D. Fanteria, M. Montemurro, C. Froustey, Low-velocity impact tests on carbon/epoxy composite laminates: A benchmark study, Composites Part B 107 (2016) 9-21.

34. M.A. Caminero, I. García-Moreno, G.P. Rodríguez, Damage resistance of carbon fibre reinforced epoxy laminates subjected to low velocity impact: Effects of laminate thickness and ply-stacking sequence, Polymer Testing 63 (2017) 530-541.

35. Yi-Tang Kao, Anish Ravindra Amin, Nolan Payne, Jyhwen Wang, Bruce L. Tai, Lowvelocity impact response of 3D-printed lattice structure with foam reinforcement, Composite Structures 192 (2018) 93-100.

36. Sy, B.; Bougherara, H.; Fawaz, Z.; and Sarwar, A.; Low Velocity Impact Assessment of Kevlar/Flax- Epoxy Composite Using IR Thermography, CANCON 2017; May 2017.

37. https://www.princeton.edu/ eturkoz/assets/images/impact test.JPG

38. Sy, Benedict; Low Energy Pendulum Impact Testing Apparatus, Ryerson University 2016. 